\title{
Anomalias na Camada de Apresentação de Aplicativos Android
}

\author{
Suelen Goularte Carvalho
}

\section{DISSERTAÇÃO APRESENTADA}

$\mathrm{AO}$

Instituto DE MATEMÁticA E EstatísticA

DA

Universidade DE SÃo PAUlo

PARA

OBTENÇÃO DO TÍTULO

DE

Mestre em CiênCIAS

Programa: Ciência da Computação

Orientador: Prof. Dr. Marco Aurélio Gerosa 


\section{Anomalias na Camada de Apresentação de Aplicativos Android}

Esta é a versão original da dissertação elaborada pela candidata Suelen Goularte Carvalho, tal como submetida à Comissão Julgadora. 
Com amor, à minha mãe, Sonia Maria Goularte. 


\section{Agradecimentos}

É com grande prazer que enfim escrevo esta seção da minha dissertação! Certamente este manuscrito é fruto da colaboração de diversas pessoas.

Primeiramente gostaria de agradecer a minha mãe! A pessoa mais importante pra mim e que com muito carinho me ensinou os valores fundamentais para superar desafios tão intensos, como é cursar um mestrado. Obrigada mãe esteja você onde estiver!

Agradeço ao meu orientador Marco Aurélio Gerosa por ter aceitado me acompanhar nessa trajetória, não ter desistido de mim nos momentos difíceis e por me orientar sempre de forma sincera e respeitosa. Muito obrigada!

Agradeço ao meu amigo, colega de mestrado e conselheiro Maurício F. Aniche que com sua experiência e empatia me guiou e ajudou de perto, em todos os momentos, antes e durante o mestrado. Certamente sua ajuda foi essencial e espero poder retribuir à altura!

Agradeço aos meus colegas de mestrado e professores, em especial a minha amiga Ana Paula e ao Prof. Alfredo Goldman vel Lebman, que também foram muito especiais!

Agradeço aos desenvolvedores que disponibilizaram alguns minutos do seu tempo para responder aos questionários! Sem uma comunidade engajada e colaborativa esta pesquisa não teria acontecido!

Certamente agradeço a todos os pesquisadores anteriores, pelo qual pude obter o conhecimento necessário para partir de um ponto que não o zero. Espero, como eles, agregar valor na comunidade acadêmica de modo a também colaborar com outros pesquisadores que vierem a utilizar meus resultados.

Agradeço a todos que participaram de alguma forma direta ou indiretamente e por ventura ou emoção do momento eu esqueça de mencionar aqui. Obrigada!

E finalmente, agradeço ao meu parceiro David Robert que, mais uma vez, me ajudou e apoiou de todas as maneiras inimagináveis durante essa (difícil) jornada. Obrigada por estar ao meu lado nos últimos anos e certamente, nos próximos! 


\section{Resumo}

CARvalho, G. S. Anomalias na Camada de Apresentação de Aplicativos Android. 2018. Dissertação (Mestrado) - Instituto de Matemática e Estatística, Universidade de São Paulo, São Paulo, 2018.

Bons códigos importam, mas como saber quando a qualidade está baixa? Maus cheiros de código, ou anomalias, auxiliam desenvolvedores na identificação de trechos de código problemáticos, porém a maioria dos maus cheiros catalogados são voltados para práticas e tecnologias tradicionais, criadas entre as décadas de 70 a 90, como orientação a objetos e Java. Ainda há dúvidas sobre maus cheiros em tecnologias que surgiram na última década, como o Android, principal plataforma móvel em 2017 com mais de $86 \%$ de participação de mercado. Alguns pesquisadores derivaram maus cheiros Android relacionados à eficiência e à usabilidade. Outros notaram que maus cheiros específicos ao Android são muito mais frequentes nos aplicativos do que maus cheiros tradicionais. Diversas pesquisas concluíram que os componentes Android mais afetados por maus cheiros tradicionais são Activities e Adapters, que pertencem à camada de apresentação. Notou-se também que em alguns aplicativos, códigos da camada de apresentação representam a maior parte do código do projeto. Vale ressaltar que a camada de apresentação Android também é composta por arquivos XML, chamados de recursos, usados na construção da interface do usuário (User Interface - UI), porém nenhuma das pesquisas citadas os considerou em suas análises. Nesta dissertação, investigamos a existência de maus cheiros relacionados à camada de apresentação Android considerando inclusive os recursos. Fizemos isso através de dois questionários e um experimento de código online, totalizando a participação de 316 desenvolvedores. Nossos resultados mostram a existência de uma percepção comum entre desenvolvedores sobre más práticas no desenvolvimento da camada de apresentação Android. Nossas principais contribuições são um catálogo com 20 maus cheiros da camada de apresentação Android e uma análise estatística da percepção de desenvolvedores sobre os 7 principais maus cheiros catalogados. Nossas contribuições servirão a pesquisadores como ponto de partida para a definição de heurísticas e implementação de ferramentas automatizadas e a desenvolvedores como auxílio na identificação de códigos problemáticos, ainda que de forma manual.

Palavras-chave: engenharia de software, android, maus cheiros, qualidade de código, ma- 
nutenção de software, anomalias de software. 


\section{Abstract}

CARvalho, G. S. Anomalies in the Presentation Layer of Android Applications. 2018. Dissertação (Mestrado) - Instituto de Matemática e Estatística, Universidade de São Paulo, São Paulo, 2018.

We are aware that good code matters, but how to know when quality is low? Code smells, or anomalies, help us identify problematic code snippets, but most of the code smells cataloged are based on traditional practices and technologies, created from the 70s through the 90s, such as object oriented programming and Java. There are still doubts about code smells in technologies that have emerged in the last decade, such as Android, the main mobile platform in 2017 with more than $86 \%$ market share. Some researchers have defined code smells related to Android efficiency and usability. Other research concludes that the components most affected by traditional code smells are related to the front-end components, such as Activities and Adapters. Also noticed in some applications, front-end code represent the larger part of the project's code. It is worth mentioning that the Android presentation layer is also composed of XML files, called resources, used to build the user interface (UI), but none of the cited research considered them in their analyzes. In this dissertation, we investigate the existence of code smells related to the Android front-end, including application resources. We performed two online surveys and one online code experiment, summing 316 developers. Our results show that there is a common perception among Android developers about bad practices on Android front-end. Our main contributions are a catalog of 20 code smells related to the Android front-end and a statistical analysis of the perceptions of developers about the 7 main code smells cataloged. Our contributions will provide to researchers a starting point for the definition of heuristics and implementation of automated tools and to developers as an aid in identifying problematic codes.

Palavras-chave: software engineering, android, code smells, code quality, software maintenance, software anomalies. 


\section{Sumário}

Lista de Abreviaturas $\quad$ viii

$\begin{array}{ll}\text { Lista de Figuras } & \text { ix }\end{array}$

Lista de Tabelas $\quad$ xi

1 Introdução 1

1.1 Questões de Pesquisa . . . . . . . . . . . . . . . . . . 3

1.2 Principais Contribuições . . . . . . . . . . . . . . . . 4

1.3 Organização do Trabalho . . . . . . . . . . . . . . . . . . . . . . . 4

2 Fundamentação Conceitual $\quad 6$

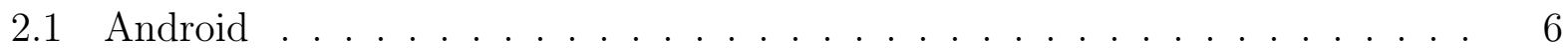

2.1.1 Fundamentos do Desenvolvimento Android . . . . . . . . . . . . . 7

2.1.2 Elementos da Camada de Apresentação Android . . . . . . . . . . . . 8

2.1.3 Desafios no Desenvolvimento da Camada de Apresentação Android 10

2.2 Qualidade de Software . . . . . . . . . . . . . . . . . . 12

2.3 Boas Práticas de Software . . . . . . . . . . . . . . . . . 16

2.3 .1 Padrões de Projeto . . . . . . . . . . . . . . . . . 16

2.3.2 Anti-Padrões . . . . . . . . . . . . . . . . . 18

2.4 Maus Cheiros de Código . . . . . . . . . . . . . . . . . . . . . . . 18

2.4.1 Formato dos Maus Cheiros . . . . . . . . . . . . . . . . . . . . . 19

3 Trabalhos Relacionados $\quad 22$

3.1 Maus Cheiros Tradicionais . . . . . . . . . . . . . . . 23 
3.2 Maus Cheiros Específicos a uma Tecnologia . . . . . . . . . . . . . . 24

3.3 Maus Cheiros em Aplicativos Android . . . . . . . . . . . . . . . . 25

3.3.1 Maus Cheiros Tradicionais em Aplicativos Android . . . . . . . . . . 26

3.3.2 Maus Cheiros Específicos a Aplicativos Android . . . . . . . . . . . . 27

3.3.3 Maus Cheiros Tradicionais e Específicos em Aplicativos Android . . . 27

4 Método de Pesquisa $\quad 30$

4.1 Etapas da Pesquisa . . . . . . . . . . . . . . . . . . . . 30

4.2 Etapa 1 - Boas e más práticas na camada de apresentação Android . . . . . 32

4.2 .1 Questionário . . . . . . . . . . . . . . . . . 32

4.2 .2 Participantes . . . . . . . . . . . . . . . . . 33

4.2.3 Análise dos Dados . . . . . . . . . . . . . . . . 35

4.3 Etapa 2 - Importância e Frequência dos Maus Cheiros Android . . . . . . . . 36

4.3.1 Questionário ..................... 36

4.3.2 Participantes . . . . . . . . . . . . . . . . . 39

4.3 .3 Análise dos Dados . . . . . . . . . . . . . . . . . . . . . . 41

4.4 Etapa 3 - Percepção de Desenvolvedores sobre os Maus Cheiros . . . . . . . 42

4.4.1 Experimento . . . . . . . . . . . . . ..... 43

4.4 .2 Participantes e Análise dos Dados . . . . . . . . . . . . . . . . 46

4.5 Ameaças à Validade . . . . . . . . . . . . . . . . . . . . . . . . . . 47

5 Resultados $\quad 50$

5.1 QP 1 Maus Cheiros Específicos à Camada de Apresentação Android . . . . . 50

5.1.1 Resultados Gerais e Descobertas . . . . . . . . . . . . . . . . 50

5.1 .2 Maus Cheiros Propostos . . . . . . . . . . . . . . . 52

$5.2 \mathrm{QP}_{2}$ Importância e Frequência dos Maus Cheiros Android . . . . . . . . . . . 55

5.2 .1 Resultados Gerais . . . . . . . . . . . . . . . 56

5.2 .2 Importância dos Maus Cheiros . . . . . . . . . . . . . . 57

5.2 .3 Frequência dos Maus Cheiros . . . . . . . . . . . . . . . 58

$5.3 \mathrm{QP}_{3}$ Percepção dos Desenvolvedores sobre os Maus Cheiros Android . . . . . 61

5.3 .1 Resultados . . . . . . . . . . . . . . . . . . . 61 
6 Conclusão

6.1 Questões de Pesquisa Revisitadas . . . . . . . . . . . . . . 65

6.2 Trabalhos Futuros . . . . . . . . . . . . . . . . . 66

6.3 Discussões . . . . . . . . . . . . . . . . . . . . 67

$\begin{array}{ll}\text { A Exemplos de respostas que embasaram os maus cheiros } & 69\end{array}$

B Questionário sobre boas e más práticas $\quad 72$

C Questionário sobre frequência e importância dos maus cheiros $\quad 75$

D Afirmações sobre frequência dos maus cheiros e respectivos dados estatísticos

E Afirmações sobre importância dos maus cheiros e respectivos dados estatísticos

F Gists dos Códigos Utilizados no Experimento da Etapa 3 


\section{Lista de Abreviaturas}

API Application Program Interface

SDK Software Development Kit

IDE Integrated Development Environment

APK Android Package

ART Android RunTime

LoC Lines of Code

UI User Interface

GoF Gang of Four

CSS Cascading Style Sheets

ORM Object-Relational Mapping

J2ME Java Mobile Edition

GT Ground Theory

MVC Model View Controller

MVP Model View Presenter

MVVM Model View ViewModel

SQuaRE Systems and software Quality Requirements and Evaluation

CISQ Consortium for IT Software Quality

ISO International Organization for Standardization

IEC International Electrotechnical Commission

SWEBOK Software Engineering Body of Knowledge

FURPS Functionality Usability Reliability Performance Supportability 


\section{Lista de Figuras}

2.1 Participação de mercado global de sistemas operacionais móveis do Q1 $\left(1^{\circ}\right.$ quadrimestre) de 2009 até o Q1 de 2017. . . . . . . . . . . . . 7

2.2 Comparativo do ciclo de vida de componentes Android que pertencem e não pertencem à camada de apresentação. . . . . . . . . . . . . . . . . . . . . . . 13

2.3 Características de qualidade de software segundo norma ISO/IEC 9126. . . . 14

2.4 Formatos de padrões de acordo com seu nível de maturidade e clareza segundo Joshua Kerievsky. . . . . . . . . . . . . . . . . . . . . . . . . . . . . . . . . . 17

4.1 Etapas da pesquisa. . . . . . . . . . . . . . . . . . . . 31

4.2 Escolaridade e distribuição de idade dos participantes em $\mathrm{S}_{1}$. . . . . . . . . 33

4.3 Tempo de experiência com desenvolvimento de software e desenvolvimento Android dos participantes de $\mathrm{S}_{1} \ldots \ldots \ldots$. . . . . . . . . . . . . . 34

4.4 Distribuição geográfica global e brasileira dos participantes de $\mathrm{S}_{1}$. . . . . . . 34

4.5 Escolaridade e distribuição de idade dos participantes em $\mathrm{S}_{2}$. . . . . . . . . 39

4.6 Tempo de experiência com desenvolvimento de software e desenvolvimento Android dos participantes de $\mathrm{S}_{2} \ldots \ldots \ldots$. . . . . . . . . . . . . 40

4.7 Nível de conhecimento em diversas linguagens de programação orientada a objetos dos participantes de $\mathrm{S}_{2}$. . . . . . . . . . . . . . . . 40

4.8 Distribuição geográfica global e brasileira dos participantes de $\mathrm{S}_{2}$. . . . . . . 41

4.9 Tempo de experiência com desenvolvimento de software e desenvolvimento Android dos participantes de $\mathrm{S}_{3} \ldots \ldots \ldots \ldots$. . . . . . . . . . . . .

5.1 Total de respostas para cada pergunta sobre boas e más práticas nos oito elementos da camada de apresentação Android. . . . . . . . . . . . . . . . . 51

5.2 Distribuição relativa de importância dos maus cheiros propostos. . . . . . . . 58

5.3 Distribuição relativa de frequência dos maus cheiros propostos. . . . . . . . . 60 
5.4 Análise de severidade em componentes e recursos mau cheirosos e limpos. . . 61

5.5 Análise de severidade dos códigos limpos segmentados por grupos e dos códigos afetados pelos maus cheiros avaliados. . . . . . . . . . . . . . . . 62 


\section{Lista de Tabelas}

2.1 Modelos de qualidade de software baseados no modelo de decomposição hierárquica de Boehm et al. e McCall et al. . . . . . . . . . . . . . . . . . 14

4.1 Sete maus cheiros avaliados no experimento de código sobre a percepção de desenvolvedores Android. . . . . . . . . . . . . . . . . . . 44

4.2 Listagem dos nove projetos de software livre Android utilizados para coletar os códigos do experimento. . . . . . . . . . . . . . . . .

5.1 Total de respostas sobre boas e más práticas em cada elemento da camada de apresentação Android. . . . . . . . . . . . . . . . . . .

5.2 Lista dos 20 maus cheiros na camada de apresentação Android e breve descrição dos sintomas. . . . . . . . . . . . . . . . . . 53

5.3 Mediana (ME), moda (MO) e desvio padrão (DP) sobre a percepção da importância dos maus cheiros relacionados a componentes da camada de apresentação Android. . . . . . . . . . . . . . . . . 56

5.4 Listagem dos maus cheiros da camada de apresentação Android de acordo com seu nível de importância, alta ou moderada. . . . . . . . . . . . . . 57

5.5 Listagem dos maus cheiros da camada de apresentação Android de acordo com seu nível de frequência, alta, moderada ou baixa. . . . . . . . . . . . .

5.6 Dados estatísticos sobre a percepção negativa por desenvolvedores sobre os maus cheiros avaliados no experimento de código $\left(\mathrm{S}_{3}\right) \ldots \ldots \ldots$ 
If you get tired,

learn to rest, not to quit.

- Banksy 


\section{Capítulo 1}

\section{Introdução}

"Estamos cientes de que um bom código importa, pois já tivemos que lidar com a falta dele por muito tempo" argumenta Robert Martin [74]. De fato, estamos cientes de que bons códigos importam. Mas como saber se a qualidade de um código está baixa? Uma das formas de responder essa pergunta é buscando por maus cheiros no código. Maus cheiros são certas estruturas no código que indicam a violação de princípios fundamentais de design e impactam negativamente a qualidade do projeto [91, p. 258]. Maus cheiros auxiliam desenvolvedores na identificação de trechos de códigos problemáticos, de forma que possam ser melhorados e a qualidade do software incrementada [28]. Nesta dissertação, anomalias de código e maus cheiros são sinônimos.

Existem diversos maus cheiros catalogados [28, 74, 91, 97], Método Longo e Classe Deus são dois exemplos. Muitos desses maus cheiros foram definidos baseados em conceitos e tecnologias tradicionais, como orientação a objetos e Java [65], que surgiram durante as décadas de 70 a 90. Nesta dissertação, os denominamos de "maus cheiros tradicionais". Entretanto, na última década surgiram muitas novas tecnologias, como por exemplo o Android, que levantaram questões como: "os maus cheiros tradicionais se aplicam às novas tecnologias?" ou "existem maus cheiros específicos às novas tecnologias ainda não catalogados?". Questões como essas instigaram a curiosidade de diversos pesquisadores que decidiram investigar maus cheiros em tecnologias específicas, como por exemplo o CSS [30], o Javascript [25], o arcabouço Spring MVC [9] e fórmulas de planilhas do Google [84].

Android é uma plataforma móvel que foi lançada em 2008 pela empresa Google em parceria com diversas outras empresas [7]. Em 2011 se tornou mundialmente a principal plataforma para dispositivos móveis e desde então vem aumentando sua fatia de mercado, tendo em 2017 alcançado 86\% [90].

O Android também chamou a atenção de pesquisadores da área de qualidade de software. Alguns investigaram a existência de maus cheiros tradicionais em aplicativos Android [60, 72, 95]. Outros investigaram a existência de maus cheiros específicos ao Android relacio- 
nados à eficiência (boa utilização de recursos como memória e processamento) e usabilidade (capacidade do software em ser compreendido) $[56,86]$. Outros pesquisadores focaram em entender características do desenvolvimento Android que os diferenciam do desenvolvimento de software tradicional [77].

Dentre as descobertas realizadas pelos pesquisadores, notou-se que maus cheiros específicos ao Android são muito mais frequentes em aplicativos Android do que maus cheiros tradicionais [60]. Os componentes Android mais afetados por maus cheiros tradicionais fazem parte da camada de apresentação, como Activities e Adapters [60, 77, 95], e em alguns aplicativos Android, códigos relacionados à camada de apresentação são maioria, em termos de linhas de código (LoC, do inglês Lines of Code) [77]. Vale ressaltar que a camada de apresentação Android também é composta por arquivos XML, chamados de recursos da aplicação, que são usados para a construção da interface com o usuário (UI, do inglês User Interface) [49]. Nenhuma das pesquisas mencionadas considerou esses arquivos em suas análises.

Nesta dissertação, investigamos a existência de maus cheiros de código relacionados à camada de apresentação Android. Enquanto outras pesquisas investigaram maus cheiros em termos de eficiência e usabilidade, nós buscamos por maus cheiros relacionados à manutenibilidade, que trata da facilidade do software de ser modificado ou aprimorado. Complementamos as pesquisas anteriores pois focamos na camada de apresentação Android considerando inclusive os recursos da aplicação.

Nossos dados foram obtidos por meio de dois questionários e um experimento de código online. O primeiro questionário foi de cunho exploratório onde perguntamos a desenvolvedores sobre boas e más práticas utilizadas no dia a dia do desenvolvimento da camada de apresentação Android. Obtivemos 45 respostas, das quais derivamos 20 maus cheiros Android. O segundo, foi um questionário confirmatório, onde validamos a percepção com 201 desenvolvedores Android sobre a frequência e importância dos 20 maus cheiros propostos. Por último, realizamos um experimento de código com 70 desenvolvedores Android com o objetivo de validar se códigos afetados pelos maus cheiros eram percebidos como códigos problemáticos. Ao todo, participaram da pesquisa 316 desenvolvedores.

Nossos resultados mostram que, existem maus cheiros específicos à camada de apresentação Android, que eles são considerados frequentes e importantes de se mitigar e que são percebidos como problemáticos por desenvolvedores Android quando identificados em códigos. Nossas principais contribuições são: (i) um catálogo com 20 novos maus cheiros relacionados à camada de apresentação Android, (ii) uma análise estatística da percepção de desenvolvedores sobre 7 dos 20 maus cheiros catalogados e (iii) um apêndice online $e^{1}$ com as informações necessárias para outros pesquisadores replicarem nossa pesquisa.

Acreditamos que nossas contribuições dão um passo na busca por qualidade de código na plataforma Android e que poderá servir a pesquisadores e desenvolvedores. Aos pesqui-

\footnotetext{
${ }^{1}$ Apêndice online disponível em: http://suelengc.github.io/master-degree-dissertation.
} 
sadores serve como ponto de partida para a definição de heurísticas de identificação dos maus cheiros e implementação de ferramentas que os identifiquem de forma automática. Aos desenvolvedores serve como auxílio na identificação de códigos problemáticos para serem melhorados, ainda que de forma manual.

\subsection{Questões de Pesquisa}

Maus cheiros são sintomas que podem indicar um problema mais profundo no código [28]. Geralmente são derivados da experiência e opinião de desenvolvedores [94], ou seja, são por natureza subjetivos [25]. Há ainda evidências na literatura que sugerem que maus cheiros são percebidos negativamente por desenvolvedores [82]. Desta forma, dividimos a pesquisa em três questões principais, que apresentamos a seguir.

\section{$\mathrm{QP}_{1}$ Existem maus cheiros que são específicos à camada de apresentação de aplicativos Android?}

Esta questão de pesquisa objetiva investigar a existência de maus cheiros no desenvolvimento da camada de apresentação Android. A percepção de desenvolvedores é sempre importante quando lidamos com manutenção de software $[11,82,102]$ e explorar o conhecimento empírico de desenvolvedores é relevante na busca por maus cheiros de código [25, 94]. Portanto, coletamos os dados a partir de um questionário exploratório online, submetido a desenvolvedores Android, pelo qual perguntamos sobre boas e más práticas no desenvolvimento da camada de apresentação Android.

Esse questionário nos forneceu as primeiras ideias sobre maus cheiros na camada de apresentação Android. Recebemos 45 respostas a partir das quais realizamos um processo de codificação, buscando por más práticas recorrentes, de modo a serem a base para derivação dos maus cheiros. Esse processo resultou em 46 categorias, das quais 20 apresentaram-se recorrente o suficiente, com base no número de Nielsen [79], para a derivação dos maus cheiros. Como resultado, propomos um catálogo com 20 maus cheiros específicos à camada de apresentação Android.

$\mathrm{QP}_{2}$ Com qual frequência os maus cheiros são percebidos e o quão importante são considerados pelos desenvolvedores?

Com o objetivo de validar os maus cheiros propostos em resposta à $\mathrm{QP}_{1}$, por meio de um questionário online, perguntamos a desenvolvedores Android com qual frequência os maus cheiros são percebidos no seu dia a dia e o quão importante é considerado mitigá-los. Recebemos 201 respostas, a partir das quais confirmamos que todos os maus cheiros propostos são considerados, em algum nível, importantes de se mitigar e frequentes no dia a dia de 
desenvolvimento.

\section{$\mathrm{QP}_{3}$ Desenvolvedores Android percebem os códigos afetados pelos maus chei- ros como problemáticos?}

Evidências na literatura sugerem que maus cheiros são percebidos negativamente por desenvolvedores [82]. A fim de validar a percepção negativa de desenvolvedores Android sobre os 20 maus cheiros propostos, realizamos um experimento de código. No experimento o desenvolvedor foi solicitado a avaliar 6 trechos de código, dentre os quais haviam códigos mau cheirosos (afetado por algum mau cheiro proposto) e limpos (não afetado por maus cheiros). Recebemos 70 respostas, a partir das quais extraímos dados estatísticos que confirmam que desenvolvedores percebem códigos afetados por 6 dos maus cheiros propostos como problemáticos.

\subsection{Principais Contribuições}

As principais contribuições desta dissertação são:

- Um catálogo com 20 novos maus cheiros relacionados a 8 elementos da camada de apresentação Android, sendo quatro componentes: Activities, Fragments, Adapters e Listeners e quatro recursos: Layouts, Styles, String e Drawables.

- A validação da percepção de frequência e importância dos 20 maus cheiros no dia a dia de desenvolvimento Android.

- Uma análise estatística sobre a percepção de 7 dos 20 maus cheiros propostos por desenvolvedores Android onde foi possível confirmar que códigos afetados por 6 maus cheiros são percebidos como problemáticos por desenvolvedores Android.

- Um apêndice online $e^{2}$ com todos os relatórios e dados produzidos durante a pesquisa.

\subsection{Organização do Trabalho}

Os próximos capítulos desta dissertação estão organizadas da seguinte forma:

- O Capítulo 2 introduz os temas envolvidos nesta pesquisa, a saber: Android, Qualidade de Software, Boas Práticas de Software e Maus Cheiros de Código.

\footnotetext{
${ }^{2}$ Apêndice online disponível em: http://suelengc.github.io/master-degree-dissertation.
} 
- O Capítulo 3 discute os trabalhos relacionados a (i) maus cheiros tradicionais, (ii) maus cheiros específicos a uma tecnologia, (iii) maus cheiros tradicionais em aplicativos Android, (iv) maus cheiros específicos ao Android e por fim, (v) a presença de maus cheiros tradicionais comparado a maus cheiros específicos em aplicativos Android.

- O Capítulo 4 aborda a estrutura da pesquisa bem como os detalhes dos métodos e processos de análise utilizados para responder cada questão de pesquisa.

- O Capítulo 5 apresenta os resultados e ameaças à validade da pesquisa. A Seção 5.1 apresenta a resposta da $\mathrm{QP}_{1}$, incluindo o catálogo com os 20 maus cheiros propostos relacionados à camada de apresentação Android (Seção 5.1.2). A Seção 5.2 apresenta a resposta da $\mathrm{QP}_{2}$ sobre importância e frequência dos maus cheiros. A Seção 5.3 apresenta a resposta da $\mathrm{QP}_{3}$ sobre a percepção dos maus cheiros por desenvolvedores e a Seção 4.5 trata das ameaças à validade, bem como o que fizemos para mitigá-las.

- Por fim, no Capítulo 6 respondemos as questões de pesquisa, sugerimos trabalhos futuros e discutimos alguns resultados. 


\section{Capítulo 2}

\section{Fundamentação Conceitual}

Neste capítulo introduzimos os principais temas relacionados a esta pesquisa com o objetivo de ambientar o leitor sobre as questões mais relevantes de cada tema.

A Seção 2.1 introduz a plataforma Android, abordando aspectos que a tornam interessante para a pesquisa e os principais termos e conceitos da plataforma abordados durante os capítulos seguintes. A Seção 2.2 contextualiza o leitor sobre os conceitos e sub-conceitos de qualidade de software de modo a clarificar em qual deles esta dissertação está inserida. Com objetivo similar, a Seção 2.3 introduz o conceito de boas práticas de software. Por último, a Seção 2.4 introduz mais profundamente o tema maus cheiros de código.

\subsection{Android}

O Android é uma plataforma para desenvolvimento móvel, baseada no Kernel do Linux, lançada em 2008 pelo Google em parceria com diversas empresas [7, 32]. A Figura 2.1 apresenta a participação de mercado das principais plataformas móveis desde o $1^{\circ}$ quadrimestre (Q1) de 2009 ao $2^{\circ}$ quadrimestre (Q2) de 2017 [90]. Podemos observar que, no início de 2011 o Android tomou a liderança, ultrapassando a Symbian, sua principal concorrente na época, e se tornando a plataforma móvel com maior participação no mercado global. Desde então, se mantém líder e aumenta sua participação a cada ano, tendo em 2017 atingido mais de 87\% de participação de mercado. Em 2017, seus principais concorrentes são iOS da Apple, com participação de mercado de aproximadamente $13 \%$ e o Windows Phone da Microsoft, oficialmente descontinuado nesse ano ${ }^{1}$.

Enquanto que o iOS é utilizado apenas por iPhones e iPads, que são dispositivos móveis fabricados pela Apple, totalizando aproximadamente 30 modelos diferentes [100], o Android é utilizado por mais de 24 mil dispositivos móveis diferentes segundo levantamento realizado em 2015 [81]. Em termos de desenvolvimento de software, essa grande variedade de

\footnotetext{
${ }^{1}$ https://support.microsoft.com/en-us/help/4001737/products-reaching-end-of-support-for-2017
} 


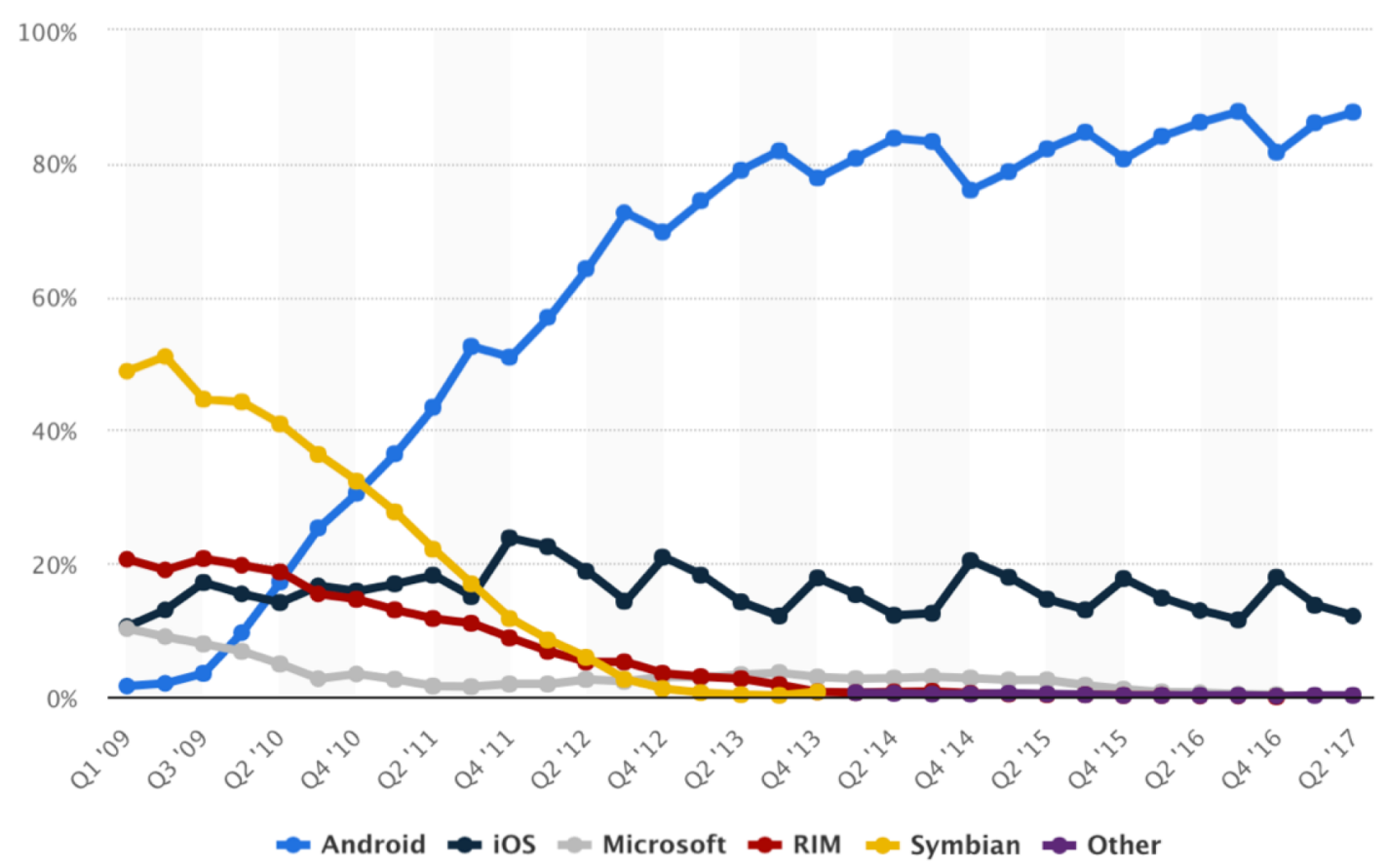

Figura 2.1: Participação de mercado global de sistemas operacionais móveis do Q1 (10 quadrimestre) de 2009 até o Q2 de 2017 [90].

dispositivos traz grandes desafios no desenvolvimento Android, desde desafios relacionados a desempenho, por conta das diferentes configurações de hardware, até desafios relacionados ao desenvolvimento da interface com o usuário, pelas diversas configurações de tamanhos de telas e resoluções.

As seções seguintes apresentam os fundamentos e principais conceitos do desenvolvimento de aplicativos Android. Todos os códigos de exemplo nesta dissertação foram implementados e testados utilizando a linguagem Java.

\subsubsection{Fundamentos do Desenvolvimento Android}

O Android Studio [47] é o ambiente integrado de desenvolvimento (IDE, do inglês Integrated Development Environment) oficial e gratuito, mantido pelo Google e comumente usado para o desenvolvimento Android. Juntamente com o Android Studio vem instalado o kit de desenvolvimento Android (SDK, do inglês Software Development Kit). O Android SDK é um conjunto de ferramentas para o desenvolvimento Android. Entre as ferramentas, podemos encontrar o compilador, depurador de código, emulador, bibliotecas de componentes bases para a criação de aplicativos Android e outras. O arquivo instalável de um aplicativo Android possui a extensão . apk, acrônimo para Android PacKage [49].

A estrutura básica de um projeto Android é composta por dois diretórios e um arquivo. O diretório src (source) contém todo o código Java, o diretório res (resource) contém todos os recursos da aplicação, que são códigos "não java", como imagens, XMLs de layout, 
dentre outros. Por fim, o arquivo AndroidManifest. xml contém configurações gerais do aplicativo, como permissões, declarações de componentes, dentre outras [53].

O Android provê diversos componentes base para o desenvolvimento de aplicativos que não estão disponíveis no desenvolvimento Java tradicional [80]. Alguns componentes são utilizados na camada de apresentação, outros para processamentos em segundo plano, outros para persistência em banco de dados local, dentre outros. Por exemplo, Activities são usadas para a criação de telas com UI pelo qual usuários podem interagir [34]. Services são usados para longos processamentos em segundo plano e não possuem UI [55]. BroadcastReceivers são usados como ouvintes, registrando interesse por mensagens enviadas pelo sistema operacional Android, como bateria baixa, ou por outros componentes [36]. AsyncTasks são usadas para curtos processamentos em segundo plano de forma assíncrona, com o objetivo de não bloquear a UI Thread, principal Thread em um aplicativo Android [37, 52].

Cada componente do Android SDK possui um conjunto de métodos de retorno que podem ou devem ser sobrescritos pelo desenvolvedor e que podem ser chamados pelo sistema operacional Android. Ciclo de vida de um componente diz respeito a como ele é criado, mantido e destruído. O ciclo de vida é composto por um conjunto de métodos de retorno que são obrigatoriamente chamados, em uma ordem específica, pelo sistema operacional Android [34, 50]. Componentes de UI como Activities costumam ter ciclos de vida mais extensos, e portanto mais complexos, que componentes que não lidam com a camada de apresentação.

Recursos são arquivos "não Java", utilizados na construção da UI e necessários para a criação de aplicativos Android [49]. Recursos podem ser imagens, arquivos de áudio ou arquivos XML, sendo as marcações e atributos usados no XML, derivados do Android SDK. Recursos de Layout são XMLs responsáveis pela estrutura da UI e o posicionamento de elementos na tela, como por exemplo botões e caixas de textos. Recursos de String são XMLs responsáveis pelo armazenamento dos textos usados no aplicativo e possibilitam a internacionalização, ou seja, traduzir o aplicativo em outros idiomas. Recursos de Style são XMLs responsáveis pelo armazenamento dos estilos usados nos recursos de layout. Recursos Drawable são gráficos que podem ser imagens ou arquivos XML que criam animações ou efeitos de estado de botões, como pressionado ou desabilitado. Apesar de ser possível implementar muitos dos recursos Android via código Java, é fortemente recomendado na documentação da plataforma que isso não seja feito [43].

\subsubsection{Elementos da Camada de Apresentação Android}

São muitos os componentes e recursos disponibilizados pelo Android SDK. Nossa pesquisa tem foco em analisar os elementos relacionados à camada de apresentação. Deste modo, para delimitarmos quais elementos Android seriam investigados, em termos de componentes da 
camada de apresentação Android (códigos Java que derivam do Android SDK) fizemos uma extensa revisão na documentação oficial do Android [48] e chegamos em quatro: Activities, Fragments, Adapters e Listeners.

Em termos de recursos Android, todos são por natureza relacionados à camada de apresentação [49]. O Android provê mais de quinze diferentes tipos de recursos [44]. Com o objetivo de focar a pesquisa, optamos por selecionar os recursos principais. Para isso, nos baseamos nos recursos existentes no projeto criado a partir do modelo padrão pelo Android Studio $[38]^{2}$, são eles: recursos de Layout, recursos de Strings, recursos de Style e recursos Drawable.

Nesta dissertação, quando estivermos nos referindo a ambos, componentes (código Java) e recursos (arquivos XML e imagens), chamaremos de elementos da camada de apresentação Android. A seguir introduzimos brevemente cada um dos 8 elementos da camada de apresentação Android, investigados nesta pesquisa:

1. Activity é um dos principais componentes de aplicativos Android e representa uma tela pelo qual o usuário pode interagir com a UI. Possui um ciclo de vida, como mencionado na seção anterior. Toda Activity deve indicar no método de retorno onCreate o recurso de layout que deve ser usado para a construção de sua UI [34, 35].

2. Fragments representam parte de uma Activity e também devem indicar seu recurso de layout correspondente. Fragments só podem ser usados dentro de Activities. Podemos pensar neles como "sub-Activities". Fragments possuem um ciclo de vida extenso, com mais de dez métodos de retorno. Seu ciclo de vida está diretamente ligado ao ciclo de vida da Activity ao qual ele está contido. O principal uso de Fragments é para o reaproveitamento de trechos de UI e comportamento em diferentes Activities [40].

3. Adapters são utilizados para popular a UI com coleções de dados, como por exemplo, uma lista de e-mails, onde o layout é o mesmo para cada item da lista mas o conteúdo é diferente [42].

4. Listeners são interfaces Java que representam eventos do usuário, por exemplo, o OnClickListener captura o clique pelo usuário. Essas interfaces costumam ter apenas um método, onde é implementado o comportamento desejado para responder a interação do usuário [33].

5. Recursos de Layout são XMLs utilizados para o desenvolvimento da estrutura da UI dos componentes Android. O desenvolvimento é feito utilizando uma hierarquia de Views e ViewGroups. Views são caixas de texto, botões, dentre outros. ViewGroups são Views especiais pois podem conter outras Views. Cada ViewGroup organiza suas

\footnotetext{
${ }^{2}$ Até a versão 3.0 do Android Studio, versão mais atual no momento desta escrita, o modelo de projeto padrão, que é pré-selecionado na criação de um novo projeto Android, é o Empty Activity.
} 
Views filhas de uma forma específica, por exemplo: horizontalmente, em tabela, posicionamento relativo, dentre outros. Esta hierarquia pode ser tão simples ou complexa quanto se precisar, mas quanto mais simples, melhor o desempenho [41, 42].

6. Recursos de String são XMLs utilizados para definir textos, conjunto de textos usados no aplicativo. As principais vantagens de se usar recursos de String é o reaproveitamento dos textos em diferentes UIs e a facilidade para internacionalizar [45].

7. Recursos de Style são XMLs utilizados para a definição de estilos a serem aplicados nos XMLs de layout. As principais vantagens em se utilizar recursos Styles é separar o código de estrutura da UI do código que define sua aparência e forma, e também possibilitar a reutilização de estilos em diferentes UIs [46].

8. Recursos de Drawable são arquivos gráficos utilizados na UI. Esses arquivos podem ser imagens tradicionais, .png, . jpg ou .gif, ou XMLs gráficos. A principal vantagem dos XMLs gráficos está no tamanho do arquivo que é comumente bem menor do que imagens tradicionais e, diferente das imagens tradicionais onde é recomendado que se tenha mais de uma versão da mesma em resoluções diferentes, para XMLs gráficos só é necessário uma versão [39].

\subsubsection{Desafios no Desenvolvimento da Camada de Apresentação Android}

Nesta seção, para exemplificarmos o problema de pesquisa, tratamos de dois desafios no desenvolvimento da camada de apresentação Android. O primeiro trata do desenvolvimento de uma tela e o segundo trata da alta complexidade do ciclo de vida de componentes da camada de apresentação em comparação a outros componentes.

\section{Desenvolvimento de Activities}

Activity é um dos principais componentes de aplicativos Android. Ela representa uma tela com UI pelo qual o usuário pode interagir através de botões, listagens, caixas de entrada de textos, dentre outros. Para implementar uma Activity é necessário criar uma classe derivada de Activity e sobrescrever alguns métodos herdados, chamados de métodos de retorno. O principal método de retorno é o onCreate. Entre suas responsabilidades estão a criação da tela e configuração da UI. O Código-Fonte 2.1 apresenta o código mínimo para a criação de uma Activity. Na linha 5 temos o código responsável pela configuração da UI que indica o recurso de layout "main_activity". 


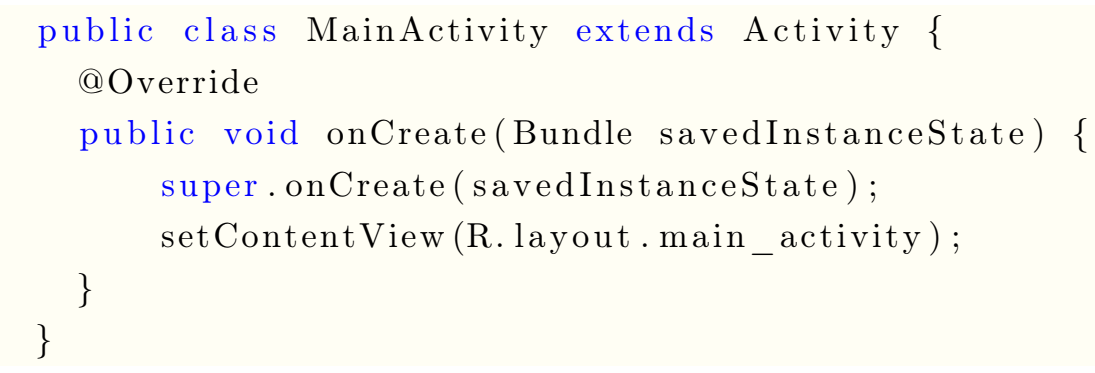

Código-Fonte 2.1: Código mínimo para a criação de uma Activity.

A UI de uma Activity é construída por meio de recursos de layout, arquivos XML cujas marcações provêm do Android SDK e representam Views ou ViewGroups. O Código-Fonte 2.2 apresenta um recurso de layout com duas Views e um ViewGroup. As Views são: um TextView (linhas 7 a 10), que representa uma caixa de entrada de texto, e um Button (linhas 12 a 15), que representa um botão. Essas duas Views estão contidas dentro do ViewGroup LinearLayout (linhas 2 a 5 e marcação de fechamento na linha 16), que as organiza verticalmente (conforme valor do atributo android:orientation na linha 5).

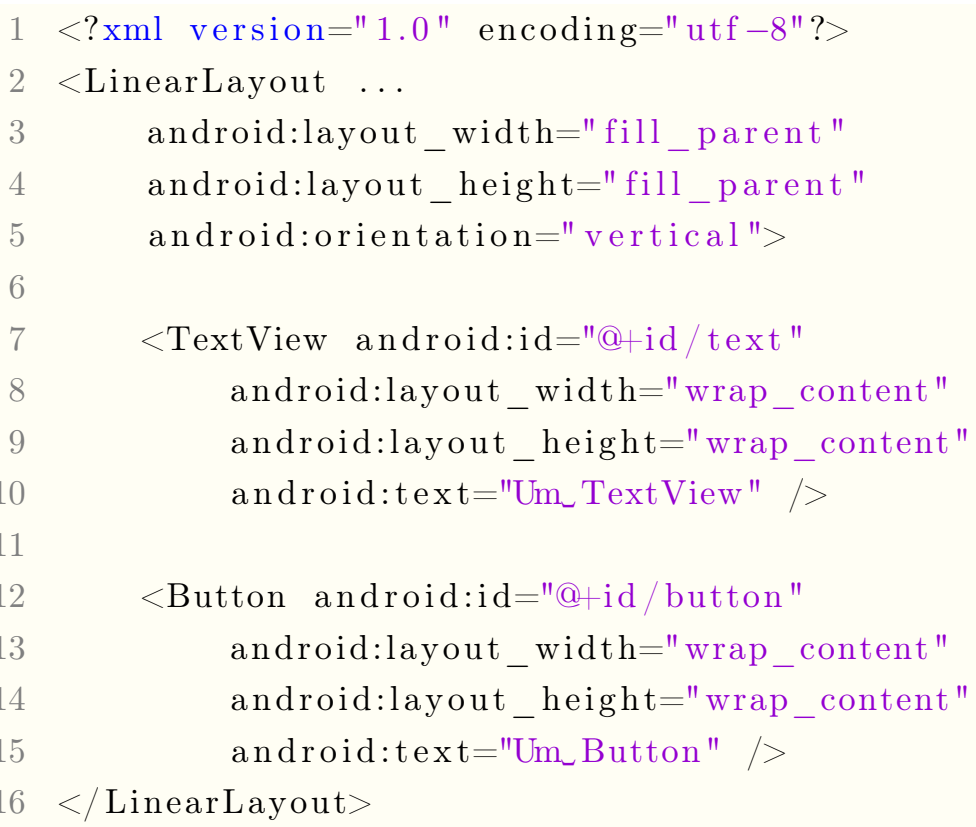

Código-Fonte 2.2: Exemplo de recurso de layout com um campo de entrada de texto e um botão organizados um abaixo do outro.

Os códigos apresentados são bem simples, entretanto, as telas e UIs tendem a ser bem mais robustas e ricas de informações e interatividade. São em contextos como esses que os desafios no desenvolvimento da camada de apresentação Android surgem. UIs ricas e robustas podem significar muitas Views e ViewGroups, resultando em recursos de layout grandes e complexos. E ainda, quanto mais ricas e robustas são as UIs, mais provavelmente o código das Activities correspondentes também serão grandes e complexos, pois são pelas Activities que Views e ViewGroups conseguem interagir com o usuário. Também são pelas Activities que os dados chegam até a UI e vice-versa, dentre muitas outras responsabilidades 
que tendem a ficar com as Activities.

\section{Ciclo de Vida de Componentes}

Toda Activity, bem como outros componentes Android, possui um ciclo de vida. O ciclo de vida de um componente é composto por um conjunto de métodos de retorno, que por sua vez, são métodos chamados pelo sistema operacional Android em uma ordem específica [34] e são responsáveis por criar, manter e destruir o componente.

Os componentes da camada de apresentação Android possuem ciclos de vida mais extensos, e portanto, mais complexos. Como exemplo, na Figura 2.2 apresentamos o ciclo de vida de três componentes Android: Activities $^{3}$ e Fragments, ambos relacionados diretamente à camada de apresentação e Services, componente usado para longos processamentos em segundo plano e portanto, não relacionado diretamente à camada de apresentação. Os métodos de retorno são representados pelos retângulos em cinza. Podemos observar que Activities e Fragments possuem respectivamente sete e onze métodos de retorno, enquanto que Services possuem apenas quatro.

Os ciclos de vida de Activities e Fragments são extensos, com mais de dez métodos de retorno [35]. A Figura 2.2a apresenta os sete principais métodos de retorno de Activities. Além desses sete principais, Activities possuem outros métodos de retorno, dentre eles, onUserLeaveHint, onPostCreate e onPostResume. O ciclo de vida de Services é bem menor se comparado com o de Activities ou Fragments, contendo até quatro métodos de retorno. A Figura 2.2c apresenta a versão mais longa, dentre duas possíveis, do ciclo de vida de Services, que varia de acordo com o método usado na sua criação, podendo ser startService ou bindService.

\subsection{Qualidade de Software}

Antes de entrarmos no tema qualidade de software, é importante abordarmos brevemente sobre qualidade. Há décadas, diversos autores e organizações vêm trabalhando em suas próprias definições de qualidade. Segundo o ISO 9000 [63] desenvolvido pela Organização Internacional de Normalização (ISO, do inglês International Organization for Standardization), qualidade é "o grau em que um conjunto de características inerentes a um produto, processo ou sistema cumpre os requisitos inicialmente estipulados para estes".

Segundo Juran [66], um dos principais autores sobre o assunto, qualidade está relacionado "às características dos produtos que atendem às necessidades dos clientes, e assim, proporcionam a satisfação do mesmo" e a "ausência de deficiências". Stefan [96, p 6] também

\footnotetext{
${ }^{3} \mathrm{~A}$ imagem do ciclo de vida de Activities ilustra apenas os métodos de retorno principais conforme a documentação oficial: https://developer.android.com/guide/components/activities/activity-lifecycle.html
} 


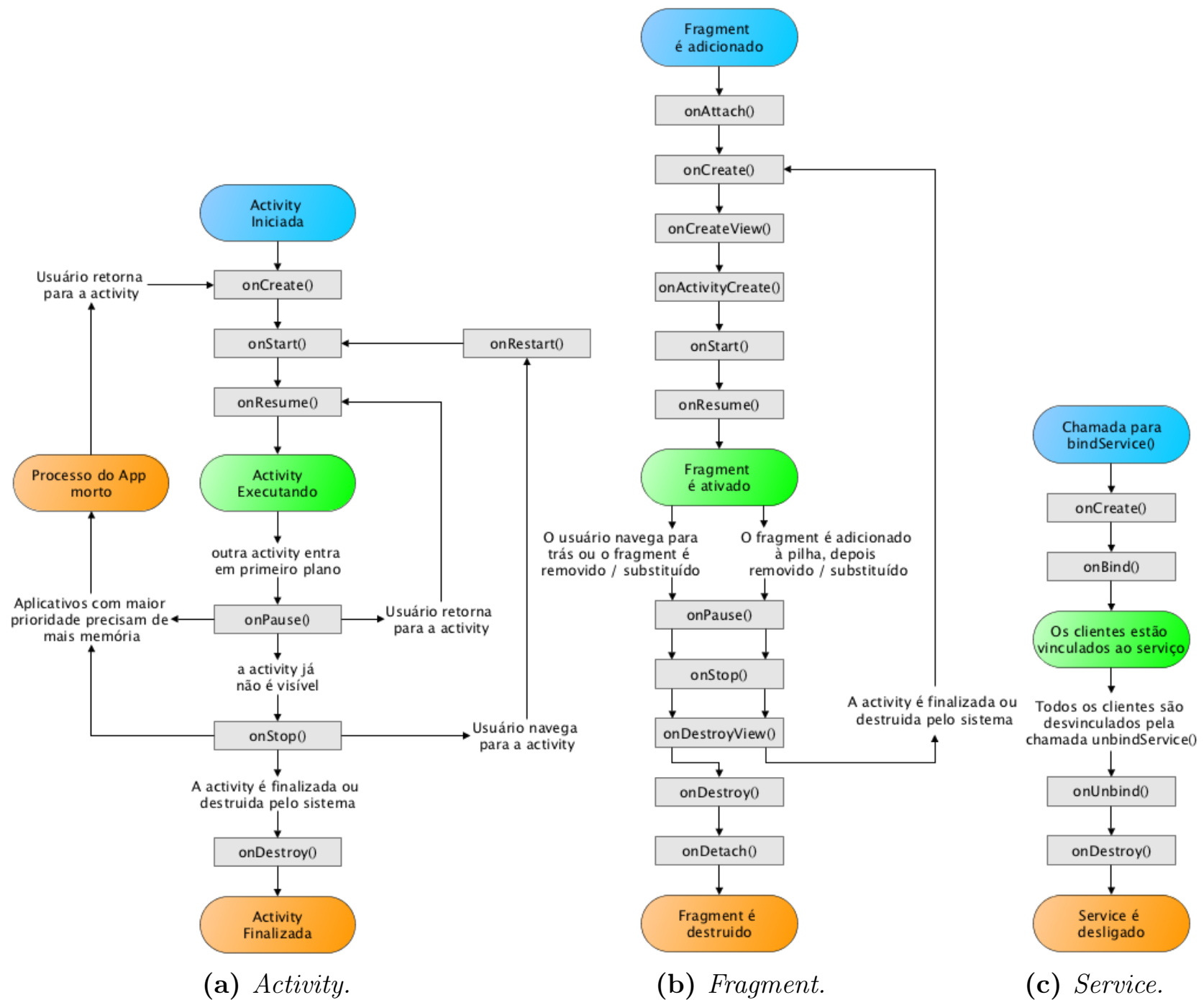

Figura 2.2: Comparativo do ciclo de vida de componentes Android que pertencem e não pertencem à camada de apresentação.

examinou diversas definições e identificou que na maioria delas é possível identificar uma mesma ideia central sobre qualidade: todas elas apontam para "requisitos que precisam ser satisfeitos para ter qualidade".

As primeiras contribuições referentes à qualidade em termos de software foram publicadas no fim da década de 70. Boehm et al. [12] e McCall et al. [75] descrevem modelos de qualidade de software através de conceitos e sub-conceitos. Ambos se utilizaram de uma estratégia de decomposição hierárquica do conceito de qualidade em fatores como manutenibilidade e confiabilidade [96, p 29-30]. Com o tempo, diversas variações desse modelo começaram a surgir. A Tabela 2.1 apresenta algumas dessas variações e uma breve descrição da forma como qualidade de software foi decomposta. Entretanto, o grande valor do modelo de decomposição hierárquico foi a ideia de decompor qualidade até um nível em que seja possível medir e estimar [96].

O padrão ISO/IEC 9126 é considerado ainda como principal referência para a definição de qualidade de software e a define como "a capacidade do produto de software satisfazer às necessidades implicitas e explícitas quando usado em condições específicas" [96, p 10]. 


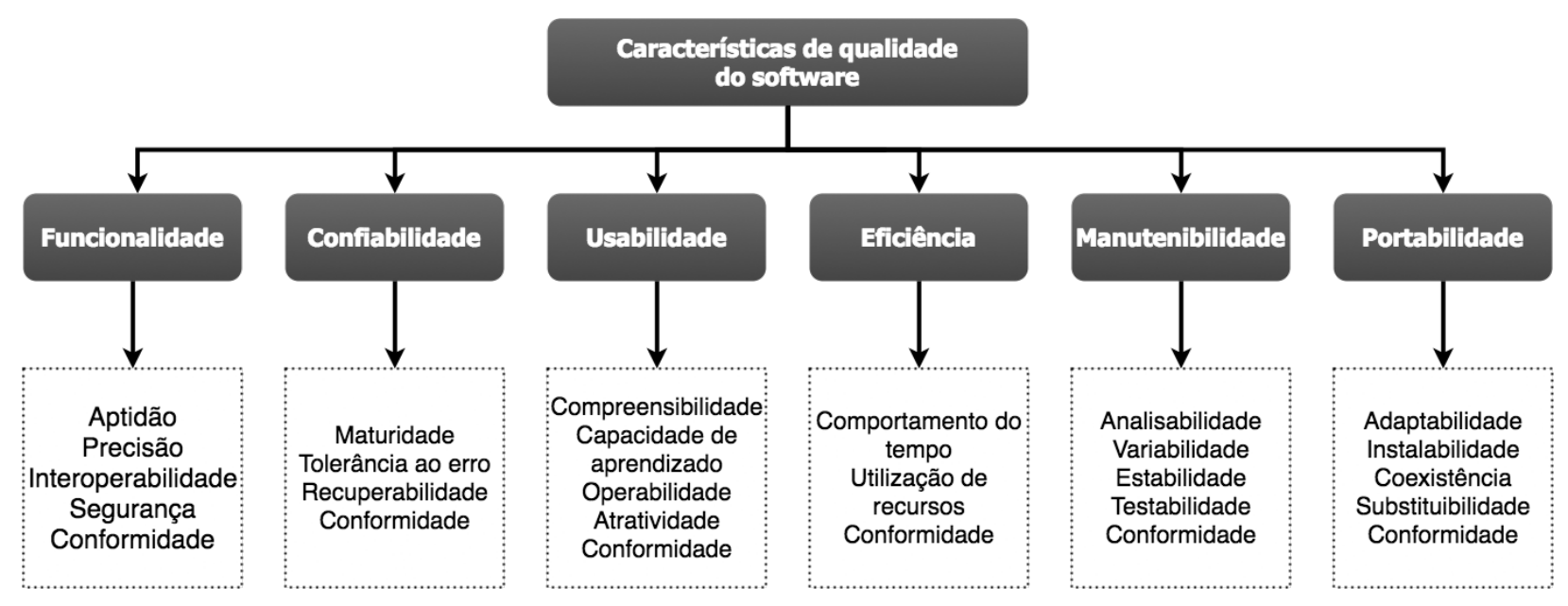

Figura 2.3: Características de qualidade de software segundo norma ISO/IEC 9126 [20].

O ISO/IEC 9126 divide qualidade de software em seis conceitos, cada qual contendo um conjunto de sub-conceitos, conforme apresentado na Figura 2.3. Dentre os conceitos apresentados, os mais relevantes nesta dissertação são manutenibilidade, pois é onde esta pesquisa está inserida, e usabilidade e eficiência, pois é o contexto onde encontramos alguns trabalhos relacionados sobre maus cheiros de código Android [56, 86].

Apresentamos uma breve descrição sobre cada um desses três conceitos a seguir:

1. Manutenibilidade é a capacidade (ou facilidade) do produto de software ser modificado, incluindo tanto as melhorias ou extensões de funcionalidade quanto as correções de defeitos, falhas ou erros. Seus sub-conceitos são:

Tabela 2.1: Modelos de qualidade de software baseados no modelo de decomposição hierárquica de Boehm et al. [12] e McCall et al. [75].

Nome do Modelo Descrição

ISO/IEC 9126

Teve sua primeira publicação em 1991, foi revisado em 2001 e em 2011 substituído pela ISO/IEC 25010, conhecida por SQuaRE (do inglês Systems and software Quality Requirements and Evaluation). Decompõe qualidade de software em 6 áreas: manutenibilidade, eficiência, portabilidade, confiabilidade, funcionalidade e usabilidade [20].

ISO/IEC 25010 (SQuaRE) Teve sua primeira publicação em 2005, revisado em 2011, quando passou a substituir a ISO/IEC 9126. Decompõe qualidade de software em 8 áreas: manutenibilidade, eficiência, portabilidade, confiabilidade, funcionalidade, usabilidade, compatibilidade e segurança [62].

CISQ

Fundado em 2009 [93], decompõe qualidade de software em 4 características: segurança, confiabilidade, desempenho/eficiência e manutenibilidade. Se baseia nas definições do Systems and software Quality Requirements and Evaluation (SQuaRE) [18].

FURPS

FURPS é um acrônimo para: Funcionalidade, Usabilidade, Confiabilidade (do inglês Reliability), Desempenho (do inglês Performance) e Suportabilidade [57]. 
- Analisabilidade Facilidade em se diagnosticar eventuais problemas e identificar as causas das deficiências ou falhas.

- Modificabilidade Facilidade com que o comportamento do software pode ser modificado.

- Estabilidade Capacidade do software de evitar efeitos colaterais decorrentes de modificações introduzidas.

- Testabilidade Capacidade de se testar o sistema modificado, tanto quanto as novas funcionalidades quanto as não afetadas diretamente pela modificação.

2. Usabilidade é a capacidade do produto de software ser compreendido, seu funcionamento aprendido, ser operado e ser atraente ao usuário. Os sub-conceitos são:

- Inteligibilidade Facilidade com que o usuário pode compreender as suas funcionalidades e avaliar se o mesmo pode ser usado para satisfazer as suas necessidades específicas.

- Apreensibilidade Facilidade de aprendizado do sistema para os seus potenciais usuários.

- Operacionalidade Como o produto facilita a sua operação por parte do usuário, incluindo a maneira como ele tolera erros de operação.

- Proteção frente a erros de usuários Como produto consegue prevenir erros dos usuários.

- Atratividade Envolve características que possam atrair um potencial usuário para o sistema, o que pode incluir desde a adequação das informações prestadas para o usuário até os requintes visuais utilizados na sua interface gráfica.

- Acessibilidade Prática inclusiva de fazer softwares que possam ser utilizados por todas as pessoas que tenham deficiência ou não. Quando os softwares são corretamente concebidos, desenvolvidos e editados, todos os usuários podem ter igual acesso à informação e funcionalidades.

3. Eficiência é o tempo de execução e os recursos envolvidos são compatíveis com o nível de desempenho do software. Seus sub-conceitos são:

- Comportamento em Relação ao Tempo Avalia se os tempos de resposta (ou de processamento) estão dentro das especificações.

- Utilização de Recursos Mede tanto os recursos consumidos quanto a capacidade do sistema em utilizar os recursos disponíveis.

Esta pesquisa está inserida no contexto de manutenibilidade, mais especificamente analisabilidade e modificabilidade, pois, conforme descrito na Seção 2.4, maus cheiros de código visam apontar trechos de códigos possivelmente problemáticos que podem se beneficiar de refatorações, melhorando a manutenibilidade do software. 
Muito embora tenhamos ciência de que investir em qualidade pode reduzir os custos de um projeto [14] e aumentar a satisfação dos usuários [13], qualidade de software costuma ser esquecida ou deixada em segundo plano ${ }^{4}$. Frases como "depois eu testo" ou "depois eu refatoro" são comuns no dia a dia de desenvolvimento. Segundo Slaughter et al. [89], investimentos em qualidade são importantes porque cada quantia e hora de trabalho não gasto na correção de problemas podem ser usados para fazer melhores produtos mais rapidamente ou para melhorar produtos e processos existentes. Manutenibilidade está relacionada às "necessidades implícitas do software" [20].

\subsection{Boas Práticas de Software}

No desenvolvimento de software, boas práticas de código são um conjunto de regras que a comunidade de desenvolvimento de software aprendeu ao longo do tempo, e que pode ajudar a melhorar a qualidade do software [76].

Focado em manutenibilidade, ao longo das últimas décadas, diversas boas práticas de software vêm sendo documentadas objetivando servir de ferramenta a desenvolvedores menos experientes para aumentar a qualidade do software. Por exemplo, os padrões de projeto da Gangue dos Quatro [29] (GoF, do inglês Gang of Four) documentam as "melhores soluções para problemas comuns" originadas a partir do conhecimento empírico de desenvolvedores de software experientes.

Em contrapartida, anti-padrões são padrões antes recomendados que passaram a ser evitados, pois percebeu-se que os problemas em usá-los superavam os benefícios [15]. Um dos mais notáveis exemplos de anti-padrão é o Singleton, que visa limitar a instanciação de uma classe em um único objeto [29]. É relevante destacar que, enquanto que padrões de projetos são conceitos que indicam "o que fazer", anti-padrões e maus cheiros são conceitos que servem como alertas sobre "o que não fazer" ou sobre "o que evitar".

A seguir introduzimos conceitos sobre as seguintes boas práticas: Padrões de Projetos, Anti-Padrões e Maus Cheiros de Código.

\subsubsection{Padrões de Projeto}

"Cada padrão descreve um problema no nosso ambiente e o cerne de sua solução, de tal forma que você possa usar essa solução mais de um milhão de vezes, sem nunca fazê-lo da mesma maneira."

- Christopher Alexander, Uma Linguagem de Padrões [6]

Não podemos falar sobre padrões de projetos sem antes falarmos sobre padrões. Segundo

\footnotetext{
${ }^{4}$ http://www.ifsq.org/resources/level-2/booklet.pdf
} 
o dicionário Oxford um padrão é "algo que serve como modelo, um exemplo para os outros seguirem" [24]. Padrões não são invenção de algo novo, são uma forma de organizar o conhecimento proveniente de experiências [16].

Para engenharia de software, a principal definição sobre padrões provém do livro do arquiteto Christopher Alexander (1977) [6] onde ele define um padrão como sendo uma regra de três partes que expressa a relação entre um contexto, um problema e uma solução. Fowler [27] apresenta uma definição mais simples que diz que "um padrão é uma ideia que foi útil em algum contexto prático e provavelmente será útil em outros".

Inspirados por Alexander [6], Kent Beck e Ward Cunnigham fizeram alguns experimentos do uso de padrões na área de desenvolvimento de software e apresentaram os resultados na OOPSLA em 1987. Apoiando-se na definição de padrões de Alexander [6], o livro Padrões de Projeto (1994) [29] foi o primeiro a ser lançado sobre padrões relacionados a software, documentando 23 padrões de projetos.

Para se documentar um padrão, é comum seguir um formato específico. O formato indica onde e como cada uma das informações (problema, contexto ou solução) serão formatadas. Alguns formatos incluem uma série de outras informações além dessas três. Ao longo dos anos, alguns formatos foram se destacando. A Figura 2.4 apresenta a tradução de um gráfico criado por Joshua Kerievsky [67] contendo quatro formatos existentes de se escrever padrões. Os formatos são nomeados como Portland, Coplien, GoF e Alexandrino, e foram posicionadas no gráfico de acordo com seu nível de maturidade e clareza.

É possível observar na Figura 2.4 que quanto mais para cima e mais à direita do gráfico, mais claro e maduro é o formato do padrão. Sendo assim, o mais claro e maduro é o formato

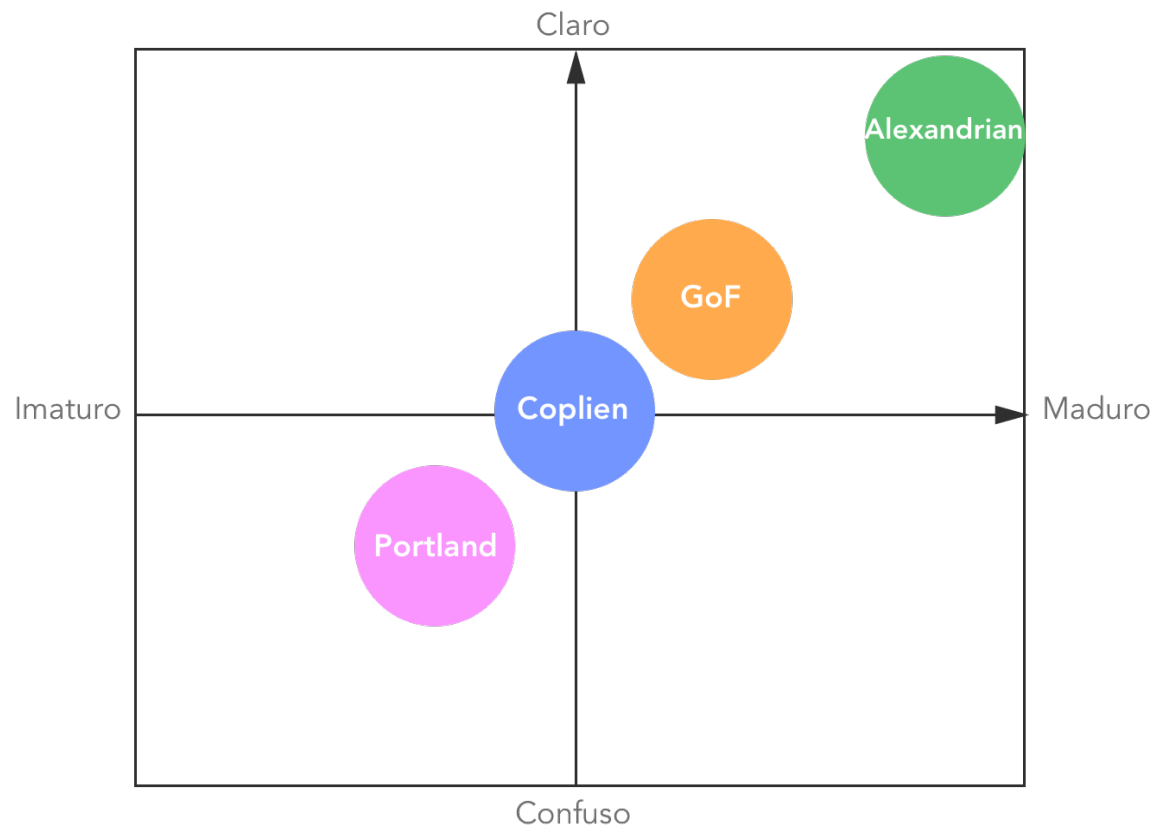

Figura 2.4: Formatos de padrões de acordo com seu nível de maturidade e clareza segundo Joshua Kerievsky [67]. 
Alexandrino seguido por GoF, Coplien e por último Portland.

\subsubsection{Anti-Padrões}

"Um anti-padrão é como um padrão, exceto que em vez de uma solução, ele dá algo que parece superficialmente como uma solução, mas não é."

- Andrew Koenig, O Manual de Padrões: Técnicas, Estratégias e Aplicações [70]

Um anti-padrão é uma resposta comumente usada para um problema recorrente que geralmente é ineficaz e corre o risco de ser altamente contraproducente. O termo foi cunhado por Andrew Koenig em um artigo publicado em 1995 [70], inspirado pelo livro GoF [29].

O termo se popularizou três anos após, no livro de Brown et al. (1998) [15]. Segundo os autores, para diferenciar um anti-padrão de um mau hábito, má prática ou ideia ruim é necessário que o anti-padrão apresente dois elementos principais:

1. Existe um processo, estrutura ou padrão de ação comumente usado que, apesar de inicialmente parecer ser uma resposta adequada e efetiva a um problema, tem mais consequências ruins do que as boas;

2. Existe outra solução que é documentada, repetitiva e provada ser eficaz.

É muito comum ver o termo anti-padrão ser equivocadamente usado para indicar mau cheiro de código. O equívoco ocorre geralmente por ambos tratarem de práticas que influenciam negativamente a manutenibilidade do software. Entretanto, anti-padrões se diferem de maus cheiros pois maus cheiros são sintomas que podem ou não indicar um problema mais profundo no código enquanto que um anti-padrão é uma solução com passos bem definidos para um problema específico, porém uma solução que deixou de ser recomendada.

\subsection{Maus Cheiros de Código}

"Maus cheiros são certas estruturas no código que indicam a violação de principios fundamentais de design e impactam negativamente a qualidade do projeto."

- Refactoring for Software Design Smells: Managing Technical Debt [91]

Um mau cheiro de código é uma sugestão de que algo não está certo no código, semelhante ao dito popular "Algo não cheira bem!" quando alguém desconfia de que há algum problema em dada situação. Segundo Fowler [28], maus cheiros "são indicações de que existe um problema que pode ser resolvido por meio de uma refatoração". Do ponto de vista de 
qualidade de software, "são certas estruturas no código que indicam a violação de princípios fundamentais de design e impactam negativamente a qualidade do projeto." [91, p. 258].

Entretanto, maus cheiros não são erros - eles não estão tecnicamente incorretos e não impedem o funcionamento do software. Em vez disso, eles indicam deficiências no código que podem dificultar a manutenibilidade do software e aumentar o risco de erros ou falhas no futuro [68, 88, 101, 103].

O livro de Webster (1995) [97] foi um dos primeiros livros a usar o conceito de maus cheiros através do termo "armadilha". No livro são apresentadas 82 armadilhas no desenvolvimento orientado a objetos originadas da experiência do autor. Método Longo e Complexidade Excessiva, por exemplo, são definidos na armadilha Letting objects Become Bloated [97, p. 180]. Há indícios informais de que o termo "maus cheiros de código" foi cunhado em meados da década de 90 por Kent Beck [98, 99]. Apesar do conceito já permear em livros e publicações sobre desenvolvimento de software desde o começo da década de 90, o termo só se popularizou após o livro de Fowler (1999) [28].

No livro de Fowler [28] são apresentados 22 maus cheiros e mais de 70 técnicas de refatoração. Código Duplicado [28, p. 63] é um exemplo de mau cheiro que trata de problemas comuns que podem resultar na duplicação de código, por exemplo, ter a mesma expressão em dois métodos da mesma classe ou em duas subclasses irmãs. Para resolver este mau cheiro é indicada a refatoração Extrair Método [28, p. 89], ou seja, extrair a expressão duplicada para um novo método e substituí-lo nos lugares onde a expressão era usada.

Maus cheiros provêm do profundo conhecimento e experiências de desenvolvedores experientes que, ao longo dos anos, desenvolveram a "intuição" para a boa arquitetura possibilitandoos olhar para uma arquitetura ou código e obter imediatamente uma intuição sobre sua qualidade, sem ter que dar argumentos logicamente detalhados sobre o porquê de sua conclusão [98]. Ou seja, maus cheiros são por natureza subjetivos, baseados em opiniões e experiências [25, 94]. No livro de Martin (2008) [74], que se tornou muito popular entre desenvolvedores de software, são definidos novos maus cheiros além de citar alguns já apresentados por Fowler [28]. O autor se apoia na definição de Fowler para explicar o conceito de mau cheiro.

\subsubsection{Formato dos Maus Cheiros}

Os primeiros maus cheiros definidos vieram em formato textual e diferente do que vimos com padrões, não encontramos referências formais sobre como documentar adequadamente um mau cheiro.

Fowler [28] por exemplo, se utiliza de título e um texto explicativo. No texto explicativo, é possível encontrar informações sobre contexto, exemplos de problemas comuns e possíveis refatorações que resolveriam o mau cheiro. Na caixa a seguir, exemplificamos o mau cheiro Código Duplicado [28, p. 71]. O título do mau cheiro indica o contexto por ele tratado. No 
parágrafo (1) podemos observar um breve resumo do que faz "cheirar mal" e uma possível refatoração. Nos parágrafos seguintes (2-4) são apresentadas em mais detalhes situações comuns que podem indicar a presença do mau cheiro.

\section{Código Duplicado}

O número um no ranking dos cheiros é o código duplicado. Se você vir o mesmo código em mais de um lugar, pode ter certeza de que seu programa será melhor se você encontrar uma maneira de unificá-los (1).

O problema mais simples de código duplicado é quando você tem a mesma expressão em dois métodos da mesma classe. Tudo o que você tem que fazer então é utilizar o Extrair Método e chamar o código de ambos os lugares (2).

Outro problema de duplicação comum é quando você tem a mesma expressão em duas subclasses irmãs. Você pode eliminar essa duplicação usando Extrair Método em ambas as classes e então Subir Método na Hierarquia. Se o código for similar mas não o mesmo, você precisa usar Extrair Método para separar as partes semelhantes daquelas diferentes. Você pode então descobrir que pode usar Criar um Método Padrão. Se os métodos fazem a mesma coisa com um algoritmo diferente, você pode escolher o mais claro deles e usar Substituir o Algoritmo (3).

Se você tem código duplicado em duas classes não relacionadas, considere usar Extrair Classe em uma classe e então usar o novo componente na outra. Uma outra possibilidade é de que o método realmente pertença a apenas uma das classes e deva ser chamado pela outra ou que o método pertença a uma terceira classe que deva ser referida por ambas as classes originais. Você tem que decidir onde o método faz mais sentido e garantir que ele esteja lá e em mais nenhum lugar (4).

Martin [74] usa a mesma estrutura usada por Fowler e adiciona a ela uma sigla. O texto explicativo é apresentado em parágrafo único e é possível encontrar contexto, alguns exemplos de problemas comuns e exemplos de código, sendo que alguns maus cheiros apresentam todas essas informações ou apenas uma combinação delas. O título usado por Martin aponta de certa forma o problema (o uso de convenção durante o desenvolvimento) e a solução (sempre que possível, preferir o uso de estruturas acima da convenção).

A seguir temos o mau cheiro G27: Estrutura acima de convenção [74, p. 301]. No texto explicativo em parágrafo único, podemos observar em orações a mesma estrutura que vimos no mau cheiro anterior, porém em parágrafos. Na oração (1) temos algo relacionado ao que faz cheirar mal, na oração (2) uma possível refatoração, na (3) é dado um exemplo e na (4) é indicado o problema resultante de se basear em convenção. 


\section{G27: Estrutura acima de convenção}

Insista para que as decisões do projeto baseiem-se em estrutura acima de convenção (1). Convenções de nomenclaturas são boas, mas são inferiores a estruturas, que forçam um certo cumprimento (2). Por exemplo, switch/ case com enumerações bem nomeadas são inferiores a classes base com métodos abstratos (3). Ninguém é obrigado a implementar a estrutura switch/case da mesma forma o tempo todo; mas as classes bases obrigam a implementação de todos os métodos abstratos das classes concretas (4).

Em pesquisas que definem novos maus cheiros, observamos um formato similar aos mencionados porém, adicionado uma estratégia de detecção, com foco em automatizar a identificação do mau cheiro $[9,30]$. Nesta pesquisa os maus cheiros serão de modo textual simples, com título e descrição, porque estão em seu estado inicial. 


\section{Capítulo 3}

\section{Trabalhos Relacionados}

Aplicativos Android são desenvolvidos, em sua maioria, utilizando a linguagem de programação Java [49]. Deste modo, um provável questionamento é: "Por que investigar maus cheiros específicos ao Android quando já existem tantos maus cheiros e boas práticas documentadas para linguagens orientada a objetos como o Java?". Para responder essa pergunta temos as seguintes seções:

- A Seção 3.1 apresenta pesquisas em torno de maus cheiros tradicionais. Existem diversos maus cheiros tradicionais catalogados. As pesquisas mais recentes buscam investigar as relações e implicações decorrentes da presença desses maus cheiros.

- A Seção 3.2 apresenta pesquisas que têm demonstrado que diferentes tecnologias podem apresentar maus cheiros específicos. Há pesquisas que concluem que, tecnologias usadas na camada de apresentação de sistemas web tradicionais, apresentam maus cheiros diferentes das tecnologias usadas no restante do sistema. Essas pesquisas reforçam nossa hipótese de que o desenvolvimento da camada de apresentação Android também pode apresentar maus cheiros específicos e distintos do restante do código do aplicativo.

- A Seção 3.3 apresenta pesquisas que investigaram (i) a presença de maus cheiros tradicionais em aplicativos Android, (ii) a existência de maus cheiro específicos ao Android e também (iii) compararam a presença de maus cheiros tradicionais com relação à presença de maus cheiros específicos em aplicativos Android. Essas pesquisas reforçam a relevância de investigarmos maus cheiros Android pois concluem que maus cheiros específicos aparecem com maior frequência do que os maus cheiros tradicionais.

Ao final desta seção esclarecemos os motivos pelo qual optamos por investigar maus cheiros de código relacionados à camada de apresentação Android e também damos uma visão sólida do estado da arte sobre o assunto. 


\subsection{Maus Cheiros Tradicionais}

Provavelmente o livro de Webster (1995) [97] foi o primeiro catálogo de maus cheiros relacionados ao desenvolvimento orientado a objetos. Desde então, diversos desenvolvedores e pesquisadores têm estudado esse assunto. Como exemplo, Riel (1996) [64] documentou mais de 60 heurísticas diferentes sobre o que representa um bom código orientado a objetos. Fowler (1999) [28] sugere refatorações para mais de 20 maus cheiros de código tradicionais. Maus cheiros como Classe Deus e Inveja dos Dados são populares entre desenvolvedores e ferramentas de detecção automática de maus cheiros como por exemplo PMD [1] e Sonar [2].

Alguns pesquisadores têm focado seus esforços em entender os impactos de maus cheiros na qualidade de projetos. Khomh et al. [68] conduziram um experimento empírico onde perceberam que classes afetadas por maus cheiros tendem a sofrer com mais alterações do que classes sem maus cheiros. Em outro estudo, Khomh et al. [69] perceberam que além de maus cheiros impactarem negativamente a tendência à mudanças, também impactam negativamente a tendência a defeitos.

Li e Shatnawi [71] também analisaram empiricamente o impacto de maus cheiros e mostraram que existe uma alta relação entre a tendência a defeitos e alguns maus cheiros. Yamashita e Moonen [103] mostraram que a existência de mais do que um único mau cheiro em uma classe pode afetar negativamente a manutenção desse trecho de código. Essa conclusão é confirmada por Abbes at al. [4] num experimento controlado para investigar o impacto de alguns maus cheiros na compreensão do sistema. Os autores mostraram que a existência de um único mau cheiro em uma classe não diminui significativamente o desempenho de um desenvolvedor durante as tarefas de manutenção. No entanto, quando uma classe apresenta mais de um mau cheiro, o desempenho do desenvolvedor é significativamente reduzido.

Outros pesquisadores têm estudado sobre como os maus cheiros são percebidos por desenvolvedores. Palomba et al. [82] conduziram um experimento empírico para avaliar a percepção por desenvolvedores sobre maus cheiros tradicionais. Os resultados mostraram que maus cheiros "simples" são facilmente percebidos por desenvolvedores. Entretanto, a experiência e conhecimento desempenham um papel importante na identificação de maus cheiros relacionados à boas práticas de desenvolvimento orientado a objetos.

Taibi et al. [92] investigaram a percepção de desenvolvedores sobre maus cheiros tradicionais, os autores focaram em desenvolvedores experientes totalizando mais de 100. Os resultados mostraram que apesar de desenvolvedores considerarem alguns maus cheiros críticos na teoria, na prática eles são mais toleráveis. Hozano et al. [61] investigaram a similaridade com que maus cheiros são percebidos por desenvolvedores. Seus resultados mostraram que desenvolvedores identificam maus cheiros de diversas formas diferentes. No entanto, grupos de desenvolvedores que utilizaram a mesma heurística apresentaram um maior grau de concordância do que grupos de desenvolvedores que apresentavam a mesma experiência. 
Arcoverde et al. [11] realizaram uma pesquisa para entender como os desenvolvedores reagem à presença de maus cheiros de código. Os resultados mostraram que desenvolvedores adiam a remoção para evitar modificações da API (do inglês Application Program Interface). Peters e Zaidman [83] analisaram o comportamento dos desenvolvedores em relação ao ciclo de vida dos maus cheiros e os resultados mostraram que, mesmo quando os desenvolvedores estão conscientes da presença de um mau cheiro, eles não refatoram.

\subsection{Maus Cheiros Específicos a uma Tecnologia}

A constante e rápida evolução de tecnologias existentes e a criação de novas tecnologias faz com que diversos temas, como manutenibilidade de sistemas, estejam também em constante alta. Muitos pesquisadores vêm pesquisando sobre a existência de maus cheiros de código específicos a uma dada tecnologia, por exemplo, arcabouços Java [9, 17], a linguagem CSS (do inglês Cascading Style Sheets) [30] e fórmulas em planilhas [84].

Chen et al. [17] viram a necessidade de estudar maus cheiros de código em arcabouços de Mapeamento Objeto-Relacional (ORM, do inglês Object-Relational Mapping) pelo grande uso pela indústria e pela desatenção de desenvolvedores sobre ao impacto de seus códigos no desempenho do banco de dados que podiam causar estouro no limite de tempo de processamento e paradas nos sistemas. Os autores implementaram um arcabouço automatizado e sistemático para detectar e priorizar anti-padrões de desempenho em aplicações desenvolvidas usando ORM e também mapearam 2 anti-padrões específicos a arcabouços ORM.

Aniche et al. [8, 9, 10] investigaram maus cheiros de código relacionado ao arcabouço Spring MVC (do inglês Model View Controller), usado para o desenvolvimento da camada de apresentação de aplicações web Java. Os autores encontraram maus cheiros específicos de cada papel arquitetural do arcabouço Spring MVC: Modelo, Visualização e Controladora. Eles afirmam que cada papel arquitetural possui responsabilidades diferentes e que isso resulta em distribuições diferentes de valores de métricas de código e maus cheiros diferentes. Dentre as principais contribuições desse estudo, está um catálogo com 6 maus cheiros específicos validados relacionados ao arcabouço Spring MVC.

Gharachorlu [30] investigou maus cheiros em código CSS, linguagem amplamente utilizada na camada de apresentação de aplicações web para separar a semântica de apresentação do conteúdo HTML. De acordo com o autor, apesar da simplicidade de sintaxe do CSS, as características específicas da linguagem tornam a criação e manutenção de CSS uma tarefa desafiadora. Foi realizado um estudo empírico de larga escala onde os resultados indicaram que o CSS de hoje sofre significativamente de padrões inadequados e está longe de ser um código bem escrito. O autor propõe o primeiro modelo de qualidade de código CSS derivado de uma grande amostra de modo a ajudar desenvolvedores a obterem uma estimativa do 
número total de cheiros de código em seu código CSS. Sua principal contribuição foi um conjunto de 8 novos maus cheiros CSS detectados com o uso da ferramenta CSSNose, também implementada e disponibilizada pelo autor.

Fard e Ali [25] investigaram maus cheiros de código no Javascript, que é uma flexível linguagem de script para o desenvolvimento do comportamento do lado do cliente, que faz parte da camada de apresentação de aplicações web. Os autores afirmam que, devido a essa flexibilidade, o JavaScript é uma linguagem particularmente desafiadora para escrever e manter código. Um dos desafios citados é que, diferentemente de aplicativos Android, que são compilados, o Javascript é interpretado. Isso significa que normalmente não há compilador no ciclo de desenvolvimento para ajudar desenvolvedores a detectar código incorreto ou não otimizado. Além desses desafios, os autores também indicam como problema a natureza dinâmica, fracamente tipificada e assíncrona do Javascript. Eles propõem um conjunto de 13 maus cheiros de código JavaScript, sendo 7 maus cheiros tradicionais adaptados para o JavaScript e 6 maus cheiros específicos ao JavaScript derivados da pesquisa. Também é apresentada uma técnica automatizada, chamada JSNOSE, para detectar esses maus cheiros.

Uma interessante relação que vemos é que muitas pesquisas buscaram por maus cheiros específicos em tecnologias usadas na camada de apresentação de aplicações web [9, 25, 30] o que reforça nossa hipótese de que aplicativos Android podem seguir o mesmo comportamento possivelmente apresentando maus cheiros específicos à camada de apresentação não encontrados necessariamente nos demais códigos do aplicativo.

\subsection{Maus Cheiros em Aplicativos Android}

Pesquisas relacionadas a maus cheiros em aplicativos Android ainda são poucas. Umme et al. [73] afirmam que, das principais conferências de manutenção de sistemas, dentre 2008 a 2015, apenas $10 \%$ dos artigos consideraram em suas pesquisas projetos Android. Nenhuma outra plataforma móvel foi considerada. As conferências consideradas foram: ICSE, FSE, OOPSLA/SPLASH, ASE, ICSM/ICSME, MRS e ESEM.

Dentre as pesquisas relacionadas, para efeito desta pesquisa, temos: a Seção 3.3.1 com pesquisas que buscaram por maus cheiros tradicionais em aplicativos Android, a Seção 3.3.2 com pesquisas que buscaram por maus cheiros específicos a aplicativos Android, grupo ao qual nossa pesquisa está inserida e a Seção 3.3.3 com pesquisas que buscaram ambos os maus cheiros, específicos e tradicionais, em aplicativos Android e comparam a frequência e relevância entre eles. 


\subsubsection{Maus Cheiros Tradicionais em Aplicativos Android}

Linares-Vásquez et al. [72] usaram a ferramenta DECOR para realizar a detecção de 18 diferentes anti-padrões orientado a objetos em aplicativos móveis desenvolvidos com J2ME (do inglês Java Mobile Edition) e entender a relação dos maus cheiros com o domínio do negócio e métricas de qualidade. Dentre as principais conclusões do estudo temos que, existe uma grande diferença nos valores das métricas de qualidade em aplicativos afetados pelos maus cheiros e pelos que não são, e que enquanto há maus cheiros presentes em todos os domínios, alguns são mais presentes em domínios específicos.

Verloop [95] investigou a presença de maus cheiros de código tradicionais propostos por Fowler [28] (Método Longo, Classes Grande, Lista de Parâmetros Longa, Inveja dos Dados e Código Morto) em aplicativos Android para determinar se esses maus cheiros ocorrem mais frequentemente em "classes núcleo", classes no projeto Android que precisam herdar de classes do Android SDK, como por exemplo Activities, Fragments e Services, comparando com classes "não núcleo". Para isso, ele fez uso de 4 ferramentas de detecção automática de maus cheiros: JDeodorant, Checkstyle, PMD e UCDetector.

O autor afirma que classes núcleos tendem a apresentar os maus cheiros: Classe Deus, Método Longo, Comandos Switch e Checagem de Tipo pela sua natureza de muitas responsabilidades. As classes mais observadas com esses maus cheiros foram Activities, que é o principal componente da camada de apresentação Android. O autor também conclui que o mau cheiro tradicional Longa Lista de Parâmetros é menos provável de aparecer em classes núcleo pois, nessas classes, a maioria dos métodos são sobrecargas de métodos da classe herdada proveniente do Android SDK, e como para se realizar uma sobrecarga de método é necessário seguir a assinatura do método original, este normalmente não é afetado por este mau cheiro. Maus cheiros tradicionais não foram pensados considerando a natureza de projetos Android, que neste caso está relacionada à herança de classes núcleo.

Verloop [95] conclui propondo cinco refatorações com o objetivo de mitigar o mau cheiro Método Longo que se apresentou por diversos motivos em Activities e Adapters. Dentre essas cinco propostas de refatoração, ele implementou e experimentou três. porém após as refatorações, alguns códigos ainda apresentavam o mau cheiro.

É interessante notar que dentro da definição de Verloop [95] de classes núcleo, estão incluídas classes que herdam de Services e todas as demais que herdam de alguma classe do SDK Android, porém as únicas classes que apresentaram maus cheiros foram Activities e Adapters. Como vimos em 2.1, essas classes são responsáveis por lidar com a camada de apresentação Android. Isso reforça nossa hipótese de que podem haver maus cheiros específicos à camada de apresentação Android, não existentes no restante dos códigos do aplicativo, e por isso é interessante estudar mais a fundo. 


\subsubsection{Maus Cheiros Específicos a Aplicativos Android}

Gottschalk et al. [56] conduziram um estudo sobre formas de detectar e refatorar maus cheiros de código relacionados ao uso eficiente de energia. Os autores compilaram um catálogo com 6 maus cheiros de código extraídos de outros trabalhos, e trabalharam sob um trecho de código Android para exemplificar um deles, o Carregar Recurso Muito Cedo, quando algum recurso é alocado muito antes de precisar ser utilizado. Essa pesquisa é relacionada à nossa por ambas considerarem a tecnologia Android e se diferenciam pois focamos na busca por maus cheiros de código relacionados à manutenibilidade enquanto os autores tratam de eficiência, conforme conceitos de qualidade de sistemas apresentados da Seção 2.2.

Reimann et al. [86] correlacionam os conceitos de mau cheiro, qualidade e refatoração a fim de introduzir o termo mau cheiro de qualidade. Segundo os autores, um mau cheiro de qualidade é uma estrutura que influencia negativamente requisitos de qualidade específicos, que podem ser resolvidos por refatorações [85]. Os autores compilaram um catálogo de 30 maus cheiros de qualidade para Android. O formato dos maus cheiros de qualidade inclui: nome, contexto, requisitos de qualidade afetados e descrição. Esse formato foi baseado nos catálogos de Brown et al. [15] e Fowler [28]. Todo o catálogo pode ser encontrado online ${ }^{1}$ e os mesmos também foram implementados no arcabouço Refactory [85]. Os requisitos de qualidade tratados por Reimann et al. [86] são: centrados no usuário (estabilidade, tempo de inicio, conformidade com usuário, experiência do usuário e acessibilidade), consumo inteligente de recursos de hardware do dispositivo (eficiência no uso de energia, processamento e memória) e segurança.

Reimann et al. [86] citam que "o problema no desenvolvimento móvel é que os desenvolvedores estão cientes dos maus cheiros de qualidade apenas indiretamente, que suas definições são informais como melhores práticas e discussões em fóruns". Continua dizendo que "os recursos para encontrá-los são distribuídos pela web e que é difícil coletar e analisar todas essas fontes sob um ponto de vista comum e fornecer suporte de ferramentas para desenvolvedores". Os autores derivaram os 30 maus cheiros de boas e más práticas documentadas na documentação online oficial do Android e de postagens em blogs de desenvolvedores que reportaram suas experiências.

\subsubsection{Maus Cheiros Tradicionais e Específicos em Aplicativos An- droid}

Hetch [59] utilizou a ferramenta de deteç̧ão de maus cheiros Páprika² para identificar 8 maus cheiros, dos quais 4 são tradicionais: Classe Blob [15], Canivete Suíço [15], Classe Complexa [28] e Método Longo [28] e 4 são Android: Internal Getter/Setter [86], No Low

\footnotetext{
${ }^{1}$ http://www.modelrefactoring.org/smell_catalog

${ }^{2}$ https://github.com/geoffreyhecht/paprika
} 
Memory Resolver [86], Member Ignoring Method [86] e Leaking Inner Class [86]. O autor buscou os maus cheiros em 15 aplicativos Android populares como Facebook, Skype e Twitter. Isso foi possível pois a ferramenta Páprika utiliza o APK, arquivo instalável Android, para extrair os dados para análise e mesmo esses aplicativos não sendo software livre, o Páprika consegue extrair os dados a partir do instalável. Um ponto importante é que apesar de o autor utilizar o termo anti-padrão, ele se baseia em outras pesquisas que definiram os "anti-padrões" por ele analisado como maus cheiros de código. Logo, seguiremos com o termo mau cheiro daqui em diante.

Hetch [59] afirma que os maus cheiros tradicionais são tão frequentes em aplicativos Android como em não Android, com exceção do Canivete Suíço. Essa afirmação nos leva a entender que ele teria comparado a presença dos maus cheiros tradicionais em sistemas tradicionais com os mesmos maus cheiros em aplicativos Android, entretanto, não há informações de como o autor obteve a informação da presença de maus cheiros em projetos de sistemas tradicionais para compará-la com o resultado obtido em aplicativos Android.

Segundo o autor, Activities tendem a ser mais sensíveis ao mau cheiro Classe Blob [15] (semelhante aos maus cheiros Classe Deus [64] e Classe Grande [28]). Conclusão essa muito similar a de Verloop [95]. Esses resultados reforçam nossa hipótese de que, códigos pertencentes à camada de apresentação Android, são mais propensos a apresentar trechos de códigos problemáticos. Ainda segundo o autor, maus cheiros específicos Android são muito mais frequentes do que os maus cheiros tradicionais. Essa constatação reforça a importância de se investigar quais seriam outros possíveis maus cheiros específicos ao Android, uma vez que eles tendem a se manifestar mais do que os maus cheiros tradicionais em aplicativos Android.

Podemos notar algumas semelhanças nos trabalhos citados. A primeira semelhança importante é que diversas pesquisas que analisam a presença de maus cheiros, sejam tradicionais ou específicos ao Android, sentem a necessidade de delimitar o código a ser analisado. Podemos observar isso nos trabalhos de Verloop [95] e Minelli e Lanza [77] através do termo "classes/códigos núcleos" onde, em ambas as pesquisas, significam classes que herdam do Android SDK. Essa delimitação exclui todo o código puramente Java existente no projeto Android, chamado pelos autores de "classes não núcleo", que são classes Java tradicionais, pelo qual continua sendo possível a utilização de diversas boas práticas já existentes na literatura.

Ainda com relação à delimitação do código, outra semelhança interessante é que, apesar de a definição de classes núcleo incluir classes como Services, AsyncTasks e muitas outras existentes no Android SDK, as classes que apareceram nos resultados se limitaram a $A c$ tivities e Adapters, utilizadas respectivamente para a construção e resposta a eventos da camada de apresentação Android.

Essas semelhanças reforçaram nosso intuito de focar nossa pesquisa no código relacionado 
à camada de apresentação Android, partindo da hipótese de que existem maus cheiros específicos a ela. De modo que pretendemos pela primeira vez catalogar maus cheiros de código, relacionados à manutenibilidade, especificamente relacionados à camada de apresentação de aplicativos do Android. 


\section{Capítulo 4}

\section{Método de Pesquisa}

O objetivo desta pesquisa é catalogar maus cheiros da camada de apresentação Android. Deste modo, optamos por realizar uma pesquisa exploratória de gênero empírico e de abordagem mista [23]. Segundo pesquisas [11, 82, 102], a percepção empírica desempenha um importante papel na definição de maus cheiros de código relacionados a uma tecnologia específica, principalmente considerando a natureza subjetiva intrínseca a maus cheiros [25, 94].

Nossa abordagem mista se apresenta de modo que os maus cheiros são originados a partir de dados qualitativos coletados por meio de dois questionários online respondidos por 246 desenvolvedores Android. Enquanto os dados quantitativos provêm de um experimento de código online onde obtivemos 70 respostas. Nesse experimento buscamos avaliar a percepção negativa dos maus cheiros propostos, por desenvolvedores Android, pelo qual, devido a quantidade de participantes, foi possível avaliar 7 maus cheiros. Os resultados mostraram que desenvolvedores percebem os códigos afetados por 6 dos maus cheiros avaliados como problemáticos.

Esta pesquisa foi realizada em três etapas conforme apresentado na Figura 4.1. Cada qual objetivando responder a uma questão de pesquisa. Nesta seção apresentamos detalhes sobre cada etapa bem como a qual questão de pesquisa pretendia-se responder.

\subsection{Etapas da Pesquisa}

A primeira etapa objetiva responder a $\mathbf{Q P}_{1}$ Existem maus cheiros que são específicos à camada de apresentação de aplicativos Android? Visto que maus cheiros possuem uma relação direta com o conhecimento empírico de desenvolvedores, optamos por um questionário exploratório online para obter os dados iniciais [11, 82, 102]. Nosso objetivo foi entender o que desenvolvedores Android consideram como boas e más práticas no desenvolvimento da camada de apresentação de aplicativos Android. Obtivemos 45 respostas das quais realizamos um processo de codificação e derivamos 20 maus cheiros de código relacionados à 


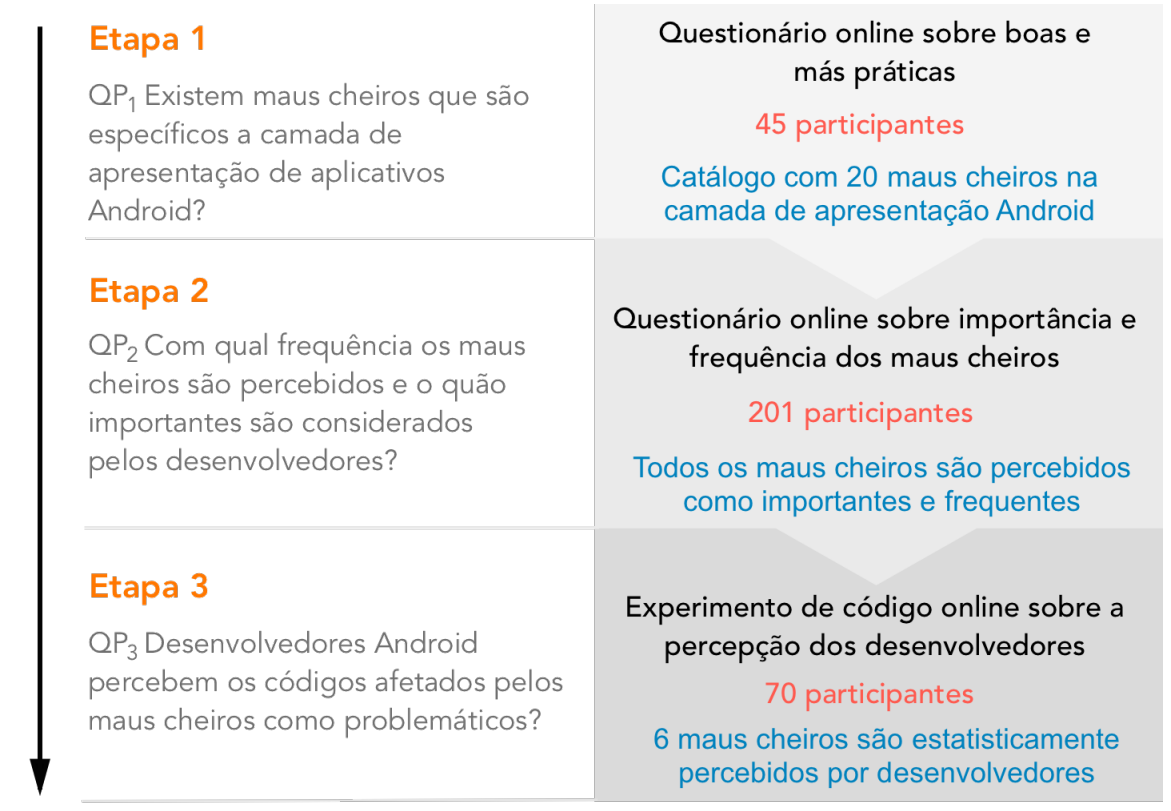

Figura 4.1: Etapas da pesquisa.

camada de apresentação Android. Apresentamos na Seção 4.2 os detalhes desta etapa.

Na segunda etapa, objetivamos responder a $\mathbf{Q P}_{2}$ Com qual frequência os maus cheiros são percebidos e o quão importante são considerados pelos desenvolvedores? Os dados foram coletados a partir de um segundo questionário online respondido por 201 desenvolvedores Android. Nessa etapa foi possível validar a percepção de frequência e importância dos 20 maus cheiros no dia a dia do desenvolvimento Android, sendo todos considerados em algum nível importantes e frequentes. Apresentamos os detalhes desta etapa na Seção 4.3.

$\mathrm{Na}$ terceira e última etapa, objetivamos responder a $\mathbf{Q P}_{3}$ Desenvolvedores Android percebem os códigos afetados pelos maus cheiros como problemáticos? Coletamos os dados a partir de um experimento de código online respondido por 70 desenvolvedores Android. Com esses dados foi possível extrair estatísticas sobre a percepção de desenvolvedores Android com relação a 7 dos 20 maus cheiros propostos. Esses maus cheiros foram considerados os mais frequentes pelos participantes de $\mathrm{S}_{2}$. Os detalhes desta etapa são apresentados na Seção 4.4 .

Por fim, concluímos com um catálogo com 20 maus cheiros relacionados à camada de apresentação Android, considerados importantes e frequentes por desenvolvedores Android. Avaliamos a percepção no código de 7 deles, os mais frequentes, e extraímos dados estatísticos que confirmam que desenvolvedores percebem códigos afetados por 6 deles como códigos problemáticos. O catálogo com os 20 maus cheiros é apresentado na Seção 5.1.2. 


\subsection{Etapa 1 - Boas e más práticas na camada de apre- sentação Android}

Iniciamos nossa pesquisa com algumas hipóteses de quais práticas poderiam ser consideradas más práticas, e portanto possíveis sintomas de maus cheiros no desenvolvimento da camada de apresentação Android. Apesar de haver algumas hipóteses, com o objetivo de não limitar ou influenciar esta primeira etapa, para responder a $\mathrm{QP}_{1}$, submetemos um questionário online com perguntas exploratórias sobre boas e más práticas em cada um dos componentes da camada de apresentação Android: Activities, Fragments, Adapters, Listeners, e recursos do aplicativo: Layout, Strings, Styles e Drawables. Obtivemos 45 respostas a partir do qual extraímos 46 categorias que resultaram em 20 maus cheiros, dentre os quais, estavam maus cheiros que confirmaram nossas hipóteses iniciais.

A seguir, na Seção 4.2.1 apresentamos detalhes sobre a concepção do questionário, na Seção 4.2.2 os detalhes sobre os participantes e na Seção 4.2.3 detalhes sobre o processo de análise dos dados. Os resultados desta etapa podem ser conferidos na Seção 5.1.2.

\subsubsection{Questionário}

Este questionário $\left(\mathrm{S}_{1}\right)$ foi baseado em um estudo anterior feito por Aniche et al. [8, 10], onde os autores buscaram por maus cheiros em aplicações MVC. Elaboramos o questionário em inglês porém havia um texto informativo avisando que tanto respostas em inglês ou português seriam aceitas. No cabeçalho do questionário inserimos algumas informações para o participante, dentre elas, informamos que o questionário fazia parte de uma pesquisa sobre qualidade de código Android e que os dados fornecidos poderiam futuramente ser publicados de forma anônima. O questionário foi composto por 25 questões separadas em três seções.

A primeira seção teve o objetivo de traçar o perfil demográfico do participante (idade, estado de residência, experiência em desenvolvimento de software, experiência com desenvolvimento Android e escolaridade) e foi composta de 6 perguntas. A segunda seção teve como objetivo entender o que os desenvolvedores consideravam boas e más práticas no desenvolvimento da camada de apresentação Android. Foi composta por 16 perguntas opcionais e abertas, 8 sobre boas práticas em cada um dos 8 elementos da camada de apresentação Android e 8 sobre más práticas. O questionário completo pode ser visto no Apêndice B. Por exemplo, para o elemento Activity a segunda seção continha as seguintes perguntas:

P1 Do you have any good practices to deal with Activities? (Você tem alguma boa prática para lidar com Activities?) Pergunta aberta.

P2 Do you have anything you consider a bad practice when dealing with Activities? (Você considera alguma coisa uma má prática ao lidar com Activities?) Pergunta aberta. 
A terceira seção foi composta por 3 perguntas opcionais e abertas, 2 para captar qualquer última ideia sobre boas e más práticas não captadas nas questões anteriores e 1 solicitando o email do participante caso o mesmo tivesse interesse em participar de etapas futuras da pesquisa.

Antes da divulgação, realizamos um teste piloto com 3 desenvolvedores Android. Na primeira configuração do questionário, todas as perguntas, de todas as seções com exceção do email, eram obrigatórias. Com o resultado do teste piloto, percebemos que nem sempre o desenvolvedor tem alguma boa ou má prática para comentar sobre todos os 8 elementos questionados. Deste modo, removemos a obrigatoriedade das perguntas da segunda e terceira seção tornando-as opcionais e permitindo que o participante respondesse apenas as boas e más práticas sobre os elementos que lhe fizesse sentido. As respostas dos participantes piloto foram desconsideradas para mitigar efeitos de viés.

O questionário foi divulgado em redes sociais como Facebook, Twitter e LinkedIn, em grupos de discussão sobre Android como Android Dev Brasil ${ }^{1}$, Android Brasil Projetos ${ }^{2}$ e o grupo do Slack Android Dev Br ${ }^{3}$, maior grupo de desenvolvedores Android do Brasil com 2622 participantes até o momento desta escrita ${ }^{4}$. O questionário esteve aberto por aproximadamente 3 meses e meio, de 9 de Outubro de 2016 até 18 de Janeiro de 2017 e foi respondido por 45 desenvolvedores.

\subsubsection{Participantes}

Participaram desta etapa da pesquisa 45 desenvolvedores Android. Dos participantes, $13 \%$ possui uma ou mais pós-graduações e $62 \%$ são graduados, esses dados podem ser observados na Figura 4.2a. A Figura 4.2b apresenta a distribuição de idade dos participantes, onde a maioria possui de 25 a 34 anos.

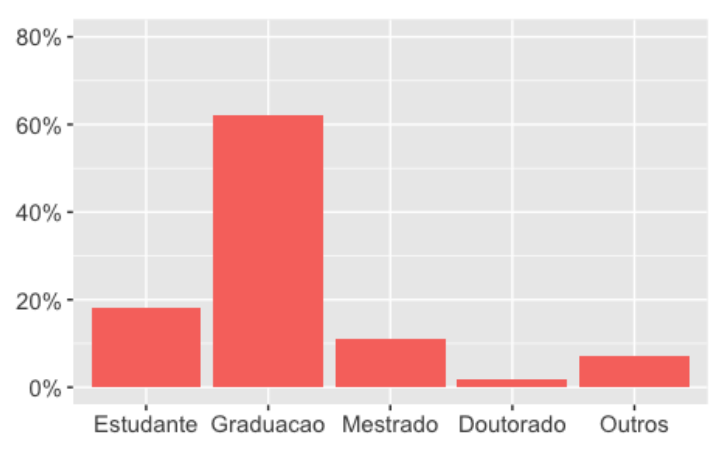

(a) Distribuição de escolaridade.

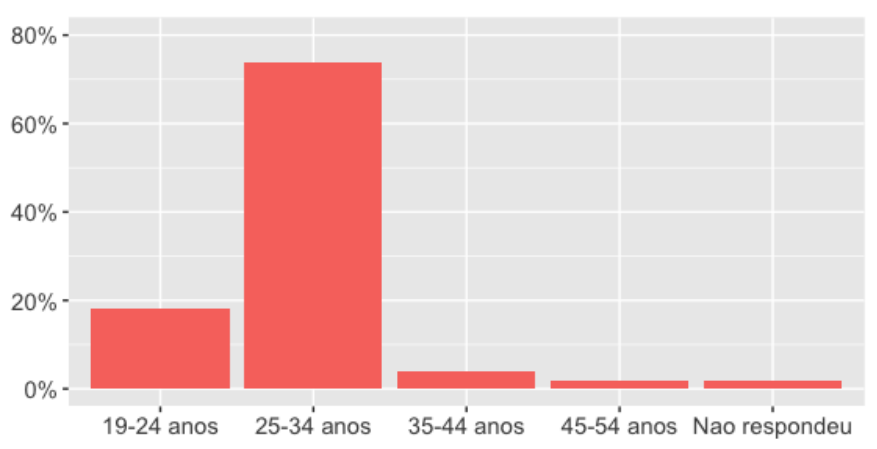

(b) Distribuição de idade.

Figura 4.2: Escolaridade e distribuição de idade dos participantes em $S_{1}$.

\footnotetext{
${ }^{1}$ https://groups.google.com/forum/\#!forum/androidbrasil-dev

${ }^{2}$ https://groups.google.com/forum/\#!forum/android-brasil-projetos

${ }^{3} \mathrm{http}: / /$ slack.androiddevbr.org

${ }^{4}$ Dado verificado em $25 / 11 / 2017$.
} 
Conforme apresentado na Figura 4.3, 90\% dos respondentes indicaram ter 2 anos ou mais de experiência com desenvolvimento de software e $71 \%$ indicaram 2 anos ou mais de experiência com desenvolvimento Android. Vale ressaltar que a plataforma Android completa 10 anos em 2018, ou seja, 5 anos de experiência nessa plataforma representa $50 \%$ do tempo de existência dela desde seu anúncio em 2008.

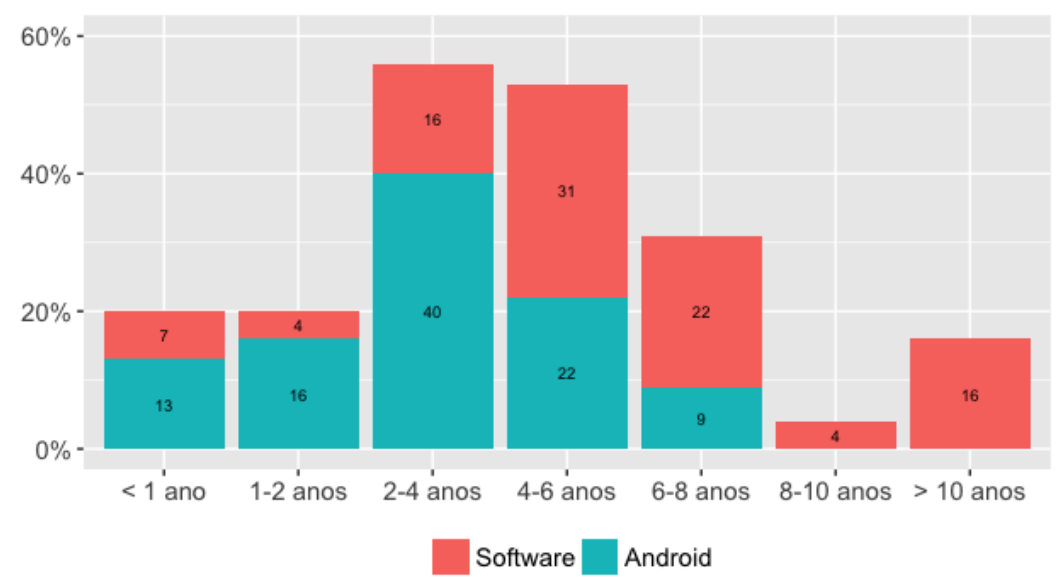

Figura 4.3: Tempo de experiência com desenvolvimento de software e desenvolvimento Android dos participantes de $S_{1}$.

Nosso questionário exploratório foi respondido por profissionais de 3 continentes e mais de 7 países diferentes porém, a maior representatividade dos dados é originada do Brasil com pouco mais de $81 \%$ dos participantes de 11 estados diferentes. No Brasil, os estados com maior representatividade foram: São Paulo com 55\%, Rio de Janeiro e Goiás cada com $8 \%$ e Rio Grande do Sul e Santa Catarina, cada um com pouco mais de 5\%. 14\% dos participantes são originados de países Europeus. Nos Estados Unidos tivemos apenas 2\% (1 participante) da Califórnia. Estes dados são apresentados na Figura 4.4. Podemos concluir que tivemos certa abrangência geográfica, no entanto, acreditamos que o mais apropriado seja dizer que os maus cheiros derivados das boas e más práticas representam a opinião de desenvolvedores brasileiros, principalmente de São Paulo.

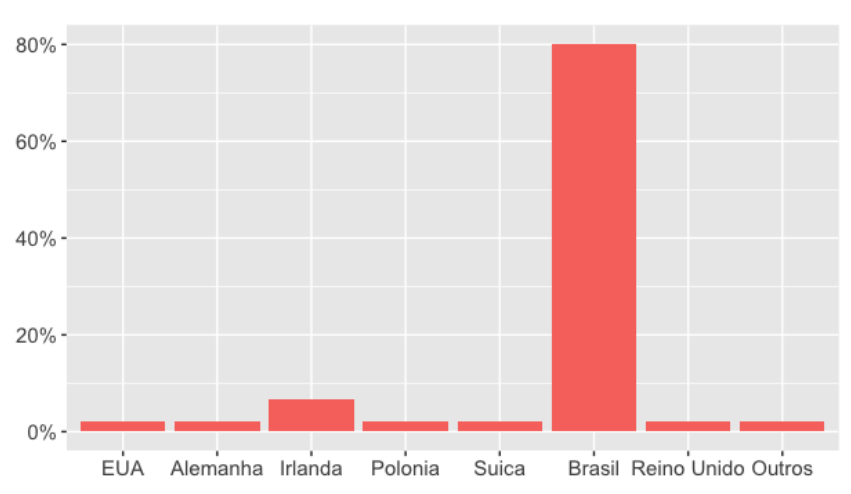

(a) Distribuição geográfica global.

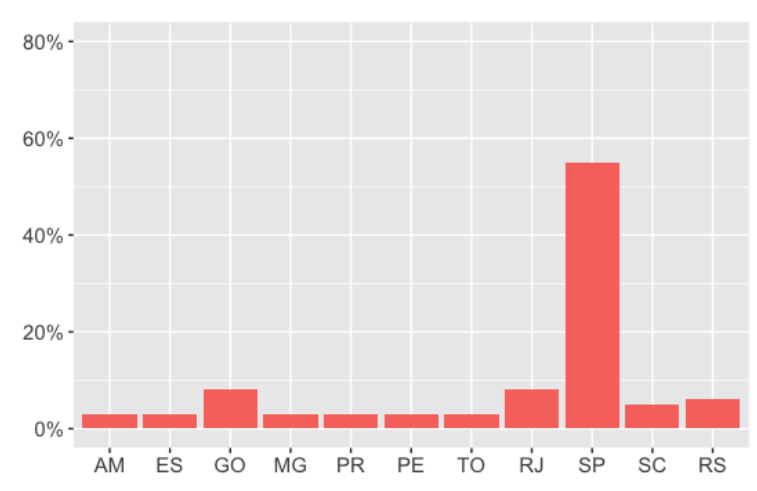

(b) Distribuição geográfica brasileira.

Figura 4.4: Distribuição geográfica global e brasileira dos participantes de $S_{1}$. 


\subsubsection{Análise dos Dados}

Para análise dos dados nos inspiramos na abordagem Ground Theory (GT), um método de pesquisa originado nas ciências sociais [22, 31], mas cada vez mais popular em pesquisas de engenharia de software [5]. A GT é uma abordagem indutiva, pelo qual dados provenientes, por exemplo, de entrevistas ou questionários, são analisadas para derivar uma teoria. O objetivo é descobrir novas perspectivas mais do que confirmar alguma já existente. O processo de análise partiu da listagem das 45 respostas do questionário e se deu em 4 passos: verticalização, limpeza dos dados, codificação e divisão, detalhados a seguir.

O processo que denominamos de verticalização consistiu em considerar cada resposta de boa ou má prática como um registro individual a ser analisado. Ou seja, cada participante respondeu 18 perguntas sobre boas e más práticas na camada de apresentação Android (2 perguntas para cada elemento e mais duas perguntas genéricas). Com o processo de verticalização, cada uma dessas respostas se tornou um registro, ou seja, cada participante resultava em 18 respostas a serem analisadas, totalizando 810 respostas (18 perguntas multiplicado por 45 participantes) sobre boas e más práticas.

O passo seguinte foi realizar a limpeza dos dados. Esse passo consistiu em remover respostas obviamente não úteis como respostas em branco, respostas contendo frases como "Não", "Não que eu saiba", "Eu não me lembro" e similares, as consideradas vagas como "Eu não tenho certeza se são boas praticas mas uso o que vejo por ai", as consideradas genéricas como "Como todo código java..." e as que não eram relacionadas a boas ou más práticas de código. Das 810 boas e más práticas, 352 foram consideradas e 458 desconsideradas. Das 352, 45\% foram apontadas como más práticas e 55\% como boas práticas.

Em seguida, realizamos a codificação sobre as boas e más práticas [22, 87]. Codificação é o processo pelo qual são extraídos categorias de um conjunto de afirmações através da abstração de ideias centrais e relações entre as afirmações [22]. Durante esse processo, cada resposta recebeu uma ou mais categorias. Neste passo desconsideramos mais algumas respostas, isso ocorreu pois não eram respostas "obviamente" descartáveis como as do passo anterior e foi necessária a análise para chegarmos a essa conclusão de desconsiderá-las. Para cada resposta desconsiderada nesse passo registramos o motivo, que pode ser conferido nos arquivos em nosso apêndice online ${ }^{5}$.

Por último, realizamos o passo de divisão. Esse passo consistiu em dividir as respostas que receberam mais de uma categoria em duas ou mais respostas, de acordo com o número de categorias identificadas, de modo a resultar em uma categoria por resposta. Por exemplo, a resposta "Não fazer Activities serem callbacks de execuções assincronas. Herdar sempre das classes fornecidas pelas bibliotecas de suporte, nunca diretamente da plataforma" indica na primeira oração uma categoria e na segunda oração, outra categoria. Ao dividi-la, man-

\footnotetext{
${ }^{5}$ Apêndice online disponível em: http://suelengc.github.io/master-degree-dissertation.
} 
tivemos apenas o trecho da resposta relativo à categoria, como se fossem duas respostas distintas e válidas. Em algumas divisões realizadas, a resposta completa era necessária para entender ambas as categorizações, nesses casos, mantivemos a resposta original, mesmo que duplicada, e categorizamos cada uma de modo diferente.

Ao final da análise constavam 359 respostas sobre boas e más práticas individualmente categorizadas em 46 categorias. Para derivação dos maus cheiros foram consideradas 20 categorias que apresentaram frequência de recorrência maior ou igual a cinco. Segundo Nielsen [79], cinco repetições é o suficiente para se obter dados necessários para definir um problema, as repetições seguintes tendem a não agregar novas informações relevantes, se não as já observadas. Cada categoria considerada resultou em um mau cheiro de código Android, dos quais 9 são relacionados a componentes da camada de apresentação Android e 11 relacionados a recursos do aplicativo, totalizando 20 maus cheiros na camada de apresentação Android.

\subsection{Etapa 2 - Importância e Frequência dos Maus Chei- ros Android}

Para responder a $\mathrm{QP}_{2}$, buscamos generalizar os maus cheiros encontrados na $\mathrm{QP}_{1}$ entendendo a percepção dos desenvolvedores com relação à frequência e importância dos maus cheiros. Coletamos esta percepção por meio de um questionário online com três seções sendo a primeira para coleta de dados demográficos da mesma forma da etapa 1, a segunda para coleta da percepção de frequência dos maus cheiros no dia a dia de desenvolvimento e a terceira para coleta da percepção de importância.

Coletamos 201 respostas de desenvolvedores Android de 3 continentes e 14 países diferentes. Nossos resultados mostraram que os 20 maus cheiros são considerados, de algum modo, frequentes e importantes. A seguir, na Seção 4.3.1 apresentamos detalhes sobre a concepção do questionário, na Seção 4.3.2 detalhes sobre os participantes e na Seção 4.3.3 detalhes sobre o processo de análise dos dados. Os resultados desta etapa podem ser conferidos na Seção 5.2 .

\subsubsection{Questionário}

Foram criadas duas versões do questionário, inglês e português, de forma que de um era possível acessar o outro, possibilitando o participante escolher o idioma mais apropriado a ele. No cabeçalho do questionário inserimos algumas informações para o participante, dentre elas, informamos que o questionário fazia parte de uma pesquisa sobre qualidade de código Android e que os dados fornecidos poderiam futuramente ser publicados de forma anônima. 
O questionário $\left(\mathrm{S}_{2}\right)$ continha 3 seções. A primeira seção, como em $\mathrm{S}_{1}$, tinha o objetivo de traçar o perfil demográfico do participante (idade, estado de residência, experiência em desenvolvimento de software, experiência com desenvolvimento Android e escolaridade) e foi composta de 6 perguntas.

A segunda seção objetivou capturar a percepção dos desenvolvedores com relação à frequência em que eles percebiam os maus cheiros no seu dia a dia. Fizemos isso apresentando uma lista de afirmações onde cada afirmação descrevia um sintoma de um dos maus cheiros. Para cada afirmação o participante podia escolher uma entre cinco opções da escala likert de frequência: muito frequente, frequente, às vezes, raramente e nunca.

As afirmações foram baseadas nas respostas de $S_{1}$, por exemplo, para o mau cheiro Classes de UI Acopladas algumas das respostas sobre más práticas foram "Acoplar o Fragment a Activity ao invés de utilizar interfaces é uma prática ruim" (P19) e "Acoplar o Fragment com a Activity" (P10, P31 e P45), e boa prática foi "Seja um componente de UI reutilizável. Então evite dependência de outros componentes da aplicação" (P6). Com base nessas e outras respostas extraímos a seguinte frase para representar o sintoma do mau cheiro:

- Fragments, Adapters ou Listeners com referência direta para quem os usa, como Activities ou outros Fragments.

Para contemplar os 20 maus cheiros, foram apresentadas 25 afirmações sobre frequência. Essa diferença do número total de maus cheiros e o número de afirmações ocorreu pois, para 4 dos maus cheiros (Comportamento Suspeito, Layout Longo ou Repetido, Longo Recurso de Estilo e Atributos de Estilo Repetidos), foram apresentadas mais de uma afirmação, cada qual abordando um dos sintomas apresentados por ele. Optamos por separar os sintomas em afirmações para entender qual(is) sintoma(s) era(m) percebido(s) no dia a dia pelo desenvolvedor. Por exemplo, para o mau cheiro Comportamento Suspeito apresentamos três afirmações, onde cada uma representou uma forma diferente, considerada má prática pelos participantes de $\mathrm{S}_{1}$, sobre como implementar a resposta a eventos do usuário no Android:

- Activities, Fragments ou Adapters com classes anônimas para responder a eventos do usuário, como clique, duplo clique e outros.

- Activities, Fragments ou Adapters implementando algum Listener, através de polimorfismo (implements), para responder a eventos do usuário como clique, duplo clique e outros.

- Activities, Fragments ou Adapters com classes internas implementando algum Listener para responder a eventos do usuário como clique, duplo clique e outros. 
A terceira seção objetivou capturar a percepção dos desenvolvedores com relação à importância em mitigar os sintomas dos maus cheiros, para isso foi solicitado que indicasse o quão importante ele considerava as afirmações apresentadas. Para contemplar os 20 maus cheiros, apresentamos 21 afirmações de importância que basicamente negavam as afirmações relacionadas à percepção de frequência do mau cheiro. A divergência do total de maus cheiros e o total de afirmações apresentadas se dá pelo mesmo motivo encontrado na seção anterior do questionário, sobre percepção de frequência. Para cada afirmação o participante podia escolher uma dentre as cinco opções da escala likert de importância: muito importante, importante, razoavelmente importante, pouco importante, não é importante. A seguir apresentamos a afirmação apresentada nesta seção para o mau cheiro ClAsses DE UI ACOPLADAS:

- Fragments, Adapters e Listeners não ter referência direta à quem os utiliza.

Em nenhuma das seções indicamos que seriam apresentados sintomas de maus cheiros, nem mencionamos os nomes dos maus cheiros usados nesta dissertação, foram apresentadas somente as afirmações. Optamos por fazer desta forma para abstrair a ideia de que as frases representavam maus cheiros e portanto, não exigir do participante um conhecimento prévio sobre maus cheiros de código.

Antes da divulgação do questionário realizamos a validação de cada uma das afirmações, por meio de entrevista individual, com dois desenvolvedores Android experientes, $D E V$ $A$ e $D E V$-B. $D E V$ - $A$ possui 10 anos de experiência com desenvolvimento de software e 5 anos de experiência com desenvolvimento Android, se considera proficiente nas tecnologias Java, Objective C, Swift e Android e possui bacharel em Tecnologia de Informação. DEV$B$ possui 7 anos de experiência com desenvolvimento de software e 6 anos de experiência com desenvolvimento Android, se considera proficiente nas tecnologias Java, Objective C e Android e possui pós-graduação em Engenharia de Software Orientada a Serviços. Ambos os desenvolvedores trabalham atualmente com desenvolvimento de aplicativos móveis em startups brasileiras.

A entrevista de validação das afirmações foi conduzida de modo que o desenvolvedor procedia respondendo o questionário e quando tinha dúvida sobre uma frase, o mesmo questionava e então ela era discutida e quando necessário, reestruturada ou reescrita, de acordo com o comentário dado. Após a discussão, o desenvolvedor a respondia, considerando a conclusão das discussões, e seguia para a próxima. Essa dinâmica seguiu até passar por todas as afirmações e ao final o desenvolvedor era incentivado a dar qualquer outro comentário que considerasse relevante.

Alguns importantes ajustes foram realizados após a primeira entrevista de validação. O principal ajuste foi relacionado a escala likert utilizada, sendo que, na primeira versão do questionário, respondido por $D E V$ - $A$, foi usada tanto para validar importância quanto para 
validar frequência a mesma escala likert de nível de concordância (concordo totalmente, concordo, não concordo nem discordo, discordo, discordo totalmente), deixando para com a frase a responsabilidade de indicar do que se tratava, frequência ou importância. Durante a validação percebemos que as afirmações ficavam muito maiores de ler e difíceis de serem interpretadas, então trocamos para escalas de frequência e importância e ajustamos as afirmações. Também foram sugeridas melhorias em algumas poucas afirmações. Com o segundo desenvolvedor, $D E V-B$, tivemos apenas dois ajustes em afirmações. Para efeitos de viés, as respostas dos desenvolvedores que participaram das entrevistas de validação foram desconsideradas.

Após a validação das afirmações, executamos um teste piloto com dois desenvolvedores, dos quais, não solicitaram alterações no questionário, considerando-o apropriado para lançamento. Essas respostas foram consideradas nas análises pois não houve necessidade de ajustes no questionário após elas ocorrerem. O questionário foi divulgado em redes sociais como Reddit, Facebook, Twitter e LinkedIn, grupos de discussão sobre Android como Android Dev Brasil ${ }^{6}$, Android Brasil Projetos ${ }^{7}$ e o grupo do Slack Android Dev Br ${ }^{8}$, maior grupo de desenvolvedores Android do Brasil com 2622 participantes até o momento desta escrita. Para engajar os participantes ofertamos o sorteio de um Google Chromecast Áudio.

O questionário esteve aberto por aproximadamente três semanas em meados de Setembro de 2017. As afirmações eram apresentadas de forma randômica. Ao final, o questionário foi respondido por 201 desenvolvedores. A versão completa do questionário pode ser conferida no Apêndice C.

\subsubsection{Participantes}

Participaram desta etapa da pesquisa 201 desenvolvedores. 145 respostas vieram da versão em português do questionário e 56 da versão em inglês. Dos participantes, $15 \%$ possuem

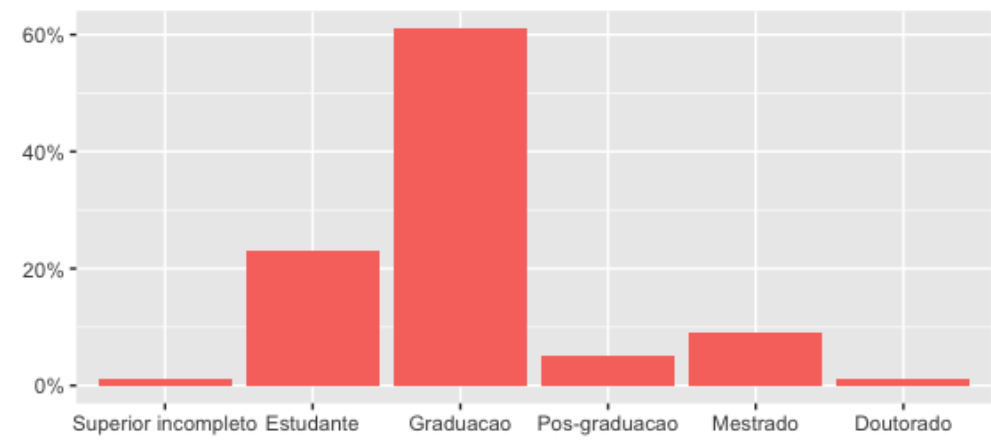

(a) Distribuição de escolaridade.

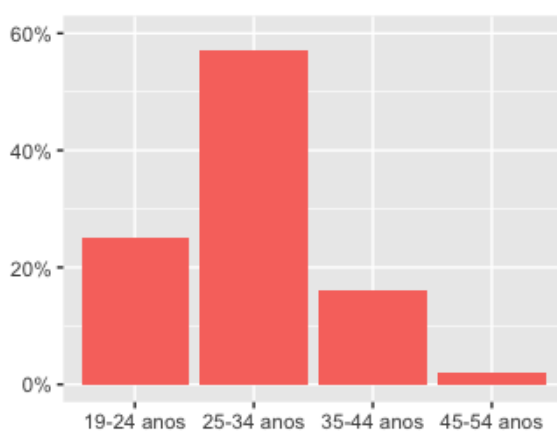

(b) Distribuição de idade.

Figura 4.5: Escolaridade e distribuição de idade dos participantes em $S_{2}$.

\footnotetext{
${ }^{6}$ https://groups.google.com/forum/\#!forum/androidbrasil-dev

${ }^{7}$ https://groups.google.com/forum/\#!forum/android-brasil-projetos

${ }^{8}$ http://slack.androiddevbr.org
} 


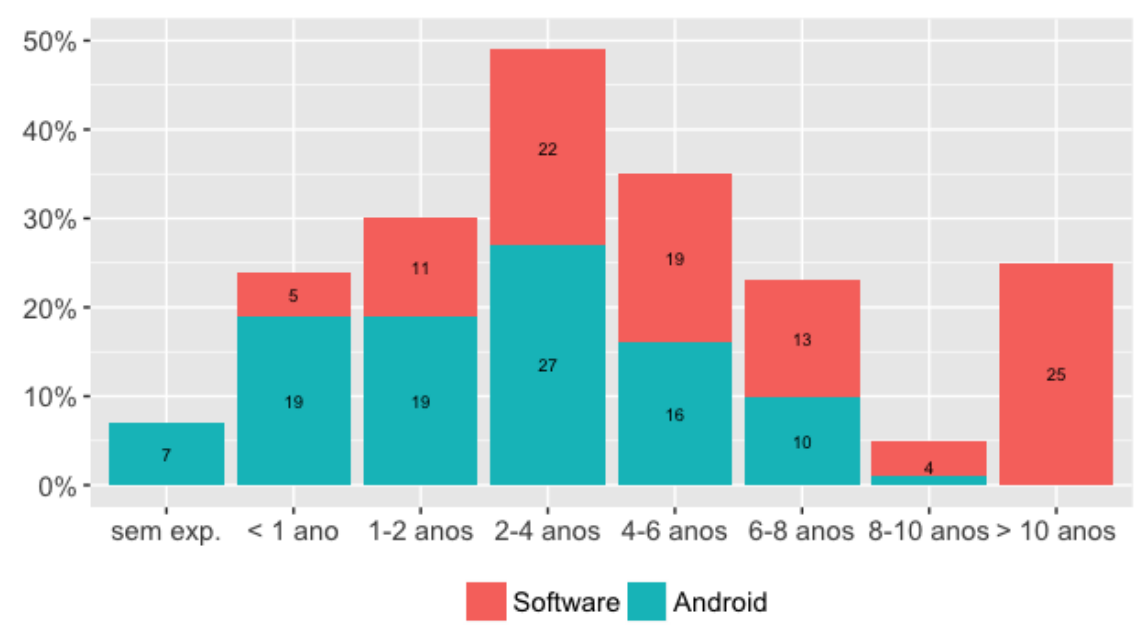

Figura 4.6: Tempo de experiência com desenvolvimento de software e desenvolvimento Android dos participantes de $S_{2}$.

uma ou mais pós-graduações e $61 \%$ são graduados, esses dados podem ser observados na Figura 4.5a. A Figura 4.5b apresenta o histograma de idade dos participantes, onde podemos observar que tivemos uma abrangência considerável de idade, onde a maior parte possui de 20 a 35 anos.

Conforme apresentado na Figura 4.6, 94\% participantes indicaram ter 2 anos ou mais de experiência com desenvolvimento de software e $74 \%$ indicaram 2 anos ou mais de experiência com desenvolvimento Android. Esse resultado nos indica que atingimos desenvolvedores com experiência considerável em desenvolvimento de software e Android.

Perguntamos aos desenvolvedores qual seu nível de conhecimento em diversas linguagens orientadas a objetos. Na Figura 4.7 podemos observar que mais de $80 \%$ afirmam ter conhe-

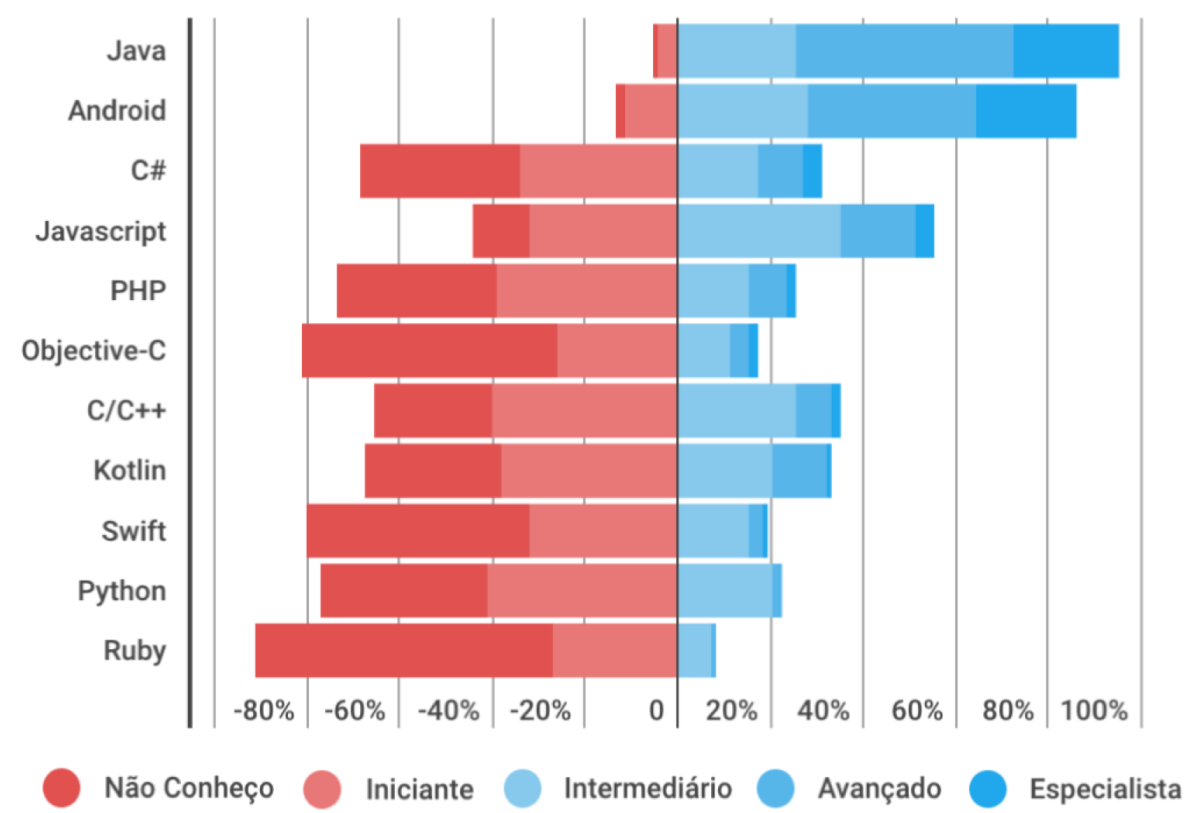

Figura 4.7: Nivel de conhecimento em diversas linguagens de programação orientada a objetos dos participantes de $S_{2}$. 
cimento de intermediário a especialista em Java e Android. De 20\% a 58\% dos participantes afirmam ter conhecimento de intermediário a especialista em outras linguagens orientadas a objetos. 5 participantes (2\%) afirmaram não ter conhecimento sobre Android, por este motivo suas respostas foram desconsideradas da análise.

A Figura 4.8 apresenta a distribuição geográfica global e brasileira dos participantes. Nosso questionário foi respondido por profissionais de 3 continentes e 14 países diferentes porém a maior representatividade dos dados é originada do Brasil, com pouco mais de $78 \%$ dos participantes. Os brasileiros somam 157 profissionais de 18 estados diferentes. Desse total, os estados com maior representatividade foram, na ordem: São Paulo com 57\%, Rio de Janeiro e Minhas Gerais com quase 6\% cada e Rio Grande do Sul com quase 5\%. 10\% dos participantes são originados de países Europeus. Nos Estados Unidos tivemos $2 \%$ provenientes da Califórnia, Pensilvânia, Indiana e Utah e 0,5\% (1 participante) de Ontário no Canadá.

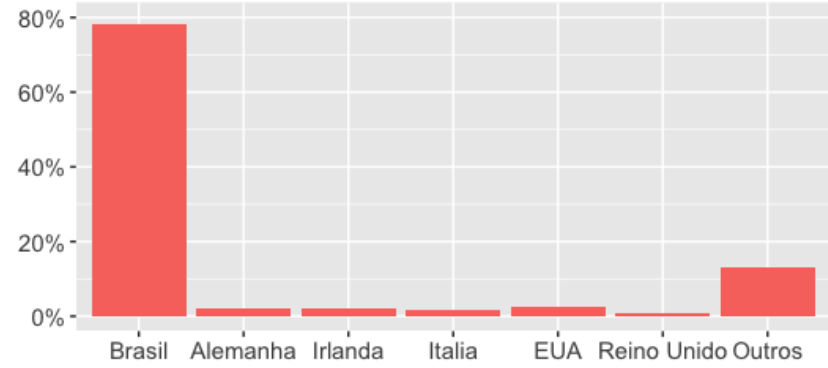

(a) Distribuição geográfica global.

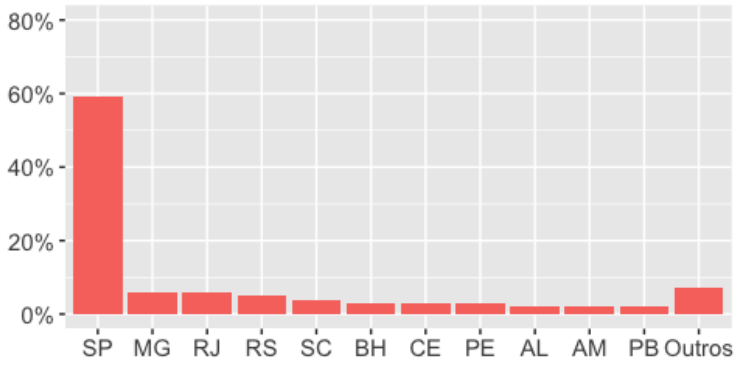

(b) Distribuição geográfica brasileira.

Figura 4.8: Distribuição geográfica global e brasileira dos participantes de $S_{2}$.

Podemos concluir que tivemos certa abrangência geográfica, porém o padrão geográfico obtido em $\mathrm{S}_{1}$ se repetiu em $\mathrm{S}_{2}$, e apesar de termos tido certa abrangência global, a maior representatividade é proveniente do Brasil, logo, continuamos acreditando que o mais apropriado seja dizer que a percepção de frequência e importância dos maus cheiros propostos representam a opinião de desenvolvedores brasileiros, principalmente de São Paulo.

\subsubsection{Análise dos Dados}

Para análise dos dados, as opções das escalas likert de frequência e importância foram codificadas em números de 1 a 5. Por exemplo, as opções "Nunca" (da escala de frequência) e "Não é importante" (da escala de importância) foram codificadas com 1, as opções "Raramente" (frequência) e "Pouco importante" (importância) com 2, e assim sucessivamente até as opções "Muito frequente" (frequência) e "Muito importante" (importância) que foram codificadas com 5 .

De modo a avaliar a percepção dos desenvolvedores Android sobre a frequência e importância dos maus cheiros propostos, para análise dos dados extraímos de cada afirmação a 
mediana, moda e desvio padrão. Para os maus cheiros que apresentamos mais de uma afirmação, extraímos a média desses dados para representá-los. Por exemplo, foram apresentadas três afirmações de frequência sobre o mau cheiro Comportamento Suspeito, a moda que o representa é a média das modas de cada afirmação, que neste caso foi $(3+4+4) \div 3=3,7 \approx 4$.

De modo a avaliar quais maus cheiros são considerados frequentes realizamos uma simplificação da escala likert de frequência. Classificamos de frequência baixa as resposta "Raramente", de frequência moderada as respostas "Às vezes" e por último, classificamos de frequência alta as respostas "Frequente" e "Muito frequente". Não obtivemos nenhuma afirmação com moda (MO) igual 1, ou seja, "Nunca", e por isso não criamos uma classificação para ela.

De modo similar, para avaliar quais maus cheiros são considerados importantes, também realizamos uma simplificação da escala likert de importância. Classificamos de importância baixa as resposta "Pouco importante", de importância moderada as respostas "Razoavelmente importante" e classificamos de importância alta as respostas de "Importante" e "Muito importante". Também não foi necessário criar uma classificação para respostas "Não é importante" pois nenhuma das afirmações obteve MO igual a 1.

\subsection{Etapa 3 - Percepção de Desenvolvedores sobre os Maus Cheiros Android}

Para responder a $\mathrm{QP}_{3}$ validamos a percepção de desenvolvedores Android sobre códigos afetados por 7 maus cheiros, os considerados mais frequentes (vide Tabela 4.1) pelos respondentes de $\mathrm{S}_{2}$. Os dados foram coletados por meio de um experimento de código online $\left(\mathrm{S}_{3}\right)$ onde cada participante foi solicitado a avaliar a qualidade de 6 códigos-fonte relativos à camada de apresentação Android. Recebemos 70 respostas. Vale ressaltar que esse experimento já foi realizado em pesquisas similares, como as de Aniche et al. [8, 9] e Palomba et al. [82], com o mesmo objetivo de validar a percepção de desenvolvedores sobre maus cheiros de código.

Nossos resultados confirmam estatisticamente que desenvolvedores Android percebem 6 dos 7 maus cheiros avaliados. Não obtivemos dados suficientes para tirar conclusões estatísticas sobre um dos maus cheiros. A seguir, na Seção 4.4.1, apresentamos detalhes sobre o experimento e na Seção 4.4.2, detalhes sobre os participantes e como realizamos a análise dos dados. Os resultados desta etapa podem ser conferidos na Seção 5.3. 


\subsubsection{Experimento}

O questionário do experimento foi elaborado no idioma português, divulgado em redes sociais como Twitter e LinkedIn e o grupo do Slack Android Dev $\mathrm{Br}^{9}$ e esteve disponível por 1 mês. No cabeçalho informamos que o experimento fazia parte de uma pesquisa sobre qualidade de código Android e que os dados fornecidos poderiam futuramente ser publicados de forma anônima.

O experimento continha duas seções principais ambas com todas as perguntas sendo opcionais. A primeira seção teve como objetivo coletar informações demográficas, principalmente com relação à experiência dos participantes. Na segunda seção os participantes foram solicitados a analisar 6 códigos-fontes, 4 "mau cheirosos", ou seja, afetados por um dos maus cheiros avaliados, e 2 "limpos", ou seja, não afetado pelos maus cheiros avaliados. Para cada código, o participante também foi solicitado a responder as seguintes perguntas:

P1 Na sua opinião, este código apresenta algum problema de design e/ou implementação? $(\mathrm{SIM} / \mathrm{NA} \mathrm{O})$

P2 Se SIM, por favor explique quais são, na sua opinião, os problemas que afetam este código. (Pergunta aberta)

P3 Se SIM, por favor avalie a severidade do problema de design e/ou implementação selecionando dentre as opções a seguir. (Escala Likert de 5 pontos de 1, muito baixa, até 5 , muito alta).

Segundo Fink (1995) [26], o tamanho da amostra se refere ao número de respondentes necessários para que os resultados obtidos sejam precisos e confiáveis, e que o aumento no tamanho da amostra diminui o erro. Moscarola (1990) [78] resume essa ideia com " $a$ lei dos grandes números", segundo a qual ele argumenta que "com uma amostra inferior a 30 observações se tem chances de encontrar tanto um valor errôneo ou defasado como um valor se aproximando da realidade". Sendo assim, para termos maior confiabilidade sobre os resultados, objetivamos coletar em média 30 pontos por mau cheiro avaliado. Isso significa cada mau cheiro ter em média 30 desenvolvedores avaliando um código afetado por ele. Portanto, o cálculo necessário para obter o número total de participantes necessários para avaliar todos os maus cheiros é (MC remete a Mau Cheiro):

$$
\left(M C_{\text {total }} \times M C_{\text {pontos }}\right) \div M C_{\text {avaliados }}
$$

Onde $M C_{\text {total }}$ indica o total de maus cheiros a serem avaliados, $M C_{\text {pontos }}$ indica o total de pontos que se deseja obter para cada mau cheiro e $M C_{\text {avaliados }}$ indica o total de maus cheiros avaliados por cada participante, ou seja, quantos códigos mau cheirosos serão apresentados,

\footnotetext{
${ }^{9}$ http://slack.androiddevbr.org
} 
que no nosso caso são 4. Aplicando esse cálculo ao nosso contexto, concluímos que seriam necessários aproximadamente 150 participantes:

$$
(20 \times 30) \div 4=150
$$

Visto que este experimento exige um esforço maior dos participantes (analisar 6 códigosfontes) optamos por iniciá-lo com um subconjunto menor de maus cheiros objetivando obter 30 pontos por mau cheiro rapidamente.

Iniciamos o experimento com 7 maus cheiros, considerados mais frequentes (maior somatória de frequência alta e moderada), conforme apresentamos na Tabela 4.1. Entendemos que este foco agrega mais valor do que focar nos mais importantes pois, segundo Taibi et al. [92] apesar de alguns maus cheiros serem considerados na teoria muito críticos por desenvolvedores, na prática eles são mais toleráveis. O experimento foi elaborado de modo que, conforme um mau cheiro alcançasse os 30 pontos, era possível substituí-lo ou mesmo removê-lo do experimento.

Tabela 4.1: Sete maus cheiros avaliados no experimento de código sobre a percepção de desenvolvedores Android.

\begin{tabular}{llc}
\hline$\#$ & Mau Cheiro & Frequência Alta + Moderada \\
\hline 1 & Longo ReCurso de Estilo & $74.38 \%$ \\
2 & Adapter CompleXo & $70.65 \%$ \\
3 & Componente De UI Acoplado & $69.65 \%$ \\
4 & LAyout Profundamente Aninhado & $66.67 \%$ \\
5 & Componente De Ui CÉREBRo & $66.67 \%$ \\
6 & Atributos De Estilo Repetidos & $65.92 \%$ \\
7 & Comportamento Suspeito & $65.67 \%$ \\
\hline
\end{tabular}

Os 6 códigos apresentados foram randomicamente selecionados de um conjunto de 50 códigos. Esse conjunto foi composto por 35 códigos mau cheirosos (cinco para cada mau cheiro avaliado) e 15 códigos limpos. Vale salientar que, para mitigar possíveis vieses de confundimento, nos dois grupos de códigos (mau cheirosos e limpos) selecionamos apenas Activities, Fragments, Adapters, Listeners, recursos de Layout, String e Style, uma vez que são esses os elementos da camada de apresentação Android, cujo os maus cheiros propostos e avaliados tratam.

Os códigos utilizados no experimento foram extraídos de projetos de software livre Android selecionados aleatoriamente do repositório F-Droid ${ }^{10}$. A Tabela 4.2 apresenta esses projetos, bem como informações sobre avaliação (estrelas), total de instalações e versão atual do aplicativo na Google Play Store, loja oficial de aplicativos Android, para os aplicativos que lá estão disponíveis.

\footnotetext{
${ }^{10}$ f-droid.org é um repositório que lista projetos gratuitos e software livre Android (FOOS, do inglês Free and Open Source Software).
} 
Tabela 4.2: Listagem dos nove projetos de software livre Android utilizados para coletar os códigos do experimento.

\begin{tabular}{llll}
\hline \multirow{2}{*}{ Código-Fonte } & \multicolumn{3}{c}{ Google Play Store } \\
\cline { 2 - 4 } & Estrelas & Instalações & Versão \\
\hline https://github.com/uberspot/2048-android & 4.2 & $1.000 .000-5.000 .000$ & 2.08 \\
https://github.com/jereksel/Bucket & 4.2 & $1.000-5.000$ & 0.2 .1 -play \\
https://github.com/TeamAmaze/AmazeFileManager & 4.3 & $500.000-1.000 .000$ & 3.2 .1 \\
https://gitlab.com/cfabio/AltcoinPrices & & & \\
https://github.com/pinetum/AirUnlock-for-Android & & & 1.1 \\
https://github.com/SecUSo/privacy-friendly-weather & 3.8 & $1.000-5.000$ & \multirow{2}{*}{$\begin{array}{l} \\
\text { https://github.com/Xlythe/Calculator }\end{array}$} \\
https://github.com/mkulesh/microMathematics & 4.7 & $500-1.000$ & 0.7 .4 \\
https://github.com/openfoodfacts/openfoodfacts- & 4.0 & $1.000-5.000$ & \\
androidapp & & & \\
\hline
\end{tabular}

A seleção dos códigos foi feita de forma manual, pois como os maus cheiros estão sendo propostos nesta pesquisa, ainda não existem heurísticas definidas ou ferramentas que os detectem automaticamente em projetos Android. Para cada mau cheiro a ser avaliado, buscamos nos projetos pelo tipo de código que poderia ser afetado por ele. Por exemplo, o mau cheiro Atributos de Estilo Repetidos pode afetar recursos de Layout ou Style, mas não Activities, deste modo, para encontrar códigos afetados por ele, buscamos nos projetos por recursos de Layout ou Style. Após encontrado, o código era analisado de modo a verificar se apresentava algum dos sintomas do mau cheiro (o catálogo com a definição dos sintomas dos maus cheiros Android pode ser conferido na Seção 5.1.2). Caso o código apresentasse o sintoma, ele era separado para ser usado no experimento.

Repetimos esse procedimento para cada mau cheiro a ser avaliado, passando por cada um dos projetos selecionados. Quando não encontrávamos códigos nos projetos já selecionados, selecionávamos aleatoriamente outro projeto e repetíamos a busca pelo mau cheiro. Deste modo, 9 projetos foram necessários para encontrarmos códigos exemplos, maus cheirosos e limpos, para os 7 maus cheiros.

Para cada código separado para o experimento, foi criado um gist $^{11}$. A lista com todos os gists pode ser conferida no Apêndice F. Pequenas modificações foram feitas nos códigos com o objetivo de reduzir o esforço cognitivo do participante ao ler o código-fonte apresentado e isolar o mau cheiro a ser avaliado. Desse modo, reduzimos o esforço cognitivo através da remoção de declarações de packages, imports e comentários. Para isolar o mau cheiro, diversas e variadas pequenas mudanças foram realizadas a depender do código e do mau cheiro a ser isolado. Deste modo, cada gist com código mau cheiroso, apresentava apenas um dos maus cheiros avaliados.

Para mitigar possíveis vieses de seleção, foram criados cinco gists diferentes para cada mau cheiro, totalizando 35 gists mau cheirosos diferentes. Sobre os gists com códigos lim-

\footnotetext{
${ }^{11}$ Gist é uma forma de compartilhar conteúdo, inclusive trechos de código, pela plataforma GitHub [3].
} 
pos, selecionamos cinco códigos de componentes da camada de apresentação Android, dentre eles Activities, Fragments, Adapters e Listeners, cinco recursos de Layout e cinco recursos de Style, totalizando 15 gists de códigos limpos. Nenhum dos maus cheiros avaliados afetava recursos de String ou Drawables, e por este motivo não foram selecionados códigos desses tipos.

Para reduzir efeitos de aprendizagem e viés de ordem, cada participante recebeu os seis códigos randomicamente selecionados, em ordem aleatória. Como essa forma de apresentação do experimento eram bem particular desta pesquisa, não foi encontramos nenhuma ferramenta existente que atendesse. Deste modo foi desenvolvido um software específico ${ }^{12}$ para aplicá-lo. Além disso, os participantes não foram informados de quais códigos pertenciam a quais grupos (maus cheirosos ou limpos). Os participantes foram informados apenas de que a pesquisa tinha como objetivo estudar a qualidade de códigos da camada de apresentação de aplicativos Android nativos. Não foi imposto nenhum limite de tempo para completar a tarefa.

Durante o tempo em que o experimento esteve aberto, de 05 de Dezembro de 2017 à 5 de Janeiro de 2018, obtivemos respostas suficientes para avaliar os 7 maus cheiros lançados inicialmente.

\subsubsection{Participantes e Análise dos Dados}

Participaram desta etapa da pesquisa 70 desenvolvedores. Dos participantes, $82 \%$ possui 2 anos ou mais de experiência com desenvolvimento de software e $52 \%$ possui 2 anos ou mais de experiência com desenvolvimento Android. Das 70 respostas, 14 foram desconsideradas ou pelo desenvolvedor não ter experiência com desenvolvimento Android (11\%) ou ter respondido não à pergunta "Na sua opinião, este código apresenta algum problema de design e/ou implementação?" para todos os 6 códigos apresentados. Estes dados podem ser observados na Figura 4.9. Perguntamos aos participantes quantos aplicativos Android nativo eles já haviam publicado, $55 \%$ dos participantes afirmam ter publicado pelo menos um aplicativo, destes, $25 \%$ afirmam já terem publicado mais de cinco aplicativos.

Para comparar as distribuições de severidade para os dois grupos de códigos (mau cheirosos e limpos), utilizamos o teste não pareado de Mann-Whitney [21]. Esse teste é usado para analisar a significância estatística das diferenças entre a severidade atribuída pelos respondentes aos problemas que eles observaram nos códigos. Os resultados são considerados estatisticamente significativos em "valor p" ou $\alpha \leq 0,05$. Também estimamos a magnitude das diferenças usando o Delta de Cliff $(d)$, uma medida de tamanho de efeito não paramétrico [58] para dados ordinais. Seguimos diretrizes bem estabelecidas [58] para interpretar os valores do tamanho do efeito, sendo: desprezível para $|d|<0,14$, pequeno para $0,14 \leq|d|$

\footnotetext{
${ }^{12}$ Repositório do software desenvolvido para aplicação do experimento de código: github.com/suelengc/code-experiment-survey-app
} 
$<0,33$, médio para $0,33 \leq|d|<0.474$, e grande para $|d| \geq 0,474$. Finalmente, relatamos resultados qualitativos derivados das respostas abertas dos participantes.

Para medir a significância estatística das diferenças, comparamos as severidades dos códigos mau cheirosos às severidades dos códigos limpos. Os códigos limpos foram segmentados em três grupos: componentes limpos, ou seja, Activities, Fragments, Adapters ou Listeners limpos, recursos de style limpos e recursos de layout limpos. As severidades dos maus cheiros que afetam componentes, ou seja: Componente de UI Cérebro, Componente de UI Acoplado, Adapter Complexo e Comportamento Suspeito, foram comparadas às severidades do grupo de componentes limpos.

As severidades dos maus cheiros que afetam recursos de layout, ou seja: LAYOUT ProfunDamente Aninhado e Atributos de Estilo Repetidos foram comparada às severidades do grupo de recursos de layout limpos. As severidades dos maus cheiros que afetam recursos de style, ou seja: Longo Recurso de Estilo e Atributos de Estilo Repetidos foram comparadas com às severidades do grupo de recursos de style limpos.

Fizemos também duas análises consolidativas. Uma consolidou a percepção sobre maus cheiros que afetam componentes Android, ou seja, comparamos as severidades de todos os maus cheiros que afetam componentes da camada de apresentação Android com componentes limpos. De modo similar, consolidamos a percepção sobre maus cheiros que afetam recursos Android, comparando as severidades de todos os maus cheiros que afetam recursos às severidades dos grupos de recursos de layout e style limpos.

\subsection{Ameaças à Validade}

Nesta seção, apresentamos as ameaças à validade seguindo os critérios de validade definidos por Claes et al. [19].

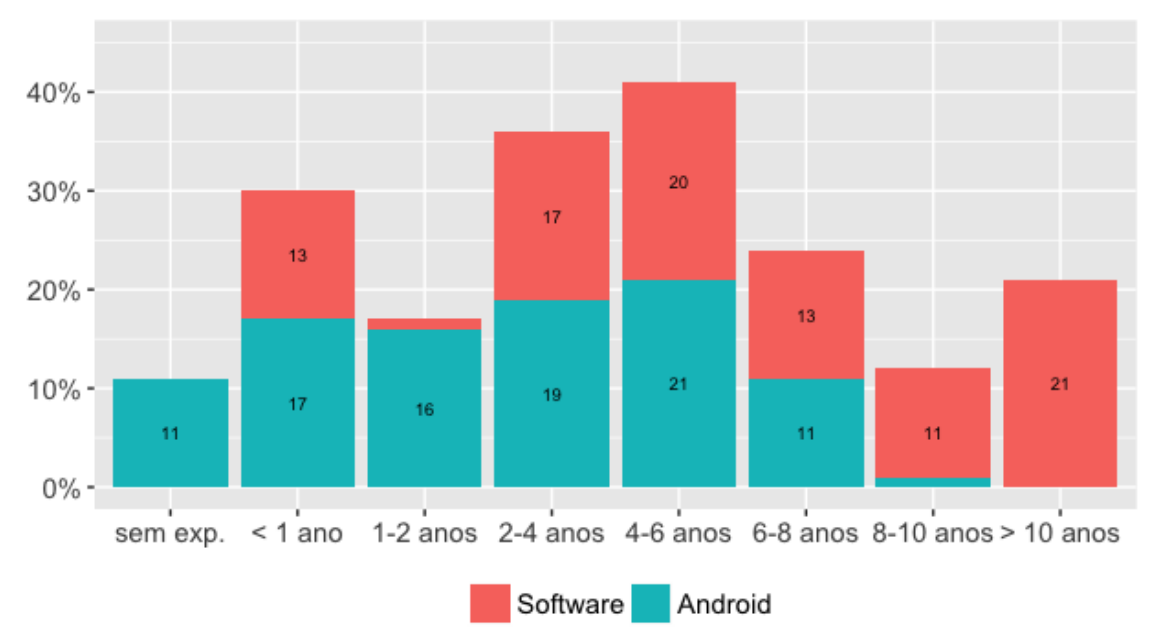

Figura 4.9: Tempo de experiência com desenvolvimento de software e desenvolvimento Android dos participantes de $S_{3}$. 
As ameaças à validade de conclusão dizem respeito à relação entre o tratamento e o resultado. Embora este seja principalmente um estudo observacional, sempre que possível, utilizamos um suporte apropriado de procedimentos estatísticos, integrados com medidas de tamanho de efeito que, além da significância das diferenças encontradas, destacam a magnitude de tais diferenças.

As ameaças à validade interna dizem respeito a fatores externos que não consideramos que possam afetar as variáveis e as relações que estão sendo investigadas. Utilizamos escalas padrões de importância e frequência em $\mathrm{S}_{2}$, mesmo não tendo uma opção neutra, para caso o participante não soubesse opinar sobre alguma afirmação. Apesar de ser possível utilizar outras escalas, até o momento não encontramos nenhuma pesquisa sobre qual escala é mais apropriada para o contexto de validar a importância e frequência de maus cheiros. De modo a mitigar esse problema, o processo de preparação de $\mathrm{S}_{2}$ incluiu a validação com 2 desenvolvedores experientes e 2 testes piloto.

Na literatura, maus cheiros são derivados do conhecimento empírico de desenvolvedores experientes [28, 64, 74, 97]. Pesquisas também mostraram que a experiência e conhecimento desempenham um importante papel na percepção de maus cheiros [82, 92]. Embora não tenhamos restringido nenhum dos questionários $\left(\mathrm{S}_{1}\right.$ e $\left.\mathrm{S}_{2}\right)$ ou experimento $\left(\mathrm{S}_{3}\right)$ a desenvolvedores com determinado tempo de experiência, todos eles possuíam perguntas que nos possibilitaram avaliar a experiência dos respondentes. Por fim, obtivemos a maioria das respostas de desenvolvedores com 2 anos ou mais de experiência em desenvolvimento de software e Android.

Não controlamos se um participante de uma etapa da pesquisa participou de outra, deste modo, não podemos ignorar possíveis vieses de participantes recorrentes. Entretanto, ambos os questionários e experimento eram independentes e não faziam qualquer referência um ao outro.

Também é possível que imprecisões ocorram devido a algum erro de implementação no sistema desenvolvido por nós para o experimento de código. Para mitigar esse risco, nosso sistema foi desenvolvido com base no sistema de software livre desenvolvido por Aniche et al. $[8,9]$ para validar a percepção de maus cheiros relacionados ao arcabouço Spring MVC.

Embora nossa pesquisa tenha sido realizada em três etapas, estamos cientes que os dados foram todos coletados por questionários online, podendo trazer imprecisões devido ao uso de um único meio de coleta de dados. Para mitigar esse problema, nossas etapas se basearam em metodologias já usadas em outras pesquisas similares e também realizamos validações e testes piloto antes de lançarmos os questionários.

As ameaças à validade do constructo dizem respeito à relação entre a teoria e a observação, e neste trabalho são principalmente devido à codificação realizada. Uma vez que a codificação das respostas de $S_{1}$ foi realizada apenas pelo autor, estamos cientes que imprecisões podem ser introduzidas. Para mitigar esse problema, validamos por meio de $\mathrm{S}_{2}$, que os 
sintomas extraídos são considerados frequentes e importantes por desenvolvedores Android. Vale lembrar que o processo de preparação de $\mathrm{S}_{2}$ incluiu duas validações com desenvolvedores experientes e dois pilotos. Além disso, os dados usados para a codificação, bem como as categorias derivadas estão disponíveis para inspeção no apêndice online ${ }^{13}$.

A seleção dos códigos usados em $\mathrm{S}_{3}$ foi feita manualmente buscando pelos sintomas dos maus cheiros detalhados na seção 5.1.2. Podem haver melhores maneiras de proceder com essa seleção. Pesquisas adicionais precisam ser conduzidas para otimizar esse processo. No entanto, nossa seleção atual foi capaz de detectar códigos percebidos como problemáticos pelos desenvolvedores. Entretanto, estamos cientes de que essa seleção manual pode introduzir imprecisões. De modo a mitigá-las, selecionamos cinco diferentes códigos maus cheirosos para cada mau cheiro analisado e cinco diferentes códigos para cada componente Android e recursos de Style e Layout.

As ameaças à validade externa referem-se à generalização dos resultados. Definimos como camada de apresentação os oito elementos aqui pesquisados. Embora essa definição tenha sido embasada na documentação oficial, sabemos que existem recursos não investigados e podem haver classes menos comumente usadas também não avaliadas que de alguma forma se relacionem também à camada de apresentação. Logo, não afirmamos que camada de apresentação se limita apenas aos oito elementos aqui estudados.

Validamos com sucesso a percepção de forma negativa de 6 maus cheiros com desenvolvedores Android por meio de um experimento de código online. Embora este experimento tenha sido usado em outras pesquisas similares com o mesmo objetivo [8, 9, 82] e tenhamos obtido pontos por mau cheiro suficientes para ter confiabilidade estatística, não afirmamos que todo desenvolvedor Android irá perceber os maus cheiros validados.

Embora tenhamos tido certa abrangência geográfica nas respostas de $\mathrm{S}_{1}$ e $\mathrm{S}_{2}$, nossos resultados foram majoritariamente de brasileiros, principalmente de São Paulo. Logo, não afirmamos que nossos resultados são generalizáveis globalmente. Mais pesquisas precisam ser conduzidas neste sentido para verificar a validade dos maus cheiros por desenvolvedores de outras regiões.

Nosso catálogo é composto de 20 maus cheiros na camada de apresentação Android. Entretanto, coletamos poucas respostas em $\mathrm{S}_{1}$ e deste modo, não afirmamos que este é um catálogo abrangente ou mesmo completo. Pesquisas adicionais são necessárias para investigar outras possíveis más práticas na camada de apresentação de aplicativos Android e mesmo validar se os maus cheiros aqui definidos, porém não validados, são realmente percebidos e relevantes.

\footnotetext{
${ }^{13}$ Apêndice online disponível em: http://suelengc.github.io/master-degree-dissertation.
} 


\section{Capítulo 5}

\section{Resultados}

\section{1 $\mathrm{QP}_{1}$ Maus Cheiros Específicos à Camada de Apre- sentação Android}

Nesta seção apresentamos resultados gerais sobre o processo de derivação dos maus cheiros (Seção 5.1.1) e o catálogo com os 20 maus cheiros propostos relacionados à camada de apresentação Android (Seção 5.1.2).

\subsubsection{Resultados Gerais e Descobertas}

Todas as 16 perguntas sobre boas e más práticas, nos elementos da camada de apresentação Android (segunda seção de $\mathrm{S}_{1}$ ) foram opcionais, de modo que algumas receberam mais respostas do que outras. A Figura 5.1 apresenta o total de respostas recebidas por cada pergunta. Podemos observar que 35 dos 45 participantes responderam a pergunta sobre boas práticas em Activities: "Do you have any good practices to deal with Activities?". Enquanto que 38 responderam sobre más práticas em Activities: "Do you have anything you consider a bad practice when dealing with Activities?".

O elemento que recebeu menos respostas sobre boas práticas foi o Listener, sendo respondida por 10 dos 45 participantes. Os elementos que receberam menos respostas sobre más práticas foram os recursos de Style e Drawable, sendo que ambos foram respondidos por apenas 9 dos 45 participantes. Dentre os componentes, os que receberam mais respostas foram Activities e Fragments, ambos sendo respondidos por pelo menos 27 participantes. Dentre os recursos, o que recebeu mais resposta foi o recurso de Layout, sendo respondido por pelo menos 22 dos 45 participantes. De modo geral, perguntas sobre boas práticas foram mais respondidas do que as perguntas sobre más práticas, exceto sobre Activities e Listeners.

O processo de codificação resultou em 46 categorias, das quais consideramos para a derivação dos maus cheiros todas as que apresentaram ocorrências maior ou igual a cinco, 

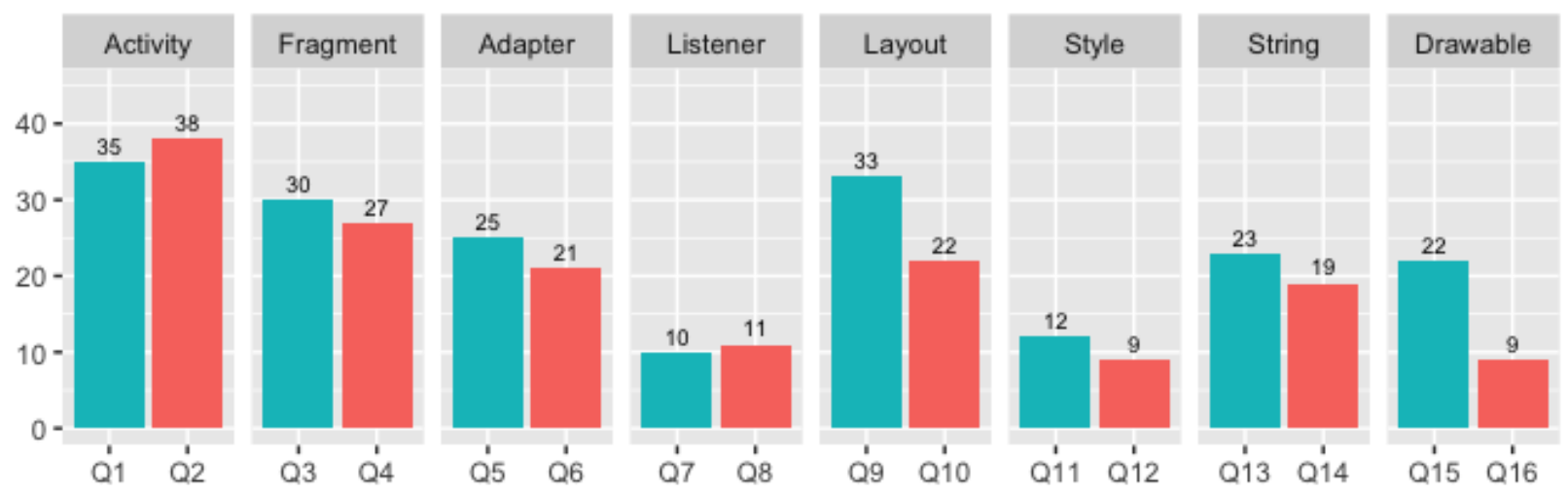

Boas Práticas

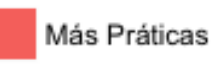

Figura 5.1: Total de respostas para cada pergunta sobre boas e más práticas nos oito elementos da camada de apresentação Android.

com base no número de Nielsen [79]. Deste modo, 22 categorias foram consideradas. Dessas 22, desconsideramos mais 2 por se tratar de (i) um mau cheiro tradicional (Classe Grande) e (ii) um aspecto da orientação a objetos (Herança). Resultando em 20 categorias para a derivação dos maus cheiros da camada de apresentação Android.

A Tabela 5.1 apresenta o total de ocorrências segmentadas por elemento da camada de apresentação Android das 20 categorias consideradas para a derivação dos maus cheiros. Por exemplo, a categoria Componente de UI CÉReBro apresenta 29 na coluna Activity, 16 na coluna Fragment, 14 na coluna Adapter e 1 na coluna Listener, isso significa que 29 ocorrências foram em respostas sobre boas e más práticas em Activities, 16 ocorrências foram em respostas sobre boas e más práticas em Fragments e assim por diante. O número sobrescrito, entre parênteses, ao lado do nome da categoria indica o total de ocorrências, ou seja, a soma das ocorrências em todos os elementos Android.

Na Figura 5.1 o total de respostas sobre boas e más práticas em Activities é de 73 (somatória das colunas Q1 e Q2), e na Tabela 5.1 o total de respostas na coluna Activity é de 49. Essa diferença ocorre pois, na figura estamos considerando as respostas de todas as 46 categorias, enquanto na tabela estamos consideramos apenas as respostas às 20 categorias consideradas.

Vale observar que um mesmo mau cheiro pode afetar mais de um elemento da camada de apresentação Android. Por meio da Tabela 5.1, podemos obter sugestões sobre quais elementos Android um mau cheiro afeta através do cruzamento do número de ocorrências, ou seja, se há ocorrências, possivelmente o mau cheiro respectivo afeta o elemento respectivo. Por exemplo, o mau cheiro Componente de UI Cérebro se apresenta em 4 componentes: Activities com 29 ocorrência, Fragments com 16, Adapters com 14 e Listeners com 1, e de fato, esse mau cheiro pode afetar todos esses componentes.

Entretanto, para outros maus cheiros, essa sugestão não é verdade. Por exemplo, no 
Tabela 5.1: Total de respostas sobre boas e más práticas em cada elemento da camada de apresentação Android.

\begin{tabular}{|c|c|c|c|c|c|c|c|c|}
\hline Mau Cheiro & $\Delta^{c+i v i}$ & $y^{20 b^{40}}$ & $\Delta d a e^{t}$ & $\mathrm{e}^{\mathrm{s}}+\mathrm{e}^{\mathrm{ter}}$ & 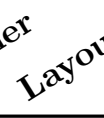 & $5+r^{-i 08}$ & $5+y^{10}$ & $D^{r^{a^{*}}}$ \\
\hline Componente de Ui CÉrebro(60) & 29 & 16 & 14 & 1 & - & - & - & - \\
\hline Componente de UI Acoplado $^{(18)}$ & 2 & 10 & 3 & 3 & - & - & - & - \\
\hline COMportamento Suspeito $^{(17)}$ & 4 & - & 3 & 10 & - & - & - & - \\
\hline AdAPTER CONSUMista ${ }^{(13)}$ & - & - & 13 & - & - & - & - & - \\
\hline Uso Excessivo DE Fragments ${ }^{(9)}$ & - & 9 & - & - & - & - & - & - \\
\hline COMPONENTE de UI FAZENDO IO I $^{(9)}$ & 5 & 3 & 1 & - & - & - & - & - \\
\hline NÃO USO DE FraGMENT ${ }^{(8)}$ & 4 & 4 & - & - & - & - & - & - \\
\hline AusêNCIA DE ARQuitetura ${ }^{(6)}$ & 4 & 2 & - & - & - & - & - & - \\
\hline AdAPter COMPLEXo ${ }^{(6)}$ & - & - & 5 & - & 1 & - & - & - \\
\hline Nome de Recurso Despadronizado ${ }^{(24)}$ & - & - & - & - & 5 & 10 & 5 & 3 \\
\hline RECURSO MÁGICO ${ }^{(23)}$ & - & - & - & - & 6 & 15 & 2 & - \\
\hline LAYOut Profundamente AnINhado ${ }^{(19)}$ & - & - & 1 & - & 18 & - & - & - \\
\hline Imagem Tradicional DisPensável ${ }^{(18)}$ & - & - & - & - & 1 & - & - & 17 \\
\hline LAYOUT LONGO OU REPETIDO ${ }^{(14)}$ & - & - & - & - & 14 & - & - & - \\
\hline IMAGEM FALTANTE $^{(12)}$ & - & - & - & - & 2 & - & - & 10 \\
\hline Longo ReCurso de Estilo ${ }^{(8)}$ & - & - & - & - & - & - & 8 & - \\
\hline RECURSO DE StRING BAGUNÇADO ${ }^{(8)}$ & - & - & - & - & - & 8 & - & - \\
\hline Atributos de Estilo Repetidos ${ }^{(7)}$ & - & - & - & - & 3 & - & 4 & - \\
\hline Reúso Inadequado De String ${ }^{(6)}$ & - & - & - & - & - & 6 & - & - \\
\hline LISTENER ESCONDIDO $^{(5)}$ & - & - & - & 5 & - & - & - & - \\
\hline
\end{tabular}

caso do mau cheiro Layout Profundamente Aninhado, apesar de haver 1 ocorrência em Adapter, esse mau cheiro não o afeta. A resposta que originou essa ocorrência indicou na verdade, uma boa prática em recursos de layout: "Criar layouts realmente leves." (P36). Esse tipo de análise da resposta foi cuidadosamente realizado para a escrita da definição textual dos maus cheiros a serem apresentados na próxima seção.

\subsubsection{Maus Cheiros Propostos}

A Tabela 5.2 apresenta a lista e uma breve descrição dos 20 maus cheiros Android propostos derivados das 20 categorias com cinco ocorrências ou mais, resultante do processo de codificação. Os 9 primeiros maus cheiros afetam componentes da camada de apresentação Android, os 11 seguintes afetam recursos Android.

As definições foram embasadas nas respostas obtidas ${ }^{1}$. Por exemplo, algumas respostas que embasaram o mau cheiro Componente de UI CÉREBRo foram: "Fazer lógica de negócio [em Activities]" (P16). "Colocar regra de negócio no Adapter" (P19), "Manter lógica de negócio em Fragments" (P11), "Elas [Activities] representam uma única tela e apenas interagem com a UI, qualquer lógica deve ser delegada para outra classe" (P16) onde de P1 a P45 representam cada um dos 45 respondentes. Com o objetivo de tornar a leitura mais simples,

\footnotetext{
${ }^{1}$ Todo texto em inglês foi traduzido livremente ao longo da dissertação
} 
as respostas usadas para embasá-los estão disponíveis no Apêndice A.

Nos parágrafos seguintes apresentamos de forma textual a definição dos maus cheiros, bem como os elementos afetados por cada mau cheiro e os sintomas relacionados.

Tabela 5.2: Lista dos 20 maus cheiros na camada de apresentação Android e breve descrição dos sintomas.

\begin{tabular}{|c|c|}
\hline Nome & Descrição \\
\hline COMPONENTE DE UI CÉREBRO ${ }^{(60)}$ & Componentes de UI com lógicas de negócio. \\
\hline COMPONEnTE dE UI ACOPLAdO $^{(18)}$ & Componentes de UI com referência concreta um para o outro. \\
\hline COMPORTAMENTO SUSPEITo $^{(17)}$ & Listener sendo implementado dentro de outro componente de UI. \\
\hline AdAPter CONSUMista ${ }^{(13)}$ & Adapters que não usam o padrão ViewHolder. \\
\hline Uso Excessivo de Fragments ${ }^{(9)}$ & Uso de fragments sem uma necessidade explícita. \\
\hline Componente de UI FAZEndo IO ${ }^{(9)}$ & Componentes de UI fazendo acesso a internet ou banco de dados. \\
\hline NÃo Uso DE FraGment ${ }^{(8)}$ & Não usar nenhum Fragment. \\
\hline AusÊNCIA DE ARQuitetura ${ }^{(6)}$ & Aplicativos sem uma arquitetura conhecida. \\
\hline ADAPTER COMPLEXo ${ }^{(6)}$ & Adapters com condicionais e loops. \\
\hline \multicolumn{2}{|c|}{ Nome de Recurso Despadronizado ${ }^{(24)}$ Recursos com nomes despadronizados. } \\
\hline RECURSO MÁGICO ${ }^{(23)}$ & Textos, números ou cores "hardcoded". \\
\hline Layout Profundamente Aninhado ${ }^{(19)}$ & Recurso de layout com mais de três níveis de Viwes aninhadas. \\
\hline Imagem Tradicional Dispensável ${ }^{(18)}$ & Imagens que poderiam ser transformadas em recurso gráfico. \\
\hline LAYOUt LONGO OU REPETIDO ${ }^{(14)}$ & $\begin{array}{l}\text { Recurso de layout muito longo ou com trechos de código similares } \\
\text { ou repetidos. }\end{array}$ \\
\hline Imagem Faltante $^{(12)}$ & Imagem sem todas as resoluções padrões. \\
\hline LONGO RECURSO DE Estilo ${ }^{(8)}$ & Recurso de estilo único e longo. \\
\hline RECurso de String BAGunÇAdo ${ }^{(8)}$ & Recursos de string sem um padrão de nomenclatura. \\
\hline Atributos de Estilo Repetidos ${ }^{(7)}$ & Atributos de estilo repetidos em recursos de layout ou style. \\
\hline Reúso InAdequado de String ${ }^{(6)}$ & Strings sendo reutilizadas indevidamente. \\
\hline LISTENER ESCONDIDO ${ }^{(5)}$ & Atributo onClick em recursos de layout. \\
\hline
\end{tabular}

Componente de UI Cérebro ${ }^{(60)}$ Activities, Fragments, Adapters e Listeners devem conter apenas códigos responsáveis por apresentar, interagir e atualizar a UI. São indícios do mau cheiro a existência de códigos relacionados à lógica de negócio, operações de $\mathrm{IO}^{2}$, conversão de dados ou campos estáticos nesses elementos.

Componente de UI ACoplado ${ }^{(18)}$ Fragments, Adapters e Listeners, para que possam ser reutilizados, não devem ter referência direta para quem os utiliza. São indícios do mau cheiro a existência de referência direta para Activities ou Fragments nesses elementos.

Comportamento Suspeito ${ }^{(17)}$ Activities, Fragments e Adapters não devem ser responsáveis pela implementação do comportamento dos eventos. São indícios do mau cheiro o uso de classes anônimas, classes internas ou polimorfismo (através de implements) para implementar Listeners de modo a responder a eventos do usuário.

Adapter Consumista ${ }^{(13)}$ São indícios do mau cheiro quando Adapters não reutilizam instâncias das views que representam os campos a serem populados para cada item da coleção através do padrão View Holder ou quando os mesmos possuem classes internas para reaproveitamento das views porém não são estáticas.

\footnotetext{
${ }^{2}$ Ver mau cheiro Classes de UI FAZENdo IO.
} 


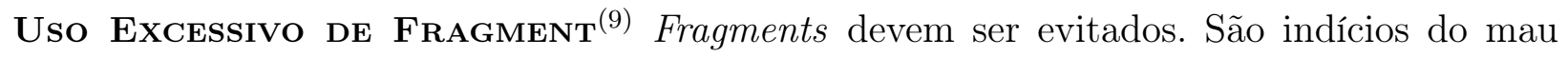
cheiro quando o aplicativo não é utilizado em Tablets ou não possuem ViewPagers e ainda assim faz o uso de Fragments ou quando existem Fragments no projeto que não são utilizados em mais de uma tela do aplicativo.

Componente de UI FAzendo IO ${ }^{(9)}$ Activities, Fragments e Adapters não devem ser responsáveis por operações de IO. São indícios do mau cheiro implementações de acesso a banco de dados ou internet a partir desses elementos.

Não Uso de Fragment ${ }^{(8)}$ Fragments devem ser usados sempre que possível em conjunto com Activities. É indício do mau cheiro a não existência de Fragments na aplicação ou o uso de EditTexts, Spinners ou outras views diretamente por Activities.

Adapter Complexo ${ }^{(6)}$ Adapters devem ser responsáveis por popular uma view a partir de um único objeto, sem realizar lógicas ou tomadas de decisão. São indícios desse mau cheiro quando Adapters contêm muitos condicionais (if ou switch) ou cálculos no método responsável pelo preenchimento da view.

Ausência de Arquitetura ${ }^{(6)}$ São indícios do mau cheiro quando diferentes Activities e Fragments no projeto apresentam fluxos de código complexos, possivelmente são CompoNENTE DE UI CÉREBRo, onde não é possível identificar uma organização padronizada entre eles que aponte para algum padrão arquitetural, como por exemplo, MVC, MVP (do inglês Model View Presenter), MVVM (do inglês Model View ViewModel) ou Arquitetura Limpa (do inglês Clean Architecture).

Nome de Recurso Despadronizado ${ }^{(24)}$ São indícios do mau cheiro quando recursos de layout, recursos de string, recursos de style e recursos drawables não possuem um padrão de nomenclatura, seja no nome do arquivo ou dos elementos internos a eles.

Recurso MÁGICo ${ }^{(23)}$ Todo recurso de cor, tamanho, texto ou estilo deve ser criado em seu respectivo arquivo e então ser usado. São indícios do mau cheiro quando recursos de layout, recursos de string ou recursos de style usam alguma dessas informações diretamente no código ao invés de fazer referência para um recurso existente.

Layout Profundamente Aninhado ${ }^{(19)}$ São indícios desse mau cheiro o uso de profundos aninhamentos na construção de recursos de layout, ou seja, ViewGroups contendo outros ViewGroups sucessivas vezes. O site oficial do Android conta com informações e ferramentas automatizadas para lidar com esse sintoma [51].

Imagem Tradicional Dispensável ${ }^{(18)}$ O Android possui diversos tipos de recursos drawables que podem substituir imagens tradicionais como •png, .jpg ou . gif a um custo menor em termos de tamanho do arquivo e sem a necessidade de haver versões de diferentes tamanhos/resoluções. São indícios do mau cheiro a existência de imagens com, por exemplo, cores sólidas, degradês ou estado de botões que poderiam ser substituídas por recursos drawables de outros tipos como shapes, state lists ou nine-patch file. Outro sintoma 
é a não existência de imagens vetoriais, que podem ser redimensionadas sem a perda de qualidade mitigando a necessidade de várias versões de um mesmo arquivo.

Layout Longo ou Repetido ${ }^{(14)}$ Sempre que possível, reutilizar trechos de layout. São indícios do mau cheiro quando um recurso de layout é muito grande ou possui trechos de código muito semelhantes ou iguais dentro dele ou a outras telas.

IMAGEM FALtAnte $^{(12)}$ As imagens devem ser disponibilizadas em mais de um tamanho ou resolução para que o Android possa realizar otimizações. São indícios do mau cheiro haver apenas uma versão de algum recurso drawable do tipo .png, . jpg ou .gif, ou ainda, ter imagens em diretórios incorretos em termos de $d p i$.

Longo Recurso de Estilo ${ }^{(8)}$ É indício do mau cheiro haver apenas um recurso de style ou conter recursos de style muito longos.

Recurso de String Bagunçado ${ }^{(8)}$ É indício do mau cheiro o uso de apenas um arquivo para todos os recursos de string do aplicativo e a não existência de um padrão de nomenclatura e separação para os recursos de string de uma mesma tela.

Atributos de Estilo Repetidos ${ }^{(7)}$ É indício do mau cheiro haver recursos de layout ou recursos de style com blocos de atributos de estilo repetidos.

Reúso InAdequado DE STRING ${ }^{(6)}$ Cada tela deve ter seu conjunto de recursos de string. É indício do mau cheiro reutilizar o mesmo recurso de string em diferentes telas do aplicativo apenas porque o texto coincide.

LISTENER ESCONDIDO $^{(5)}$ recursos de layout devem ser responsáveis apenas por apresentar informações. É indício do mau cheiro o uso de atributos de eventos, como o onClick, diretamente em recursos de layout para configurar o Listener que responderá ao evento.

Nossos resultados mostram que existem maus cheiros específicos a elementos da camada de apresentação Android ( $\left.\mathrm{QP}_{1}\right)$.

\section{2 $\mathrm{QP}_{2}$ Importância e Frequência dos Maus Cheiros An- droid}

Nossos resultados mostraram que os 20 maus cheiros propostos são considerados, em diferentes níveis, importantes e se apresentam com diferentes frequências no dia a dia do desenvolvimento Android. As distribuições relativas de frequência e importância, sobre cada afirmação apresentada no questionário, pode ser conferida nos Apêndices D (afirmações de frequência) e E (afirmações de importância). 


\subsubsection{Resultados Gerais}

Para análise dos maus cheiros extraímos dados estatísticos de moda (MO), mediana (ME) e desvio padrão (DP) de importância e frequência para cada um dos maus cheiros propostos. Utilizamos a MO como um classificador do mau cheiro, ou seja, se ele recebeu majoritariamente a resposta "importante", o classificamos como importante. Estes dados são apresentados na Tabela 5.3 onde podemos observar que todos os maus cheiros apresentam MO de importância maior ou igual a 3, ou seja, de "razoavelmente importante" a "muito importante". Em contrapartida, com relação à frequência, três maus cheiros (ADAPTER CoNSumista, Listener Escondido e Não Uso de Fragment) apresentaram MO igual a 2, "raramente", todos os demais apresentaram MO maior ou igual a 3, ou seja, de "às vezes" até "muito frequente".

Tabela 5.3: Mediana (ME), moda (MO) e desvio padrão (DP) sobre a percepção da importância dos maus cheiros relacionados a componentes da camada de apresentação Android.

\begin{tabular}{|c|c|c|c|c|c|c|}
\hline \multirow{2}{*}{ Mau Cheiro } & \multicolumn{3}{|c|}{ Importância } & \multicolumn{3}{|c|}{ Frequência } \\
\hline & ME & MO & DP & ME & MO & DP \\
\hline COMPONENTE DE UI CÉREBRO & 5 & 5 & 1,05 & 3 & 4 & $\overline{1,19}$ \\
\hline Recurso MáGico & 4 & 5 & 1,00 & 3 & 4 & 1,24 \\
\hline Imagem Tradicional Dispensável & 4 & 5 & 0,95 & 3 & 4 & 1,23 \\
\hline LAYOUT LONGO OU REPETIDO & 4 & 5 & 0,95 & 4 & 4 & 1,07 \\
\hline IMAGEM FALTANTE & 5 & 5 & 0,95 & 3 & 4 & 1,25 \\
\hline COMPONENTE DE UI ACOPLADO & 4 & 5 & 1,02 & 3 & 3 & 1,15 \\
\hline Classes de UI FAZENdo IO & 5 & 5 & 1,03 & 3 & 3 & 1,29 \\
\hline AusÊnCIA de ARquitetura & 5 & 5 & 0,82 & 3 & 3 & 1,30 \\
\hline ADAPTER COMPlexo & 4 & 5 & 0,91 & 3 & 3 & 1,15 \\
\hline Nome de Recurso Despadronizado & 5 & 5 & 0,88 & 3 & 3 & 1,24 \\
\hline ADAPTER CONSUMISTA & 5 & 5 & 0,93 & 2 & 2 & 1,20 \\
\hline LISTENER ESCONDIDO & 4 & 5 & 1,23 & 2 & 2 & 1,29 \\
\hline Longo Recurso de Estilo & 4 & 4 & 1,06 & 4 & 5 & 1,18 \\
\hline Recurso de String Bagunçado & 3 & 4 & 1,22 & 4 & 5 & 1,18 \\
\hline COMPORTAMENTO SUSPEITO & 3 & 4 & 1,19 & 3 & 4 & 1,19 \\
\hline Layout Profundamente Aninhado & 4 & 4 & 1,12 & 4 & 4 & 1,06 \\
\hline Atributos de Estilo Repetidos & 4 & 4 & 0,86 & 4 & 4 & 1,11 \\
\hline NÃo USO dE Fragment & 3 & 4 & 1,34 & 3 & 2 & 1,21 \\
\hline Reúso Inadequado de String & 3 & 3 & 1,29 & 4 & 4 & 1,12 \\
\hline Uso Excessivo de Fragment & 3 & 3 & 1,36 & 3 & 3 & 1,17 \\
\hline DP Médio & & & 1.05 & & & 1.19 \\
\hline
\end{tabular}

Entendemos este resultado de forma positiva pois, apesar de alguns sintomas não serem tão frequentes, ainda assim são considerados com algum nível de importância de se mitigar, reforçando também a relevância desta pesquisa pois damos os primeiros passos no sentido da automatização da identificação desses maus cheiros. Com base no DP, podemos observar que, de modo geral, existe uma concordância maior sobre a importância dos maus cheiros do que sobre a frequência, pois a média do DP de importância é de 1,05, ligeiramente menor que a média do DP de frequência, que é de 1,19.

Quanto menor o DP maior a concordância entre os participantes sobre determinado mau 
cheiro. Podemos observar que os maus cheiros que tiveram maior concordância com relação à sua importância foram: Adapter Complexo, Adapter Consumista, Atributos de Estilo Repetidos, Ausência de Arquitetura, imagem Faltante, Imagem Tradicional Dispensável, Layout Longo ou Repetido, Nome de Recurso Despadronizado, todos com DP menor que 1. Sobre a concordância relacionada à frequência, nenhum dos maus cheiros obteve DP menor que 1, mas os mais próximos, indicando maior concordância sobre sua frequência são: Layout Profundamente Aninhado com DP de 1,06 e Longo Recurso DE EsTilo com DP 1,07.

\subsubsection{Importância dos Maus Cheiros}

Para análise dos dados, simplificamos a escala likert de importância de modo que, os maus cheiros de MO 3, "razoavelmente importante", são classificados como sendo de importância moderada, os maus cheiros de MO 4 ou 5, respectivamente "importante" e "muito importante", são classificados de importância alta. Nenhum mau cheiro teve MO 1 ou 2, respectivamente "não é importante" e "pouco importante", logo, não criamos classificações para essas opções.

A Tabela 5.4 apresenta a lista dos maus cheiros de acordo com seu nível de importância, alta ou moderada. Podemos observar que as duas primeiras colunas contêm os 18 maus cheiros classificados com importância alta. Dentre eles, a maioria dos maus cheiros (10) afetam recursos Android: Longo Recurso de Estilo, Layout Profundamente Aninhado, Atributos de Estilo Repetidos, Nome de Recurso Despadronizado, Recurso Mágico, imagem Faltante, Imagem Tradicional Dispensável, Layout Longo ou Repetido, ReCURso de String Bagunçado e Listener Escondido.

Tabela 5.4: Listagem dos maus cheiros da camada de apresentação Android de acordo com seu nivel de importância, alta ou moderada.

\begin{tabular}{lll}
\hline & Importância Alta & Importância Moderada \\
\hline Adapter Complexo & Atributos de Estilo Repetidos & Réso Inadequado de String \\
Adapter Consumista & Comportamento Suspeito & Uso Excessivo de Fragment \\
Ausência de Arquitetura & Layout Profundamente Aninhado & \\
Classes de Ui Fazendo IO & Longo Recurso de Estilo \\
Componente de Ui Acoplado & Não Uso de Fragment \\
Componente de Ui Cérebro & Recurso de String Bagunçado \\
Recurso Mágico & Imagem Faltante \\
Imagem Tradicional Dispensável & Layout Longo ou Repetido \\
Listener Escondido & Nome de Recurso Despadronizado \\
\hline & 18 & \\
\hline
\end{tabular}

Enquanto que 8 dos maus cheiros de importância alta afetam componentes da camada de apresentação Android: Adapter Complexo, Adapter Consumista, Ausência de Arquitetura, Classes de Ui fazendo iO, Componente de Ui Cérebro, Atributos de Estilo Repetidos, Comportamento Suspeito e Não Uso de Fragment. Apenas 2 maus 
cheiros: Reúso Inadequado de String e Uso Excessivo de Fragment, listados na última coluna da tabela, são de importância moderada, sendo 1 relacionado a recursos e outro componentes da camada de apresentação Android.

A Figura 5.2 apresenta a distribuição relativa de importância dos maus cheiros. Apresentamos negativo (em vermelho) o percentual relacionado às respostas "não é importante".

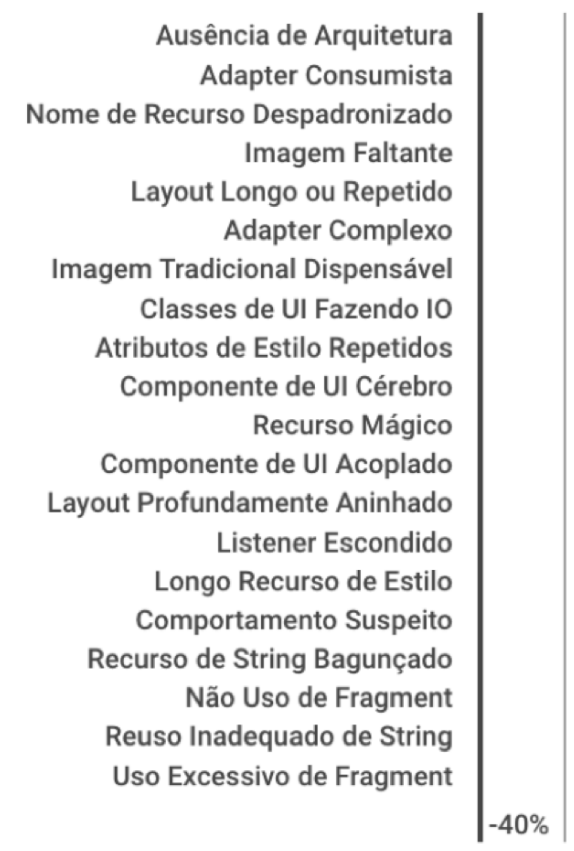

Adapter Consumista Despadronizado ongo ou Repetido Adapter Complexo Tradicional Dispensável Atributos de Estilo Repetidos Componente de UI Cérebro Recurso Mágico Componente de UI Acoplado damente Aninhado Longo Recurso de Estilo

Comportamento Suspeito

Recurso de String Bagunçado Não Uso de Fragment

Reuso Inadequado de String

Uso Excessivo de Fragment

Não é importante
Pouco importante

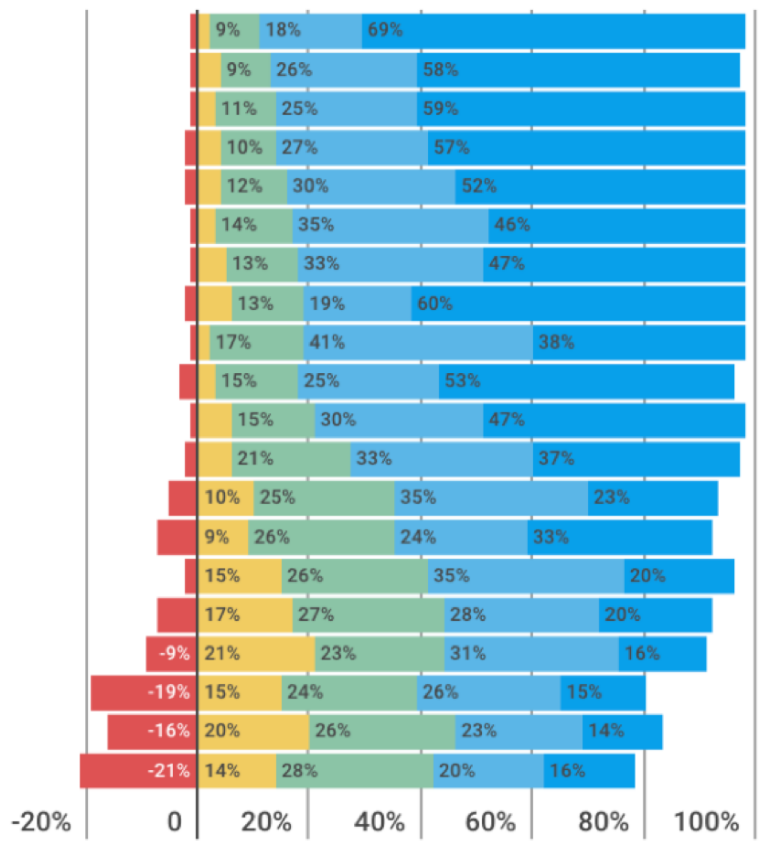

Razoavelmente importante

Importante

Muito importante

Figura 5.2: Distribuição relativa de importância dos maus cheiros propostos.

Os três maus cheiros considerados menos importantes foram Reúso INADEQUADo DE String, Não Uso de Fragment e Uso Excessivo de Fragment, com mais de $16 \%$ dos participantes indicando "não é importante", menos de $26 \%$ indicando "importante" e menos de 16\% indicando "muito importante". São os mesmos que tiveram menor concordância com relação à sua importância, todos com DP acima de 1,28. Esses dados sugerem que desenvolvedores Android ainda têm dúvidas sobre o impacto negativo desses maus cheiros no código.

\subsubsection{Frequência dos Maus Cheiros}

Para análise dos dados, simplificamos a escala likert de frequência de modo similar ao de importância, onde maus cheiros de MO 2, "raramente", são classificados como frequência baixa, os maus cheiros de MO 3, "às vezes", são classificados como frequência moderada e os maus cheiros de MO 4 ou 5, respectivamente "frequente" e "muito frequente", são classificados de frequência alta. Nenhum mau cheiro teve MO 1, "nunca", e portanto não criamos classificação para essa opção. A Tabela 5.5 apresenta a lista dos maus cheiros de acordo com 
seu nível de frequência, alta, moderada ou baixa.

Tabela 5.5: Listagem dos maus cheiros da camada de apresentação Android de acordo com seu nivel de frequência, alta, moderada ou baixa.

\begin{tabular}{lll}
\hline \multicolumn{1}{c}{ Frequência Alta } & \multicolumn{1}{c}{ Frequência Moderada } & \multicolumn{1}{c}{ Frequência Baixa } \\
\hline Atributos de Estilo Repetidos & Adapter Complexo & Adapter Consumista \\
Componente de Ui Cérebro & Ausência de Arquitetura & Listener Escondido \\
Imagem Faltante & Classes de Ui Fazendo io & Não Uso de Fragment \\
Imagem Tradicional Dispensável & Componente de Ui Acoplado & \\
Layout Longo ou Repetido & Uso Excessivo de Fragment & \\
Layout Profundamente Aninhado & Comportamento Suspeito & \\
Longo Recurso de Estilo & Nome de Recurso Despadronizado & \\
Recurso Mágico & & \\
Reúso Inadequado de String & & \\
Recurso de String Bagunçado & & \\
\hline \multicolumn{1}{c}{10} & 7 & 3 \\
\hline
\end{tabular}

É interessante notar que, maus cheiros em recursos são percebidos mais frequentemente que os maus cheiros em componentes da camada de apresentação Android. Podemos observar na Tabela 5.5 que, 9 dentre os 10 maus cheiros de frequência alta são em recursos Android: Atributos de Estilo Repetidos, Imagem Faltante, Imagem Tradicional Dispensável, Layout Longo ou Repetido, Layout Profundamente Aninhado, Longo Recurso de Estilo, Recurso Mágico, Reúso Inadequado de String e Recurso de String BagunÇADO. Enquanto que apenas o mau cheiro de frequência alta, Componente DE UI CÉREBro, é relacionado a componentes da camada de apresentação Android.

Nos demais níveis de frequência, essa situação se inverte, sendo os maus cheiros em componentes da camada de apresentação Android, maioria. Dentre os maus cheiros de frequência moderada, 6 dentre os 7 são relacionados a componentes: AdApter Complexo, Ausência de Arquitetura, Classes de Ui Fazendo iO, Componente de Ui Acoplado, Uso Excessivo de Fragment e Comportamento Suspeito. Apenas o mau cheiro Nome de Recurso Despadronizado é relacionado a recursos Android. Dentre os maus cheiro de frequência baixa, 2 dentre os 3 são relacionados a componentes da camada de apresentação Android: Adapter Consumista e Não Uso de Fragment. E apenas o mau cheiro Listener EsconDIDO é relacionado a recursos Android.

A Figura 5.3 apresenta a distribuição relativa de frequência dos maus cheiros. Apresentamos negativo (em vermelho) o percentual relacionado às respostas "nunca". Os maus cheiros menos percebidos (com mais de $20 \%$ de respostas "nunca") foram AdAPter Consumista (25\%) e Listener Escondido (24\%). Todos os demais maus cheiros são percebidos no dia a dia, com frequência moderada ou alta, por pelo menos $75 \%$ dos participantes.

Adapter Consumista foi o mau cheiro menos percebido no dia a dia por desenvolvedores Android (25\% dos participantes indicaram "nunca"). Entretanto ele é o segundo considerado mais importante (58\% dos participantes indicaram "muito importante" e $26 \%$ indicaram "importante"). Esses dados sugerem que desenvolvedores já estão cientes dos benefícios do 
Recurso de String Bagunçado Layout Profundamente Aninhado

Reuso Inadequado de String Atributos de Estilo Repetidos Longo Recurso de Estilo

Componente de UI Cérebro Imagem Tradicional Dispensável Recurso Mágico Layout Longo ou Repetido Uso Excessivo de Fragment Nome de Recurso Despadronizado Imagem Faltante Componente de UI Acoplado Adapter Complexo Ausência de Arquitetura Comportamento Suspeito Classes de UI Fazendo IO Listener Escondido Não Uso de Fragment Adapter Consumista

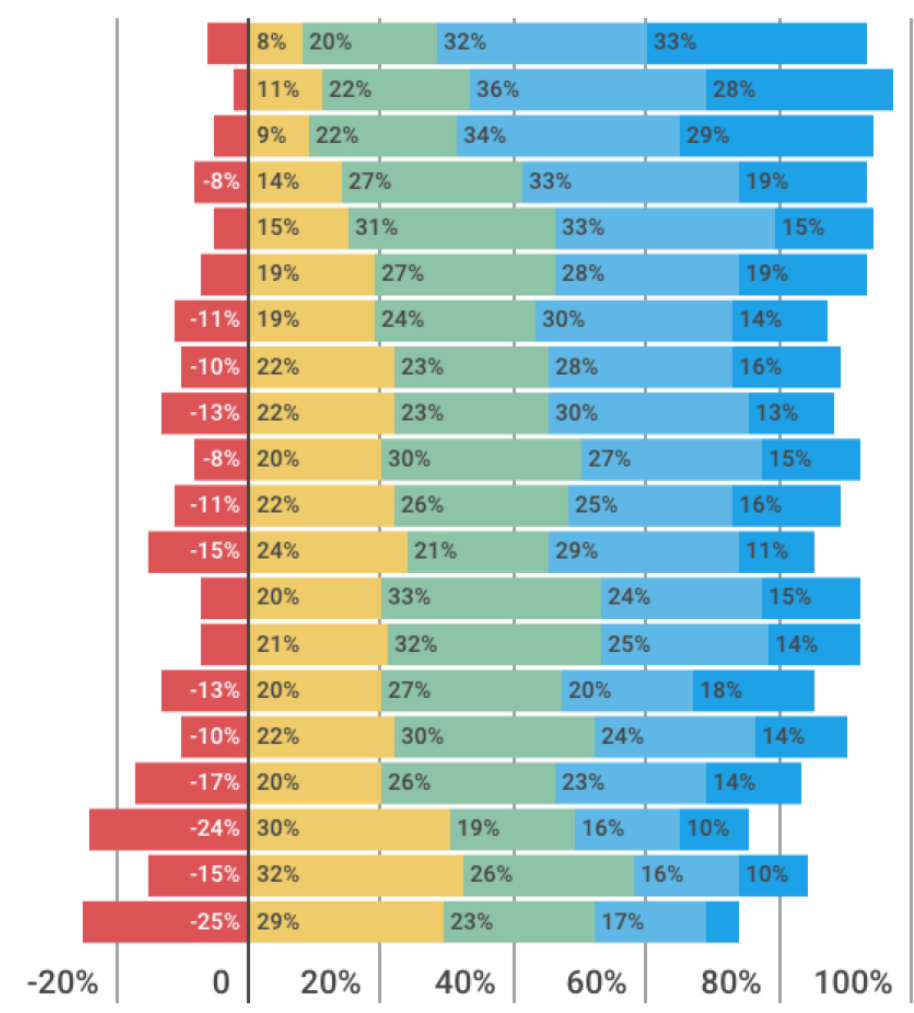

Às vezes
Frequente
Muito frequente

Figura 5.3: Distribuição relativa de frequência dos maus cheiros propostos.

uso do padrão ViewHolder [54] e encontraram formas de mitigar este mau cheiro. Na seção 6.3 realizamos uma breve discussão sobre esse resultado.

Listener Escondido foi o segundo mau cheiro menos percebido no dia a dia por desenvolvedores Android (24\% dos participantes indicaram "nunca"). Entretanto se apresenta dentre os maus cheiros considerados mais importantes (33\% dos participantes indicaram "muito importante" e 24\% indicaram "importante"). Esses dados sugerem que os desenvolvedores consideram importante evitar o uso do atributo onClick em XMLs de layout e aparentemente, muitos desenvolvedores já estão cientes disso no dia a dia, uma vez que ele se apresenta dentre os 6 menos percebidos.

Nossos resultados mostram que os maus cheiros propostos são considerados importantes e frequentes no dia a dia do desenvolvimento Android $\left(\mathrm{QP}_{2}\right)$. 


\section{3 $\mathrm{QP}_{3}$ Percepção dos Desenvolvedores sobre os Maus Cheiros Android}

Nossos resultados mostram que códigos afetados por 6 dos 7 maus cheiros avaliados são percebidos como códigos problemáticos por desenvolvedores Android, são eles: Componente de Ui Cérebro, Componente de Ui Acoplado, Comportamento Suspeito, Adapter Complexo, layout Profundamente Aninhado e Atributos de Estilo Repetidos. Não foi possível concluir a percepção sobre o mau cheiro Longo RECURSO DE EsTilo pois a média de 30 pontos não foi suficiente para chegarmos a uma conclusão, sendo necessário coletar mais dados. A seguir apresentamos detalhes das percepções dos desenvolvedores sobre os maus cheiros avaliados.

\subsubsection{Resultados}

Na Figura 5.4a, apresentamos os gráficos violino que consolidam a percepção de desenvolvedores sobre os 4 maus cheiros relacionados a componentes da camada de apresentação Android (Componente de Ui Cérebro, Componente de Ui Acoplado, Comportamento Suspeito e Adapter Complexo) contra componentes Android limpos. De modo similar, na Figura 5.4b, apresentamos os gráficos violino que consolidam a percepção de desenvolvedores sobre os 3 maus cheiros relacionados à recursos Android (LAYOut PRofundamente Aninhado, Atributos de Estilo Repetidos e Longo Recurso de Estilo) contra recursos limpos.

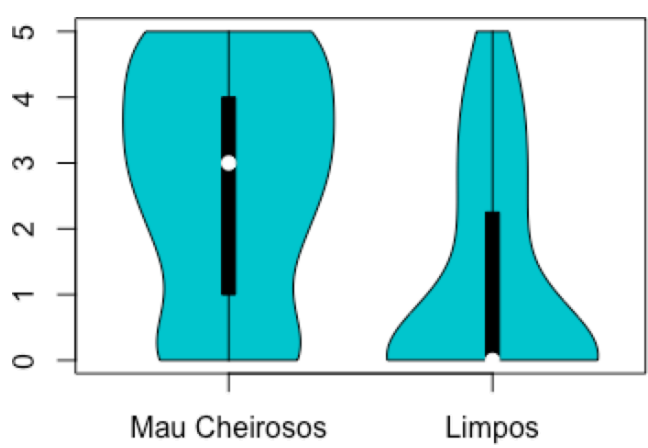

(a) Componentes.

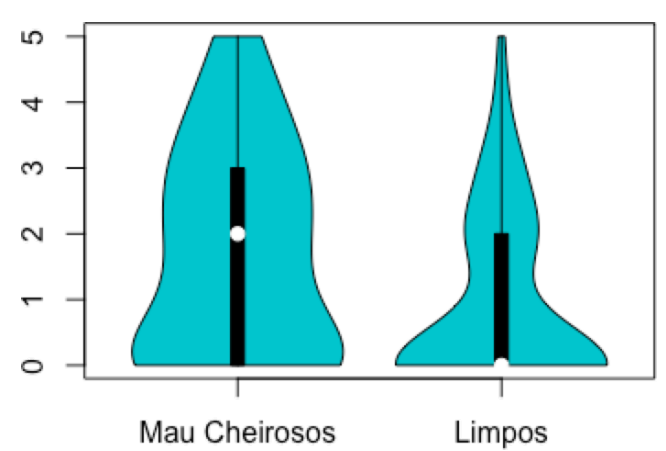

(b) Recursos.

Figura 5.4: Análise de severidade em componentes e recursos mau cheirosos e limpos.

No eixo y, 0 (zero) indica os códigos não percebidos pelos desenvolvedores como problemáticos (ou seja, responderam "não" à questão: "Esta classe exibe algum problema de design e/ou implementação?"), enquanto que os valores de 1 a 5 indicam o nível de severidade para o problema percebido pelo desenvolvedor. No eixo x, os gráficos são autoexplicativos. Nos parágrafos seguintes explicamos os dados de cada gráfico de modo que, as medianas são indicadas pela bolinha branca e o $3^{\circ}$ quartil (Q3) é representado pela linha preta mais grossa na vertical. 
Podemos observar na Figura 5.4a que componentes afetados pelos maus cheiros Android tiveram mediana de severidade igual a $3(\mathrm{Q} 3=4)$. Isso indica que, como esperado, desenvolvedores percebem códigos afetados pelos maus cheiros em componentes da camada de apresentação Android como problemáticos. Como comparação, componentes Android limpos tiveram mediana de severidade igual a $0(\mathrm{Q} 3=2)$. A diferença na percepção dos desenvolvedores entre componentes Android mau cheirosos e componentes limpos é estatisticamente significante $(\alpha=1,18 \mathrm{e}-06)$ com médio tamanho de efeito $(d=0,46)$.

Na Figura 5.4b, podemos observar que recursos afetados pelos maus cheiros Android tiveram mediana de severidade é igual a $2(\mathrm{Q} 3=3)$. Isso mostra que, recursos afetados pelos maus cheiros Android são percebidos como problemáticos, ainda que menos que os maus cheiros em componentes Android. Como comparação, recursos Android limpos tiveram mediana de severidade igual a $0(\mathrm{Q} 3=2)$. A diferença na percepção dos desenvolvedores entre os recursos mau cheirosos e recursos limpos também é estatisticamente significante ( $\alpha$ $=1,24 \mathrm{e}-03)$ com pequeno tamanho de efeito $(d=0,29)$.

Além disso, relatamos a percepção dos desenvolvedores sobre cada mau cheiro Android individualmente na Figura 5.5b. O mau cheiro Componente de UI ACoplado (CA) é o mais percebido pelos desenvolvedores e com maior gravidade, apresenta mediana de severidade igual a $4(\mathrm{Q} 3=5)$. Em seguida temos os maus cheiros Componente de UI CÉrebro (CC), Adapter Complexo (AC) e Comportamento Suspeito (CS) todos com mediana de severidade igual a 3. Isso indica que, como esperado, são percebidos pelos desenvolvedores como sendo seriamente problemáticos. Podemos notar que, de modo geral, recursos afetados pelos maus cheiros Android - Longo Recurso de Estilo (LE), Layout Profundamente Aninhado (LA) e Atributos de Estilo Repetidos (AR) - foram percebidos com menor severidade, mediana 1 e 2, do que componentes afetados pelos maus cheiros, todos com mediana de severidade maior ou igual a 3 (Q3 $\geq 3)$.

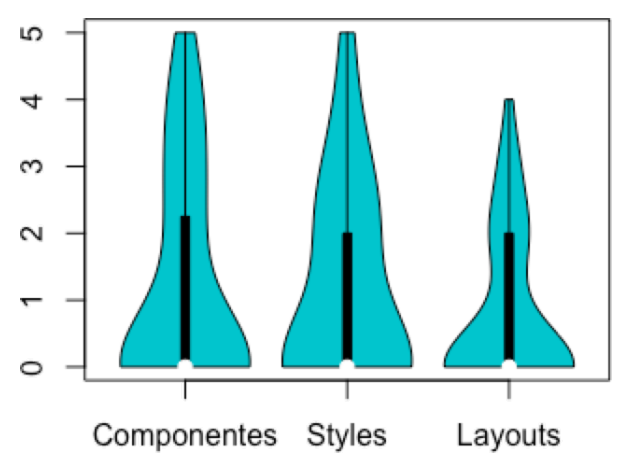

(a) Componentes=Activities, Fragments, Adapters ou Listeners limpos. Styles=Recursos de Style limpos. Layout=Recursos de Layout limpos.

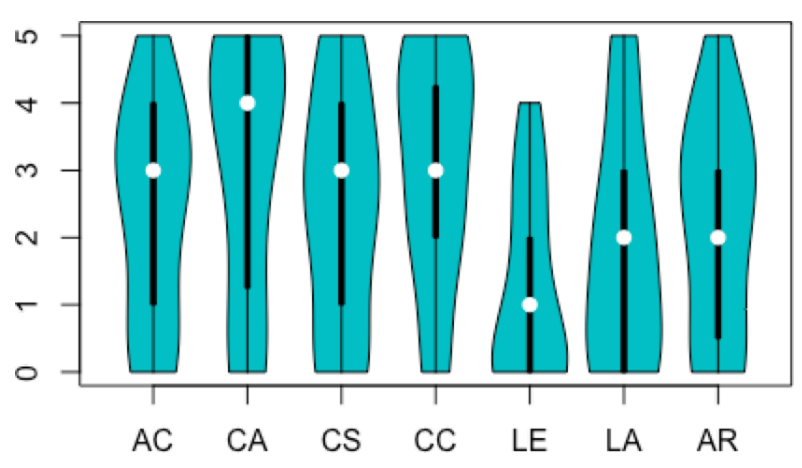

(b) AC=Adapter Complexo, $C A=$ Componente de UI Acoplado, CS=Comportamento Suspeito, $C C=$ Componente de UI Cérebro, $L E=$ Longo Recurso de Estilo, LA=Layout Profundamente Aninhado, AR=Atributos de Estilo Repetidos.

Figura 5.5: Análise de severidade dos códigos limpos segmentados por grupos e dos códigos afetados pelos maus cheiros avaliados. 
A Figura 5.5a apresenta os gráficos violino sobre a percepção dos 3 grupos de códigos limpos: componentes Android, recursos de style e recursos de layout. Podemos observar que os 3 grupos de códigos apresentam mediana de severidade 0. Isso mostra que, como esperado, os códigos limpos, no geral, foram percebidos como limpos pelos desenvolvedores.

Muitos desenvolvedores, sem conhecer nosso catálogo de maus cheiros Android, foram capazes de identificar corretamente o mau cheiro, dando uma descrição do problema percebido muito próxima a definição do mau cheiro. Por exemplo, um deles ao se deparar com um Adapter Complexo relatou: "O método getView é muito longo, com muitos ifs. Dificultando testes, debug e entendimento. me parece que muitas variações de tela podem ser desenhadas nesse método.". Outro participante disse simplesmente: "getView faz muitas coisas. Isso é perigoso para manter.".

Também o mau cheiro Longo Recurso De Estilo, foi corretamente identificado. Por exemplo, um dos participantes relatou: "Os temas e estilos poderiam ser separados em arquivos diferentes como por exemplo styles_dialog.xml, styles_text_view.xml, etc inclusive em diretórios de recursos de acordo com nível de API do Android. Também poderia usar herança.". Outro participante disse apenas: "Muitos estilos no mesmo arquivo.".

Outro participante ao se deparar com Componente de UI ACoplado, relatou: "Adapter está acoplado a MainActivity, uma vez que a recebe no construtor. O ideal seria abstrair quem está usando o Adapter para que ele possa ser usado por outras activities ou fragments.". Outros dois disseram simplesmente: "Cast direto à MainActivity." e "O DrawerAdapter está acoplado com a MainActivity.". Sobre o mau cheiro Atributos de Estilo Repetidos, um participante relatou: "1. Muitas dimensões repetidas que tem o mesmo propósito. Elas deveriam estar num lugar centralizado e nomeadas para facilidade de manutenção. 2. Mesma definição de estilo para várias text views. Deveria ser extraídas para styles para melhor manutenção...". Outro participante disse: "Muitos textViews com a mesma estilização, mas não se utiliza um arquivo de de styles para auxiliar.".

Tabela 5.6: Dados estatísticos sobre a percepção negativa por desenvolvedores sobre os maus cheiros avaliados no experimento de código $\left(S_{3}\right)$.

\begin{tabular}{|c|c|c|c|c|}
\hline Mau Cheiro & Valor de p $(\alpha)$ & Delta de Cliff $(d)$ & Mediana & Q3 \\
\hline Componente de UI ACOPLADO & $1,13 \mathrm{e}-04$ & 0,52 (grande) & 4,00 & 5,00 \\
\hline COMPORTAMENTO SUSPEITO & $1,37 \mathrm{e}-03$ & 0,38 (médio) & 3,00 & 4,00 \\
\hline COMPONEnte de UI CÉREBRo & $4,58 \mathrm{e}-06$ & 0,55 (grande) & 3,00 & 4,25 \\
\hline ADAPTER COMPLEXO & $1,11 \mathrm{e}-03$ & 0,40 (médio) & 3,00 & 4,00 \\
\hline Longo Recurso de Estilo & $7,61 \mathrm{e}-01$ & 0,05 (insignificante) & 1,00 & 2,00 \\
\hline LAYOUT PROFUndamENTE ANINHado & $6,17 \mathrm{e}-03$ & 0,35 (médio) & 2,00 & 3,00 \\
\hline Atributos de Estilo Repetidos & $5,84 \mathrm{e}-04$ & 0,44 (médio) & 2,00 & 3,00 \\
\hline
\end{tabular}

Foi possível confirmar estatisticamente a percepção dos desenvolvedores em 6 dos 7 maus cheiros Android avaliados. A Tabela 5.6 apresenta os valor de $\alpha$ e $d$ para todos eles, bem como informações de mediana e Q3. Apesar de haver respostas que identificaram correta- 
mente o mau cheiro Longo Recurso de Estilo e do gráfico violino apresentar uma leve diferença de severidade dos recursos afetados pelo mau cheiro, com mediana 1 (Q3 = 2), contra os recursos limpos, são necessários mais dados para validá-lo estatisticamente.

Nossos resultados mostram que os códigos afetados pelos maus cheiros propostos e avaliados são percebidos como problemáticos por desenvolvedores Android se comparados com códigos limpos $\left(\mathrm{QP}_{3}\right)$. 


\section{Capítulo 6}

\section{Conclusão}

Nesta dissertação nós propomos um catálogo com 20 maus cheiros que são específicos à camada de apresentação Android, investigamos a percepção de frequência e importância dos maus cheiros propostos e também validamos que 6 deles, ao apresentar-se em códigos, são percebidos por desenvolvedores como problemáticos. Estes resultados foram obtidos por meio de 2 questionários online e um experimento de código. Ao todo participaram da pesquisa 316 desenvolvedores.

Acreditamos que nossas contribuições representam um pequeno, porém importante passo, na busca por mais qualidade de código na plataforma Android. Pesquisadores e desenvolvedores Android já podem se beneficiar dos nossos resultados. Pesquisadores podem utilizar nossos resultados como ponto de partida para aprofundar o conhecimento sobre maus cheiros de código específicos em aplicativos Android. Desenvolvedores Android já podem utilizar nosso catálogo de maus cheiros Android como auxílio na identificação de códigos problemáticos para serem melhorados, ainda que de forma manual.

A seguir revisitamos as questões de pesquisa, sugerimos trabalhos futuros e discutimos alguns resultados.

\subsection{Questões de Pesquisa Revisitadas}

Esta dissertação é composta por 3 questões de pesquisa, a seguir apresentamos as respostas para cada uma delas:

\section{QP $_{1}$ Existem maus cheiros que são específicos à camada de apresentação de aplicativos Android?}

Certamente existem diversas formas de se implementar códigos em elementos da camada de apresentação Android. Percebemos que algumas dessas formas são consideradas 
melhores e outras piores por desenvolvedores Android. Partindo dessa percepção, foi possível derivar um catálogo com 20 maus cheiros de código específicos a elementos da camada de apresentação Android, sendo 9 deles relacionados a componentes Android: Componente de Ui Cérebro, Componente de Ui Acoplado, Comportamento Suspeito, Adapter Consumista, Uso Excessivo de Fragments, Componente de Ui Fazendo iO, Não Uso de Fragment, Ausência de Arquitetura e Adapter Complexo, e 11 relacionados a recursos Android: Nome de Recurso Despadronizado, Recurso Mágico, Layout Profundamente Aninhado, Imagem Tradicional Dispensável, Layout Longo ou Repetido, Imagem Faltante, Longo Recurso de Estilo, Recurso de String Bagunçado, Atributos de Estilo Repetidos, Reúso Inadequado de String e Listener Escondido.

$\mathrm{QP}_{2}$ Com qual frequência os maus cheiros são percebidos e o quão importante são considerados pelos desenvolvedores?

Os 20 maus cheiros propostos foram considerados em algum nível, importantes e frequentes no dia a dia de desenvolvimento Android, alguns mais frequentes e importantes que outros. Dentre os elementos da camada de apresentação, notamos que os desenvolvedores percebem mais frequentemente a presença de maus cheiros relacionados a recursos do que aos componentes Android. A percepção de importância em mitigá-los é alta para todos os maus cheiros. Entretanto, de modo geral, os maus cheiros são considerados mais importantes do que frequentes.

$\mathrm{QP}_{3}$ Desenvolvedores Android percebem os códigos afetados pelos maus cheiros como problemáticos?

Avaliamos a percepção de desenvolvedores sobre 7 dos 20 maus cheiros propostos. Extraímos dados estatísticos que mostram, como esperado, que desenvolvedores percebem os códigos afetados por 6 dos maus cheiros avaliados como problemáticos, são eles: Componente de Ui Cérebro, Componente de Ui Acoplado, Adapter Complexo, Comportamento Suspeito, Layout Profundamente Aninhado e Atributos de Estilo Repetidos. Não foi possível concluir a percepção sobre o mau cheiro Longo RECURSo DE Estilo pois a quantidade de pontos obtidos não foi suficiente para chegarmos a uma conclusão.

\subsection{Trabalhos Futuros}

Nós catalogamos 20 maus cheiros específicos a elementos da camada de apresentação Android e validamos se desenvolvedores percebiam os códigos afetados por eles como problemáticos de apenas 6 maus cheiros. Deste modo, sugerimos como trabalho futuro replicar o experimento realizado na etapa 3 desta pesquisa para os demais maus cheiros catalogados. Outra possibilidade é replicar o experimento nos 6 maus cheiros aqui validados, porém com 
códigos e participantes diferentes, com o objetivo de entender se outros grupos de participantes apresentam os mesmos resultados.

Os códigos usados no experimento foram extraídos de aplicativos de software livre. Uma sugestão de trabalho futuro é buscar pelos maus cheiros catalogados em aplicativos de mercado, que apresentam outro contexto que os aplicativos aqui utilizados.

Acreditamos que seria muito útil para a comunidade entender se aplicações são afetadas pelos maus cheiros propostos. Ou seja, diferente de investigar a percepção de desenvolvedores, sugerimos investigar se aplicações reais contêm códigos com os sintomas dos maus cheiros apresentados. Para isso, possivelmente será necessário definir heurísticas para os maus cheiros de modo a ser possível identificá-los de forma mais sistemática. Mais pesquisas precisam ser conduzidas neste sentido.

Também nos perguntamos sobre outros maus cheiros que podem ser importantes para desenvolvedores Android, mesmo que não focados na camada de apresentação como fizemos. Mais pesquisas precisam ser realizadas para coletar maus cheiros diferentes. Além disso, enquanto catalogamos 20 maus cheiros, podem haver outros maus cheiros de código importantes a serem explorados.

\subsection{Discussões}

É interessante notar que durante nosso processo de codificação, realizado na etapa 1 da pesquisa, também obtivemos resultados semelhantes aos resultados encontrados em algumas outras pesquisas anteriores, que afirmam que aplicativos Android são fortemente afetados pelo mau cheiro tradicional Classe Grande, conforme citado por Verloop [95], e que é pouco ou quase nada usado herança para estruturar a arquitetura do código, conforme citado por Minelli e Lanza [77]. Observamos isso pois, 2 das 46 categorias encontradas durante o processo de codificação, desconsideradas para efeitos de derivação dos maus cheiros aqui propostos, apontavam exatamente estas conclusões. Como nosso objetivo não estava em avaliar a presença de maus cheiros tradicionais ou práticas de orientações a objetos em aplicativos Android, não trabalhamos em cima desses resultados.

Outro ponto interessante que notamos é que, muitas vezes as respostas para as questões sobre boas práticas coletadas em $\mathrm{S}_{1}$, vieram na forma de sugestões de como solucionar o que o participante indicou como má prática para aquele elemento, ou seja, uma sugestão de refatoração para remover o mau cheiro. Como não foi o foco desta pesquisa validar se as sugestões dadas como soluções ao mau cheiro de fato se aplicavam, não exploramos a fundo estas informações. Entretanto, disponibilizamos uma tabela que indica essas respostas, bem como respostas sobre as más práticas, para cada mau cheiro definido no apêndice A. Também 
é possível inspecionar as respostas originais em nosso apêndice online ${ }^{1}$.

Aplicativos Android, desde seu lançamento em 2008, são desenvolvidos utilizando a linguagem de programação Java. Recentemente, em Maio de 2017, o Google anunciou o Kotlin como linguagem oficial do Android ${ }^{2}$. Para efeitos desta dissertação, utilizamos todos os códigos na linguagem Java pois, a pesquisa já havia iniciado antes desse anúncio. Acreditamos que essa inclusão não interfere na relevância da pesquisa pois durante quase uma década aplicativos Android foram desenvolvidos em Java, de modo que certamente existe uma grande base de códigos de aplicativos Android nessa linguagem que precisaram ser mantidos e evoluídos até que sejam substituídos. Além disso, Kotlin é interoperável com Java, deste modo, o código antes escritos em Java não precisam necessariamente serem migrados para Kotlin. Como este anúncio ainda é muito recente (no ano em que esta dissertação é finalizada), acreditamos que será necessário ainda algum tempo para que empresas comecem a adotar esta nova linguagem.

Vale ressaltar ainda que o Kotlin vem como uma opção à linguagem Java, entretanto, os recursos Android, também estudados nesta pesquisa, não são impactados por essa linguagem. Deste modo, os maus cheiros sobre recursos aqui discutidos continuam sendo relevantes mesmo no desenvolvimento de aplicativos Android com Kotlin, bem como já o é com Java.

O mau cheiro Adapter Consumista foi o menos percebido no dia a dia por desenvolvedores Android segundo dados obtidos em $\mathrm{S}_{2}$ (25\% dos participantes indicaram "nunca"), apesar de ser um dos considerados mais importantes ( $58 \%$ dos participantes indicaram "muito importante" e $26 \%$ indicaram "importante"). Acreditamos que esse resultado é devido a um novo tipo de Adapter, chamado RecyclerView.Adapter ${ }^{3}$, que surgiu na versão 5.1 Lollipop do Android, facilitando a implementação do padrão ViewHolder [54]. Em versões anteriores, a implementação do padrão ViewHolder tinha que ser feita de forma manual (sem auxílio de classes e interfaces para guiar a implementação), exigindo conhecimento prévio sobre o padrão. Deste modo, apesar se ser considerado realmente muito importante implementar o padrão ViewHolder, este problema não é muito mais visto, talvez porque os desenvolvedores estejam migrando suas listas para o uso de RecyclerView.Adapter.

\footnotetext{
${ }^{1}$ Apêndice online disponível em: http://suelengc.github.io/master-degree-dissertation.

${ }^{2}$ https://blog.jetbrains.com/kotlin/2017/05/kotlin-on-android-now-official

${ }^{3}$ https://developer.android.com/reference/android/support/v7/widget/RecyclerView.Adapter.html
} 


\section{Apêndice A}

\section{Exemplos de respostas que embasaram os maus cheiros}

\begin{tabular}{|c|c|}
\hline Mau Cheiro & Respostas sobre boas e más práticas \\
\hline $\begin{array}{l}\text { COMPONENTE DE } \\
\text { UI CÉREBRo }\end{array}$ & $\begin{array}{l}\text { Más práticas: "Fazer lógica de negócio [em Activities]"1 (P16). "Colocar regra de } \\
\text { negócio no Adapter" (P19). "Manter lógica de negócio em Fragments" (P11). Boas } \\
\text { práticas: "Elas [Activities] representam uma única tela e apenas interagem com a UI, } \\
\text { qualquer lógica deve ser delegada para outra classe" (P16). "Apenas código relacionado } \\
\text { à Interface de Usuário nas Activities" (P23). "Adapters devem apenas se preocupar } \\
\text { sobre como mostrar os dados, sem trabalhá-los" (P40). }\end{array}$ \\
\hline
\end{tabular}

Componente DE Más práticas: "Acoplar o fragment a activity ao invés de utilizar interfaces é uma UI ACOPlado prática ruim" (P19). "Acoplar o Fragment com a Activity" (P10, P31 e P45). "Fragments nunca devem tentar falar uns com os outros diretamente" (P37). "Interagir com outro Fragment diretamente" (P45). "[Listener] conter uma referência direta à Activities" (P4, P40). "[Adapters] alto acoplamento com a Activity" (P10). "Acessar Activities ou Fragments diretamente" (P45). Boa prática: "Seja um componente de UI reutilizável. Então evite dependência de outros componentes da aplicação" (P6).

Comportamento Más práticas: "Usar muitos anônimos pode ser complicado. Às vezes nomear coisas Suspeito torna mais fácil para depuração" (P9). "Mantenha-os [Listeners] em classes separadas (esqueça sobre classes anônimas)" (P4). "Muitas implementações de Listener com classes anônimas" (P8). "Declarar como classe interna da Activity ou Fragment ou outro componente que contém um ciclo de vida. Isso pode fazer com que os aplicativos causem vazamentos de memória." (P42). "Eu não gosto quando os desenvolvedores fazem a activity implementar o Listener porque eles [os métodos] serão expostos e qualquer um pode chamá-lo de fora da classe. Eu prefiro instanciar ou então usar ButterKnife para injetar cliques." (P44). Boas práticas: "Prefiro declarar os listeners com implements e sobrescrever os métodos (onClick, por exemplo) do que fazer um set listener no próprio objeto" (P32). "Tome cuidade se a Activity/Fragment é um Listener uma vez que eles são destruídos quando as configurações mudam. Isso causa vazamentos de memória." (P6). "Use carregamento automático de view como ButterKnife e injeção de dependência como Dagger2" (P10).

\footnotetext{
${ }^{1}$ Todo texto em inglês foi traduzido livremente ao longo da dissertação
} 


\begin{tabular}{ll}
\hline Mau Cheiro & Respostas sobre boas e más práticas \\
\hline AdAPter Consu- & Boas práticas: "Reutilizar a view utilizando ViewHolder." (P36). "Usar o padrão \\
Mista & ViewHolder" (P39). P45 sugere o uso do RecyclerView, um elemento Android para a \\
& construção de listas que já implementa o padrão ViewHolder [54]. \\
Uso ExCESSIVO DE & $\begin{array}{l}\text { Má prática: "Usar muitos Fragments é uma má prática" (P2). Boas práticas: } \\
\text { FrAGMENT }\end{array}$ \\
& "Evite-os. Use apenas com View Pagers" (P7). "Eu tento usar o Fragment para lidar \\
& apenas com as visualizações, como a Activity, e eu o uso apenas quando preciso deles \\
& em um layout de Tablet ou para reutilizar em outra Activity. Caso contrário, eu não \\
& uso" (P41).
\end{tabular}

NÃo Uso DE Más práticas: "Não usar Fragments" (P22). "Usar todas as view (EditTexts, SpinFragment ners, etc...) dentro de Activities e não dentro de Fragments" (P45). Boas práticas: "Utilizar fragments sempre que possível." (P19), "Use um Fragment para cada tela. Uma Activity para cada aplicativo." (P45).

Componente DE Más práticas: "[Activities e Fragments] fazerem requests e consultas a banco de UI FAzENDO IO dados" (P26). "[Adapters] fazerem operações longas e requests de internet" (P26). Boa prática: "Elas [Activities] nunca devem fazer acesso a dados" (P37).

AUSÊNCIA DE AR- Más práticas: "Não usar um design pattern" (P45). Boas práticas: "Usar algum QUITETURA modelo de arquitetura para garantir apresentação desacoplada do framework (MVP, MVVM, Clean Architecture, etc)" (P28). "Sobre MVP. Eu acho que é o melhor padrão de projeto para usar com Android" (P45).

AdAPter Com- Má prática: "Reutilizar um mesmo adapter para várias situações diferentes, com ifs Plexo ou switches. Código de lógica importante ou cálculos em Adapters." (P23). Boa prática: "Um Adapter deve adaptar um único tipo de item ou delegar a Adapters especializados" (P2).

Recurso MáGico Más práticas: "Strings diretamente no código" (P23). "Não extrair as strings e sobre não extrair os valores dos arquivos de layout" (P31 e P35). Boas práticas: "Sempre pegar valores de string ou dp de seus respectivos resources para facilitar" (P7). "Sempre adicionar as strings em resources para traduzir em diversos idiomas" (P36).

Nome De Re- Más práticas: "O nome das strings sem um contexto" (P8). "[Sobre Style Resources] Curso Despadro- Nada além de ter uma boa convenção de nomes" (P37). "[Sobre Layout Resource] NIZADO Mantenha uma convenção de nomes da sua escolha" (P37). Boas práticas: "Iniciar o nome de uma string com o nome da tela onde vai ser usada" (P27). "[Sobre Layout Resource] Ter uma boa convenção de nomeação" (P43). "[Sobre Style Resource] colocar um bom nome" (P11).

Layout Pro- Más práticas: "Hierarquia de views longas" (P26). "Estruturas profundamente aniFUNDAMENTE

ANINHADO nhadas" (P4). "Hierarquias desnecessárias" (P39). "Criar muitos ViewGroups dentro de ViewGroups" (P45). Boas práticas: "Tento usar o mínimo de layout aninhado" (P4). "Utilizar o mínimo de camadas possível" (P19). "Não fazer uma hierarquia profunda de ViewGroups" (P8).

Imagem Tradici- Más práticas: "Uso de formatos não otimizados, uso de drawables onde recursos OnAL DisPensá- padrão do Android seriam preferíveis" (P23). "Usar jpg ou png para formas simples VEL é ruim, apenas as desenhe [através de Drawable Resources]" (P37). Boas práticas: "Quando possível, criar resources através de xml" (P36). "Utilizar o máximo de Vector Drawables que for possível" (P28). "Evite muitas imagens, use imagens vetoriais sempre que possível" (P40). 


\begin{tabular}{ll}
\hline Mau Cheiro & Respostas sobre boas e más práticas \\
\hline LAYOUt Longo & Má prática: "Copiar e colar layouts parecidos sem usar includes" (P41). "Colocar \\
OU RePEtido & muitos recursos no mesmo arquivo de layout." (P23). Boas práticas: "Sempre quando \\
& posso, estou utilizando includes para algum pedaço de layout semelhante" (P32). \\
& "Criar layouts que possam ser reutilizados em diversas partes" (P36). "Separe um \\
& grande layout usando include ou merge" (P42) \\
IMAGEM FALTANTE & Más práticas: "Ter apenas uma imagem para multiplas densidades" (P31). "Baixar \\
& uma imagem muito grande quando não é necessário. Há melhores formas de usar \\
& memória" (P4). "Não criar imagens para todas as resoluções" (P44). Boas práti- \\
& cas: "Nada especial, apenas mantê-las em seus respectivos diretórios e ter variados \\
& tamanhos delas" (P34). "Criar as pastas para diversas resoluções e colocar as imagens \\
& corretas" (P36).
\end{tabular}

Longo Recurso Más práticas: "Deixar tudo no mesmo arquivo styles.xml" (P28). "Arquivos de estilos DE EsTILO grandes" (P8). Boas práticas: "Se possível, separar mais além do arquivo styles.xml padrão, já que é possível declarar múltiplos arquivos XML de estilo para a mesma configuração" (P28). "Divida-os. Temas e estilos é uma escolha racional" (P40).

ReCurso DE Más práticas: "Usar o mesmo arquivo strings.xml para tudo" (P28). "Não organizar StRING BAGUN- as strings quando o strings.xml começa a ficar grande" (P42). Boas práticas: "SepaÇADO rar strings por tela em arquivos XML separados. Extremamente útil para identificar quais strings pertencentes a quais telas em projetos grandes" (P28). "Sempre busco separar em blocos, cada bloco representa uma Activity e nunca aproveito uma String pra outra tela" (P32).

Atributos De Es- Má prática: "Utilizar muitas propriedades em um único componente. Se tiver que TILO REPETIDOs usar muitas, prefiro colocar no arquivo de styles." (P32). Boa prática: "Sempre que eu noto que tenho mais de um recurso usando o mesmo estilo, eu tento movê-lo para o meu style resource." (P34).

Reúso InAde- Más práticas: "Utilizar uma String pra mais de uma activity, pois se em algum QUADO DE STRING momento, surja a necessidade de trocar em uma, vai afetar outra." (P32). "Reutilizar a string em várias telas" ( $\mathrm{P} 6)$ "Reutilizar a string apenas porque o texto coincide, tenha cuidado com a semântica" (P40). Boas práticas: "Sempre busco separar em blocos, cada bloco representa uma activity e nunca aproveito uma String pra outra tela." (P32). "Não tenha medo de repetir strings [...]" (P9).

Listener Escon- Más práticas: "Nunca crie um listener dentro do XML. Isso esconde o listener de DIDO outros desenvolvedores e pode causar problemas até que ele seja encontrado" (P34, P39 e P41). Boa prática: "XML de layout deve lidar apenas com a view e não com ações" (P41). 


\section{Apêndice B}

\section{Questionário sobre boas e más práticas}

\section{Android Good \& Bad Practices}

Help Android Developers around the world in just 15 minutes letting us know what you think about good \& bad practices in Android native apps. Please, answer in portuguese or english.

Hi, my name is Suelen, I am a Master student researching code quality on native Android App's Presentation Layer. Your answers will be kept strictly confidential and will only be used in aggregate. I hope the results can help you in the future. If you have any questions, just contact us at suelengcarvalho@gmail.com.

Questions about Demographic \& Background. Tell us a little bit about you and your experience with software development. All questions throught this session were mandatory.

1. What is your age? (One choice beteen 18 or younger, 19 to 24,25 to 34,35 to 44,45 to 54,55 or older and I prefer not to answer)

2. Where do you currently live?

3. Years of experience with software development? (One choice between 1 year or less, one option for each year between 2 and 9 and 10 years or more)

4. What programming languages/platform you consider yourself proficient? (Multiples choices between Swift, Javascript, C\#, Android, PHP, C++, Ruby, C, Python, Java, Scala, Objective C, Other)

5. Years of experience with developing native Android applications? (One choice between 1 year or less, one option for each year between 2 and 9 and 10 years or more)

6. What is your last degree? (One choice between Bacharel Student, Bacharel, Master, $\mathrm{PhD}$ and Other) 
Questions about Good \& Bad Practices in Android Presentation Layer. We want you to tell us about your experience. For each element in Android Presentation Layer, we want you to describe good \& bad practices (all of them!) you have faced and why you think they are good or bad. With good \& bad practices we mean anything you do or avoid that makes your code better than before. If you perceive the same practice in more than one element, please copy and paste or refer to it. All questions throught this session were not mandatory.

1. Activities An activity represents a single screen.

- Do you have any good practices to deal with Activities?

- Do you have anything you consider a bad practice when dealing with Activities?

2. Fragments A Fragment represents a behavior or a portion of user interface in an Activity. You can combine multiple fragments in a single activity to build a multipane UI and reuse a fragment in multiple activities.

- Do you have any good practices to deal with Fragments?

- Do you have anything you consider a bad practice when dealing with Fragments?

3. Adapters An adapter adapts a content that usually comes from model to a view like put a bunch of students that come from database into a list view.

- Do you have any good practices to deal with Adapters?

- Do you have anything you consider a bad practice when dealing with Adapters?

4. Listeners An event listener is an interface in the View class that contains a single callback method. These methods will be called by the Android framework when the View to which the listener has been registered is triggered by user interaction with the item in the UI.

- Do you have any good practices to deal with Listeners?

- Do you have anything you consider a bad practice when dealing with Listeners?

5. Layouts Resources A layout defines the visual structure for a user interface.

- Do you have any good practices to deal with Layout Resources?

- Do you have anything you consider a bad practice when dealing with Layout Resources?

6. Styles Resources A style resource defines the format and look for a UI.

- Do you have any good practices to deal with Styles Resources? 
- Do you have anything you consider a bad practice when dealing with Styles Resources?

7. String Resources A string resource provides text strings for your application with optional text styling and formatting. It is very common used for internationalizations.

- Do you have any good practices to deal with String Resources?

- Do you have anything you consider a bad practice when dealing with String Resources?

8. Drawable Resources A drawable resource is a general concept for a graphic that can be drawn to the screen.

- Do you have any good practices to deal with Drawable Resources?

- Do you have anything you consider a bad practice when dealing with Drawable Resources?

Last thoughts Only 3 more final questions.

1. Are there any other ${ }^{*}$ GOOD* practices in Android Presentation Layer we did not asked you or you did not said yet?

2. Are there any other ${ }^{*} \mathrm{BAD}^{*}$ practices in Android Presentation Layer we did not asked you or you did not said yet?

3. Leave your e-mail if you wish to receive more information about the research or participate in others steps. 


\section{Apêndice C}

\section{Questionário sobre frequência e importância dos maus cheiros}

\section{Pesquisa sobre qualidade de código em projetos Android}

\section{English version? Go to https://goo.gl/forms/MFJjCGidSbWXFIn83}

Olá! Meu nome é Suelen e sou estudante de mestrado em Ciência da Computação pelo Instituto de Matemática e Estatísticas da USP.

Estou pesquisando sobre qualidade de código Android e a seguir tenho algumas afirmações e gostaria que você, com base no seu conhecimento e experiência, me indicasse sua opinião. Desde já, muito obrigada pela sua contribuição! Certamente você está ajudando a termos códigos Android com mais qualidade no futuro!

Um forte abraço! - Suelen Carvalho

Seção 1 - Primeiro precisamos saber um pouco sobre você e sua experiência com desenvolvimento de software.

1. Qual sua idade? (Resposta aberta, apenas número)

2. Em que região você mora atualmente? (Uma escolha entre a lista de estados do Brasil, Estados Unidos e Europa)

3. Anos de experiência com desenvolvimento de software? (Uma escolha entre até 1 ano, 2 anos, 3 anos e assim sucessivamente até 10 anos ou mais)

4. Anos de experiência com desenvolvimento Android nativo? (Uma escolha entre, não tenho experiência, até 1 ano, 2 anos, 3 anos e assim sucessivamente até 10 anos ou mais) 
5. Informe seu nível de conhecimento nas tecnologias e plataformas a seguir. (Uma escolha para cada tecnologia apresentada detre as opções Não conheço, Iniciante, Intermediário, Avançado e Especialista). As tecnologias apresentadas foram: Java, Ruby, C/C++, Kotlin, Objective-C, Swift, Android, C\#, Python, PHP e Javascript.

6. Qual seu grau escolar? (Uma escolha entre Tecnólogo, Bacharelado, Mestrado, Doutorado e outro)

\section{Seção 2 - Nos conte um pouco o que você costuma ver nos códigos que você desenvolve ou já desenvolveu (independente se no trabalho, acadêmico ou pes- soal).}

Indique com qual frequência você percebe as situações abaixo no seu dia a dia (Escala Likert Muito Frequente, Frequente, As Vezes, Raramente e Nunca).

1. Activities, Fragments, Adapters ou Listeners com códigos de lógica de negócio, condicionais complexos ou conversão de dados.

2. Fragments, Adapters ou Listeners com referência direta para quem os utiliza, como Activities ou outros Fragments.

3. Activities, Fragments ou Adapters com classes anônimas para responder a eventos do usuário, como clique, duplo clique e outros.

4. Activities, Fragments ou Adapters com classes internas implementando algum listener para responder a eventos do usuário como clique, duplo clique e outros.

5. Activities, Fragments ou Adapters implementando algum listener, através de polimorfismo (implements), para responder a eventos do usuário como clique, duplo clique e outros.

6. Adapters que não se utilizam do padrão ViewHolder.

7. Fragments em aplicativos que não são usados em tablets ou que não usam ViewPagers. aplicativos com Fragments que não são reutilizados em mais de uma tela do app.

8. Aplicativos que não utilizam nenhum Fragment.

9. Activities, Fragments ou Adapters com códigos que fazem acesso a banco de dados, arquivos locais ou internet.

10. Projetos que não usam nenhum padrão arquitetural como MVC, MVP, MVVM, Clean Architecture ou outros.

11. Adapters com muitas responsabilidades além de popular views, com condicionais complexos ou cálculos no método getView. 
12. Recursos de cor, tamanho ou texto sendo usados "hard coded", sem a criação de um novo recurso no arquivo de $\mathrm{xml}$ respectivo (colors.xml, dimens.xml ou strings.xml).

13. Projetos sem um padrão de nomenclatura para recursos de layout, texto, estilo ou gráficos (imagens e xmls gráficos).

14. Layouts com mais de 3 níveis de views aninhadas, por exemplo: um TextView dentro de um LinearLayout que está dentro de outro LinerarLayout.

15. Imagens (jpg, jpeg, png e gif) sendo usadas quando podiam ser substituídas por recursos gráficos do Android (xmls), como por exemplo, background de cores sólidas ou degradês.

16. Recursos de layout muito grandes.

17. Recursos de layout com trechos que se repetem, igual ou muito semelhantes, várias vezes ao longo do arquivo.

18. Projetos que possuem as imagens usadas em apenas uma resolução/densidade.

19. Projetos que possuem apenas um arquivo de estilo (styles.xml).

20. Projetos que possuem apenas um recurso de estilo (styles.xml) e este é muito grande.

21. Projetos que possuem apenas um arquivo de strings (strings.xml) e este é muito grande.

22. Arquivos de layout com alguns atributos de estilos repetidos em mais de uma view.

23. Arquivo de estilo com alguns atributos de estilos repetidos em mais de um estilo.

24. Usar uma mesma string em diferentes telas do aplicativo.

25. Usar o atributo onClick ou outro similar, diretamente no xml de layout, para responder a eventos do usuário.

\section{Seção 3 - Nos conte um pouco o que você considera importante no desenvol- vimento Android.}

Indique quão importante você considera as situações abaixo (Escala Likert Muito Importante, Importante, Razoavelmente Importante, Pouco Importante e Não é importante).

1. Activities, Fragments, Adapters e Listeners não ter códigos de lógica de negócio, condicionais complexos ou conversão de dados.

2. Fragments, Adapters e Listeners não tenham referência direta à quem os utiliza. 
3. Listeners devem ser implementados em suas próprias classes ao invés de implementálos através de classes anônimas, classes internas ou polimorfismo (uso de implements) em Activities, Fragments ou Adapters.

4. Usar o padrão ViewHolder em Adapters.

5. Evitar o uso de Fragments. Usar Fragments apenas se não houver outra alternativa.

6. Usar Fragments sempre que possível. Por exemplo, pelo menos um Fragment por Activity, etc.

7. Activities, Fragments e Adapters não terem códigos de acesso a banco de dados, acesso a arquivos locais ou internet.

8. Usar padrões arquiteturais como MVC, MVP, MVVM, Clean Architecture ou outros.

9. Adapters responsáveis apenas por popular a view, sem códigos de lógicas de negócio, cálculos ou conversões de dados/objetos.

10. Criar um recurso de tamanho, cor ou texto, em seu respectivo arquivo (dimens.xml, colors.xml, strings.xml) antes de utilizá-lo.

11. Utilizar um padrão de nomenclatura para arquivos de layout, recursos de texto, estilos e gráficos (imagens ou xmls gráficos).

12. Não utilizar mais de 3 níveis de views aninhadas em xmls de layout.

13. Sempre que possível, substituir o uso de imagens (jpg, jpeg, png ou gif) por recursos gráficos do Android (xmls), no caso, por exemplo de, background de cores sólidas ou degradês.

14. Ter recursos de layouts pequenos.

15. Extrair trechos de layout que se repetem em arquivos de layout novos, e reutilizá-los com include ou merge.

16. Disponibilizar as imagens usadas no aplicativo em mais de uma resolução/densidade diferentes.

17. Separar os recursos de estilo (styles.xml) em mais de um arquivo, por exemplo: estilos e temas.

18. Separar os recursos de strings (strings.xml) em mais de um arquivo.

19. Extrair estilos e reutilizá-los, ao invés de repetir os mesmos atributos diretamente em várias views diferentes. 
20. Separar as strings por tela, e não reutilizar uma string em mais de uma tela mesmo o texto sendo igual.

21. Não usar atributos de eventos, como o onClick, em xmls de layout para responder a eventos do usuário. 


\section{Apêndice D}

\section{Afirmações sobre frequência dos maus cheiros e respectivos dados estatísticos}

Neste apêndice, ao final de cada afirmação, entre parênteses indicamos a qual mau cheiro ela se referia, entretanto esta informação (nome do mau cheiro) não foi apresentada no questionário online.

\begin{tabular}{|c|c|c|c|c|c|c|c|c|}
\hline Afirmação & DP & MO & $\mathrm{ME}$ & 1 & 2 & 3 & 4 & 5 \\
\hline $\begin{array}{l}\text { Activities, Fragments, Adapters ou Listeners com } \\
\text { códigos de lógica de negócio, condicionais comple- } \\
\text { xos ou conversão de dados. (COMPONENTE DE UI } \\
\text { CÉREBRO) }\end{array}$ & 1.19 & 4 & 3 & $7 \%$ & $19 \%$ & $27 \%$ & $28 \%$ & $19 \%$ \\
\hline $\begin{array}{l}\text { Fragments, Adapters ou Listeners com referência } \\
\text { direta para quem os usa, como Activities ou outros } \\
\text { Fragments. (COMPONENTE DE UI ACOPLADO) }\end{array}$ & 1.15 & 3 & 3 & $7 \%$ & $20 \%$ & $33 \%$ & $24 \%$ & $15 \%$ \\
\hline $\begin{array}{l}\text { Activities, Fragments ou Adapters com classes anô- } \\
\text { nimas para responder a eventos do usuário, como } \\
\text { clique, duplo clique e outros. (COMPORTAMENTO } \\
\text { Suspeito) }\end{array}$ & 1.24 & 3 & 3 & $11 \%$ & $14 \%$ & $33 \%$ & $22 \%$ & $19 \%$ \\
\hline $\begin{array}{l}\text { Activities, Fragments ou Adapters com classes in- } \\
\text { ternas implementando algum listener para respon- } \\
\text { der a eventos do usuário como clique, duplo clique } \\
\text { e outros. (COMPORTAMENTo SusPeIto) }\end{array}$ & 1.12 & 4 & 3 & $6 \%$ & $16 \%$ & $29 \%$ & $32 \%$ & $17 \%$ \\
\hline $\begin{array}{l}\text { Activities, Fragments ou Adapters implementando } \\
\text { algum listener, através de polimorfismo (imple- } \\
\text { ments), para responder a eventos do usuário como } \\
\text { clique, duplo clique e outros. (COMPORTAMENTO } \\
\text { SuSPEITO) }\end{array}$ & 1.21 & 4 & 4 & $9 \%$ & $12 \%$ & $25 \%$ & $33 \%$ & $20 \%$ \\
\hline $\begin{array}{l}\text { Adapters que não se utilizam do padrão ViewHol- } \\
\text { der. (ADAPTER CONSUMISTA) }\end{array}$ & 1.20 & 2 & 2 & $25 \%$ & $29 \%$ & $23 \%$ & $17 \%$ & $5 \%$ \\
\hline
\end{tabular}




Afirmação
Fragments em apps que não são usados em tablets
ou que não usam ViewPagers. Apps com Fragments
que não são reutilizados em mais de uma tela do
app. (Uso ExCESSIVo DE FRAGMENT)

Apps que não utilizam nenhum Fragment. (NÃO Uso de Fragment)

Activities, Fragments ou Adapters com códigos que fazem acesso a banco de dados, arquivos locais ou internet. (Classes de Ui Fazendo IO)

Projetos que não usam nenhum padrão arquitetural como MVC, MVP, MVVM, Clean Architecture ou outros. (Ausência de Arquitetura)

Adapters com muitas responsabilidades além de popular views, com condicionais complexos ou cálculos no método getView. (Adapter Complexo)

Recursos de cor, tamanho ou texto sendo usados "hard coded", sem a criação de um novo recurso no arquivo de $\mathrm{xml}$ respectivo (colors.xml, dimens.xml ou strings.xml). (RECURSO MáGico)

Projetos sem um padrão de nomenclatura para recursos de layout, texto, estilo ou gráficos (imagens e recursos gráficos - xmls). (Nome de Recurso Despadronizado)

Layouts com mais de 3 níveis de views aninhadas, por exemplo: um TextView dentro de um LinearLayout que está dentro de outro LinerarLayout. (Layout Profundamente Aninhado)

Imagens (jpg, jpeg, png e gif) sendo usadas quando podiam ser substituídas por recursos gráficos do Android (xmls), como por exemplo, background de cores sólidas ou degradês. (Imagem Tradicional DispensáVel)

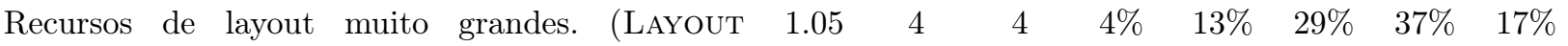
LONGO OU REPETIDO)

Recursos de layout com trechos que se repetem, igual ou muito semelhantes, vári3 ao longo do arquivo. (Layout Longo ou RePetido)

Projetos que possuem as imagens usadas em apenas uma resolução/densidade. (Imagem Faltante)

Projetos que possuem apenas um arquivo de estilo (styles.xml). (LONGO ReCurso DE Estilo)

$\begin{array}{cccccccc}\text { DP } & \text { MO } & \text { ME } & \mathbf{1} & \mathbf{2} & \mathbf{3} & \mathbf{4} & \mathbf{5} \\ 1.17 & 3 & 3 & 8 \% & 20 \% & 30 \% & 27 \% & 15 \%\end{array}$

$\begin{array}{llllllll}1.21 & 2 & 3 & 15 \% & 32 \% & 26 \% & 16 \% & 10 \% \\ 1.29 & 3 & 3 & 17 \% & 20 \% & 26 \% & 23 \% & 14 \% \\ & & & & & & & \\ 1.30 & 3 & 3 & 13 \% & 20 \% & 27 \% & 20 \% & 18 \% \\ & & & & & & & \\ 1.15 & 3 & 3 & 7 \% & 21 \% & 32 \% & 25 \% & 14 \% \\ & & & & & & & \\ 1.24 & 4 & 3 & 10 \% & 22 \% & 23 \% & 28 \% & 16 \%\end{array}$

$\begin{array}{llllllll}1.24 & 3 & 3 & 11 \% & 22 \% & 26 \% & 25 \% & 16 \%\end{array}$

$\begin{array}{llllllll}1.06 & 4 & 4 & 2 \% & 11 \% & 22 \% & 36 \% & 28 \%\end{array}$

$\begin{array}{llllllll}1.23 & 4 & 3 & 11 \% & 19 \% & 24 \% & 30 \% & 14 \%\end{array}$

$\begin{array}{llllllll}1.09 & 3 & 3 & 7 \% & 17 \% & 34 \% & 30 \% & 12 \%\end{array}$

$\mathrm{DP}=$ Desvio Padrão, $\mathrm{MO}=$ Moda e $\mathrm{ME}=$ Mediana.

$1=$ Nunca, $2=$ Raramente, $3=$ Às vezes, $4=$ Frequente e $5=$ Muito frequente. 


\begin{tabular}{|c|c|c|c|c|c|c|c|c|}
\hline Afirmação & DP & MO & ME & 1 & 2 & 3 & 4 & 5 \\
\hline $\begin{array}{l}\text { Projetos que possuem apenas um recurso de estilo } \\
\text { (styles.xml) e este é muito grande. (LONGO RE- } \\
\text { CURSO DE EsTILO) }\end{array}$ & 1.18 & 4 & 4 & $6 \%$ & $16 \%$ & $22 \%$ & $33 \%$ & $22 \%$ \\
\hline $\begin{array}{l}\text { Projetos que possuem apenas um arquivo de strings } \\
\text { (strings.xml) e este é muito grande. (RECURSO DE } \\
\text { STRING BAGUNÇADO) }\end{array}$ & 1.18 & 5 & 4 & $6 \%$ & $8 \%$ & $20 \%$ & $32 \%$ & $33 \%$ \\
\hline $\begin{array}{l}\text { Arquivos de layout com alguns atributos de estilos } \\
\text { repetidos em mais de uma view. (AtRIBUtos DE } \\
\text { Estilo REPETIDOs) }\end{array}$ & 1.07 & 4 & 4 & $5 \%$ & $13 \%$ & $31 \%$ & $35 \%$ & $15 \%$ \\
\hline $\begin{array}{l}\text { Arquivo de estilo com alguns atributos de estilos } \\
\text { repetidos em mais de um estilo. (AtRIBUTOS DE } \\
\text { Estilo REPETIDOs) }\end{array}$ & 1.16 & 4 & 3 & $9 \%$ & $17 \%$ & $28 \%$ & $33 \%$ & $13 \%$ \\
\hline $\begin{array}{l}\text { Usar uma mesma string em diferentes telas do apli- } \\
\text { cativo. (REÚso INADEQUADO DE STRING) }\end{array}$ & 1.12 & 4 & 4 & $5 \%$ & $9 \%$ & $22 \%$ & $34 \%$ & $29 \%$ \\
\hline $\begin{array}{l}\text { Usar o atributo onClick ou outro similar, direta- } \\
\text { mente no xml de layout, para responder a eventos } \\
\text { do usuário. (LISTENER ESCONDIDO) }\end{array}$ & 1.29 & 2 & 2 & $24 \%$ & $30 \%$ & $19 \%$ & $16 \%$ & $10 \%$ \\
\hline
\end{tabular}




\section{Apêndice E}

\section{Afirmações sobre importância dos maus cheiros e respectivos dados estatísticos}

Neste apêndice, ao final de cada afirmação, entre parênteses indicamos a qual mau cheiro ela se referia, entretanto esta informação (nome do mau cheiro) não foi apresentada no questionário online.

\begin{tabular}{|c|c|c|c|c|c|c|c|c|}
\hline Afirmação & DP & MO & $\mathrm{ME}$ & 1 & 2 & 3 & 4 & 5 \\
\hline $\begin{array}{l}\text { Activities, Fragments, Adapters e Listeners não ter } \\
\text { códigos de lógica de negócio, condicionais comple- } \\
\text { xos ou conversão de dados. (COMPONEnTE DE UI } \\
\text { CÉREBRo) }\end{array}$ & 1.05 & 5 & 5 & $3 \%$ & $3 \%$ & $15 \%$ & $25 \%$ & $53 \%$ \\
\hline $\begin{array}{l}\text { Fragments, Adapters e Listeners não tenham refe- } \\
\text { rência direta à quem os utiliza. (COMPONENTE DE } \\
\text { UI ACOPLADO) }\end{array}$ & 1.02 & 5 & 4 & $2 \%$ & $6 \%$ & $21 \%$ & $33 \%$ & $37 \%$ \\
\hline $\begin{array}{l}\text { Listeners devem ser implementados em suas pró- } \\
\text { prias classes ao invés de implementá-los através de } \\
\text { classes anônimas, classes internas ou polimorfismo } \\
\text { (uso de implements) em Activities, Fragments ou } \\
\text { Adapters. (COMPORTAMENTo SusPeITo) }\end{array}$ & 1.19 & 4 & 3 & $7 \%$ & $17 \%$ & $27 \%$ & $28 \%$ & $20 \%$ \\
\hline $\begin{array}{l}\text { Usar o padrão ViewHolder em } \text { Adapters. } \\
\text { (ADAPTER CONSUMISTA) }\end{array}$ & 0.93 & 5 & 5 & $1 \%$ & $4 \%$ & $9 \%$ & $26 \%$ & $58 \%$ \\
\hline $\begin{array}{l}\text { Evitar o uso de Fragments. Usar Fragments apenas } \\
\text { se não houver outra alternativa. (Uso ExCESSIVO } \\
\text { DE FrAGMENT) }\end{array}$ & 1.36 & 3 & 3 & $21 \%$ & $14 \%$ & $28 \%$ & $20 \%$ & $16 \%$ \\
\hline $\begin{array}{l}\text { Usar Fragments sempre que possível. Por exemplo, } \\
\text { pelo menos um Fragment por Activity, etc. (NÃO } \\
\text { Uso DE FraGment) }\end{array}$ & 1.34 & 4 & 3 & $19 \%$ & $15 \%$ & $24 \%$ & $26 \%$ & $15 \%$ \\
\hline
\end{tabular}




Afirmação
Activities, Fragments e Adapters não terem códigos
de acesso a banco de dados, acesso a arquivos locais
ou internet. (CLASsEs DE UI FAZENDo IO)
Usar padrões arquiteturais como MVC, MVP,
MVVM, Clean Architecture ou outros. (AUSÊNCIA
DE ARQUITETURA)
Adapters responsáveis apenas por popular a view,
sem códigos de lógicas de negócio, cálculos ou con-
versões de dados/objetos. (ADAPTER ComPLEXo)
Criar um recurso de tamanho, cor ou texto, em
seu respectivo arquivo (dimens.xml, colors.xml,
strings.xml) antes de utilizá-lo. (RECURSO MÁ-
GICO)

Utilizar um padrão de nomenclatura para arquivos de layout, recursos de texto, estilos e gráficos (imagens ou recursos xmls gráficos). (NOME DE RECURSO DESPADRONIZADO)

Não utilizar mais de 3 níveis de views aninhadas em xmls de layout. (LAyout Profundamente AnINHADO)

Sempre que possível, substituir o uso de imagens (jpg, jpeg, png ou gif) por xmls gráficos do Android, no caso, por exemplo de, background de cores sólidas ou degradês. (Imagem Tradicional DisPENSÁVEL)

Ter recursos de layouts pequenos. (LAYOUT LONGO OU REPETIDO)

Extrair trechos de layout que se repetem em arquivos de layout novos, e reutilizá-los com include ou merge. (LAyOUT LONGO OU REPETIDO)

Disponibilizar as imagens usadas no aplicativo em mais de uma resolução/densidade diferentes. (ImAGem FALtante)

Separar os recursos de estilo (styles.xml) em mais de um arquivo, por exemplo: estilos e temas ou outros. (Longo ReCurso de Estilo)

Separar os recursos de strings (strings.xml) em mais de um arquivo. (RECurso De String BAgunÇADO)

Extrair estilos e reutilizá-los, ao invés de repetir os mesmos atributos diretamente em várias views diferentes. (Atributos DE Estilo Repetidos)

$\begin{array}{cccccccc}\text { DP } & \text { MO } & \text { ME } & \mathbf{1} & \mathbf{2} & \mathbf{3} & \mathbf{4} & \mathbf{5} \\ 1.03 & 5 & 5 & 2 \% & 6 \% & 13 \% & 19 \% & 60 \%\end{array}$

$\begin{array}{llllllll}0.82 & 5 & 5 & 1 \% & 2 \% & 9 \% & 18 \% & 69 \%\end{array}$

$\begin{array}{llllllll}0.91 & 5 & 4 & 1 \% & 3 \% & 14 \% & 35 \% & 46 \%\end{array}$

$\begin{array}{llllllll}1.00 & 5 & 4 & 1 \% & 6 \% & 15 \% & 30 \% & 47 \%\end{array}$

$\begin{array}{llllllll}0.88 & 5 & 5 & 1 \% & 3 \% & 11 \% & 25 \% & 59 \%\end{array}$

$\begin{array}{llllllll}1.12 & 4 & 4 & 5 \% & 10 \% & 25 \% & 35 \% & 23 \%\end{array}$

$\begin{array}{llllllll}0.95 & 5 & 4 & 1 \% & 5 \% & 13 \% & 33 \% & 47 \%\end{array}$

$\begin{array}{llllllll}0.95 & 4 & 4 & 1 \% & 5 \% & 30 \% & 36 \% & 27 \%\end{array}$

$\begin{array}{llllllll}0.95 & 5 & 4 & 2 \% & 3 \% & 16 \% & 33 \% & 45 \%\end{array}$

$\begin{array}{llllllll}0.95 & 5 & 5 & 2 \% & 4 \% & 10 \% & 27 \% & 57 \%\end{array}$

$\begin{array}{llllllll}1.06 & 4 & 4 & 2 \% & 15 \% & 26 \% & 35 \% & 20 \%\end{array}$

$\begin{array}{llllllll}1.22 & 4 & 3 & 9 \% & 21 \% & 23 \% & 31 \% & 16 \%\end{array}$

$\begin{array}{llllllll}0.86 & 4 & 4 & 1 \% & 2 \% & 17 \% & 41 \% & 38 \%\end{array}$

$\mathrm{DP}=$ Desvio Padrão, $\mathrm{MO}=$ Moda, $\mathrm{ME}=$ Mediana, $1=$ Não é importante, $2=$ Pouco importante, $3=$ Razoavelmente importante, $4=$ Importante e $5=$ Muito importante. 


\begin{tabular}{|c|c|c|c|c|c|c|c|c|}
\hline Afirmação & DP & MO & ME & 1 & 2 & 3 & 4 & 5 \\
\hline $\begin{array}{l}\text { Separar as strings por tela, e não reutilizar uma } \\
\text { string em mais de uma tela mesmo o texto sendo } \\
\text { igual. (REúso INADEQUADO DE STRING) }\end{array}$ & 1.29 & 3 & 3 & $16 \%$ & $20 \%$ & $26 \%$ & $23 \%$ & $14 \%$ \\
\hline $\begin{array}{l}\text { Não usar atributos de eventos, como o onClick, em } \\
\text { xmls de layout para responder a eventos do usuário. } \\
\text { (LISTENER ESCONDIDO) }\end{array}$ & 1.23 & 5 & 4 & $7 \%$ & $9 \%$ & $26 \%$ & $24 \%$ & $33 \%$ \\
\hline
\end{tabular}




\section{Apêndice F}

\section{Gists dos Códigos Utilizados no Experimento da Etapa 3}

Lista de gists de códigos maus cheirosos.

\begin{tabular}{|c|c|c|}
\hline$\#$ & Mau Cheiro & Gist \\
\hline 1 & Componente de UI Cérebro & gist.github.com/SuelenGC/66f9da1dc9ba73183f0d6eef10542ae1 \\
\hline 2 & Componente de UI Cérebro & gist.github.com/SuelenGC/e4b0197cde11d7cfe1495246a218b008 \\
\hline 3 & Componente de UI Cérebro & gist.github.com/SuelenGC/298d7b5fe349000790170270144162c8 \\
\hline 4 & Componente de UI Cérebro & gist.github.com/SuelenGC/599c9c2f9d14b39c3c1d5a1278841ccb \\
\hline 5 & Componente de UI Cérebro & gist.github.com/SuelenGC/fdf1b57cace5e3b756d842d201b78095 \\
\hline 6 & Componente de UI Acoplado & gist.github.com/SuelenGC/5314cc1203cc12fdb0c07aad11f74f65 \\
\hline 7 & Componente de UI Acoplado & gist.github.com/SuelenGC/bd54fc8fb98f227a4a53d791df48e9bc \\
\hline 8 & Componente de UI Acoplado & gist.github.com/SuelenGC/b1a4e52ea77ac1be174dd2bcef919dd5 \\
\hline 9 & Componente de UI Acoplado & gist.github.com/SuelenGC/fbcbe2edabf73bb259e41a1b5ab57b6e \\
\hline 10 & Componente de UI Acoplado & gist.github.com/SuelenGC/ecbbd2cec8d0201d52a61eb72cf98e54 \\
\hline 11 & Comportamento Suspeito & gist.github.com/SuelenGC/0902b1f1103babda2b78a884bde7a616 \\
\hline 12 & Comportamento Suspeito & gist.github.com/SuelenGC/6192ef359b23fde4c8f9a3454155b604 \\
\hline 13 & Comportamento Suspeito & gist.github.com/SuelenGC/ef22d166e962d7ea6ab8233dc4dcdc2a \\
\hline 14 & Comportamento Suspeito & gist.github.com/SuelenGC/c9cddbc1781c7227ebb6d7351f82eba4 \\
\hline 15 & Comportamento Suspeito & gist.github.com/SuelenGC/ab538ce9e16aaf3df80c936bec07d20b \\
\hline 16 & Adapter Complexo & gist.github.com/SuelenGC/d2f67a44ae30c69292182a8bf1e6812a \\
\hline 17 & Adapter Complexo & gist.github.com/SuelenGC/87eb0b690056eefde7cbeaab4339c1ee \\
\hline 18 & Adapter Complexo & gist.github.com/SuelenGC/ea5896799c99c1ab25483b36604e5984 \\
\hline 19 & Adapter Complexo & gist.github.com/SuelenGC/d95978aae64760e248841ff139d7c0a8 \\
\hline 20 & Adapter Complexo & gist.github.com/SuelenGC/abe273fe3e7e616fd19863b9d848a401 \\
\hline 21 & Adapter Complexo & gist.github.com/SuelenGC/2823e7a9f25bfe878609147b99efd57d \\
\hline 22 & Longo Recurso de Estilo & gist.github.com/SuelenGC/4b0540bc573e1e9d0277a609eba1e8e8 \\
\hline 23 & Longo Recurso de Estilo & gist.github.com/SuelenGC/468eb14bdc4cb14af3681473f501d3b1 \\
\hline
\end{tabular}




\begin{tabular}{lll}
\hline$\#$ & Mau Cheiro & Gist \\
\hline 24 & Longo Recurso de Estilo & gist.github.com/SuelenGC/f399d930dc04f1971debb7f4ecd55d85 \\
25 & Longo Recurso de Estilo & gist.github.com/SuelenGC/febece2da1eba052711b16212a0a27b2 \\
26 & Longo Recurso de Estilo & gist.github.com/SuelenGC/0e11bb39c8df624cf925563c78388095 \\
27 & Layout Profundamente Aninhado & gist.github.com/SuelenGC/612c179f5a50c99c35cb50297efd0766 \\
28 & Layout Profundamente Aninhado & gist.github.com/SuelenGC/8ca89e8b15d458766c0fee9209359758 \\
29 & Layout Profundamente Aninhado & gist.github.com/SuelenGC/bd40e9a9bb1f0b3647d1bd35c6d87feb \\
30 & Layout Profundamente Aninhado & gist.github.com/SuelenGC/964f77f587cd51f1a269201499ceeb9d \\
31 & Layout Profundamente Aninhado & gist.github.com/SuelenGC/76bc7926bebc73ff1d475e239244fa4f \\
32 & Atributos de Estilo Repetidos & gist.github.com/SuelenGC/57335a2424ad70c8ffe97d1f53853296 \\
33 & Atributos de Estilo Repetidos & gist.github.com/SuelenGC/6aa82c50d999eab877407f5def84a936 \\
34 & Atributos de Estilo Repetidos & gist.github.com/SuelenGC/36e7c268fe4f193644d774bcda482015 \\
35 & Atributos de Estilo Repetidos & gist.github.com/SuelenGC/91380358ddcd023960dea2139537ab00
\end{tabular}

Lista de gists de códigos limpos.

\begin{tabular}{lll}
\hline$\#$ & Mau Cheiro & Gist \\
\hline 1 & Recurso de Layout & gist.github.com/SuelenGC/c5c03d821057a47ba3355e735de6d8dc \\
2 & Recurso de Layout & gist.github.com/SuelenGC/1411e67fba72915978aff2e38be3df80 \\
3 & Recurso de Layout & gist.github.com/SuelenGC/9d2b341138b0eb6a79ea776c0325f6e8 \\
4 & Recurso de Layout & gist.github.com/SuelenGC/c27d80b69c3bd2ebebed1adc58e4b02e \\
5 & Recurso de Layout & gist.github.com/SuelenGC/068f54f6a053b0506e7b56ac982c4eff \\
6 & Recurso de Style & gist.github.com/SuelenGC/b27a38d42f03aa0004cc7174f40c582f \\
7 & Recurso de Style & gist.github.com/SuelenGC/d73c16b575dd0470cf936d7e5478b7f6 \\
8 & Recurso de Style & gist.github.com/SuelenGC/df97964a54f42e757c9532452a724f18 \\
9 & Recurso de Style & gist.github.com/SuelenGC/a300c158eb5caed7dfe64c28e9f6afc1 \\
10 & Recurso de Style & gist.github.com/SuelenGC/69ce601ad7e6e59d5d80010415118730 \\
11 & Componente de Apresentação & gist.github.com/SuelenGC/18038e100fd16d5d18d44b01942ddde7 \\
12 & Componente de Apresentação & gist.github.com/SuelenGC/f62f6ffeb78201f592307f862fc11972 \\
13 & Componente de Apresentação & gist.github.com/SuelenGC/0802fc818241f23b71925e5e5981b435 \\
14 & Componente de Apresentação & gist.github.com/SuelenGC/ed10bff8bf7eb6e33d993e79d31edfdb \\
15 & Componente de Apresentação & gist.github.com/SuelenGC/e7f69902916ce54765d7675a0b3bfdb7 \\
\hline
\end{tabular}

Componente de Apresentação podem ser Activities, Fragments, Adapters ou Listeners. 


\section{Referências Bibliográficas}

[1] PMD (2016). https://pmd.github.io, 2016. [Último acesso em 25 de Novembro de 2017].

[2] Sonarqube (2016). http://www.sonarqube.org, 2016. [Último acesso em 25 de Novembro de 2017].

[3] About gists. https://help.github.com/articles/about-gists, 2017. [Último acesso em 25 de Dezembro de 2017].

[4] Marwen Abbes, Foutse Khomh, Yann-Gael Gueheneuc e Giuliano Antoniol. An empirical study of the impact of two antipatterns, blob and spaghetti code, on program comprehension. In Software maintenance and reengineering (CSMR), 2011 15th European conference on, pages 181-190. IEEE, 2011.

[5] Steve Adolph, Wendy Hall e Philippe Kruchten. Using grounded theory to study the experience of software development. Empirical Software Engineering, 16(4):487-513, 2011.

[6] Christopher Alexander, Sara Ishikawa, Murray Silverstein, Max Jacobson, Ingrid Fiksdahl-King e Shlomo Angel. A pattern language: Towns, buildings, construction (center for environmental structure). 1977.

[7] Open Handset Alliance. Open handset alliance releases android SDK. https://www. openhandsetalliance.com/press_111207.html, 2007. [Último acesso em 25 de Novembro de 2017].

[8] Maurício Aniche, Gabriele Bavota, Christoph Treude, Marco Aurélio Gerosa e Arie van Deursen. Code smells for model-view-controller architectures. Empirical Software Engineering, pages 1-37, 92017.

[9] Maurício Aniche, Gabriele Bavota, Christoph Treude, Arie Van Deursen e Marco Aurélio Gerosa. A validated set of smells in model-view-controller architectures. pages 233-243, 2016.

[10] Maurício Aniche e Marco Gerosa. Architectural roles in code metric assessment and code smell detection. 2016.

[11] Roberta Arcoverde, Alessandro Garcia e Eduardo Figueiredo. Understanding the longevity of code smells: preliminary results of an explanatory survey. In Proceedings of the 4th Workshop on Refactoring Tools, pages 33-36. ACM, 2011. 
[12] Boehm Berry W., Brown J.R., Kaspar H., Lipow M., Macleod G.J. e Merrit M.J. Characteristics of software quality. TRW series of software technology. North-Holland Pub. Co., 1978.

[13] N. Bevan. Measuring usability as quality of use. Software Quality Journal, 4:115-130, 1995.

[14] B. W. Boehm, J. R. Brown e M. Lipow. Quantitative evaluation of software quality. In Proceedings of the 2Nd International Conference on Software Engineering, ICSE 76, pages 592-605, Los Alamitos, CA, USA, 1976. IEEE Computer Society Press.

[15] William H Brown, Raphael C Malveau, Hays W McCormick e Thomas J Mowbray. AntiPatterns: refactoring software, architectures, and projects in crisis. John Wiley \& Sons, Inc., 1998.

[16] Suelen Goularte Carvalho e Eduardo Martins Guerra. Padrões para implantar métodos ágeis. Monografia, Instituto Tecnológico de Aeronáutica - ITA, 2011.

[17] Tse-Hsun Chen, Weiyi Shang, Zhen Ming Jiang, Ahmed E Hassan, Mohamed Nasser e Parminder Flora. Detecting performance anti-patterns for applications developed using object-relational mapping. pages 1001-1012, 2014.

[18] CISQ. Consortium for IT software quality. http://it-cisq.org, 2017.

[19] Wohlin Claes, R Per, H Martin, CO Magnus, R Björn e Anders Wesslén. Experimentation in software engineering: an introduction. 2000.

[20] Francois Coallier. Software engineering-product quality-part 1: Quality model. International Organization for Standardization: Geneva, Switzerland, 1991.

[21] W.J. Conover. Practical nonparametric statistics. Wiley, 1999.

[22] Juliet Corbin e Anselm Strauss. Basics of Qualitative Research: Techniques and Procedures for Developing Grounded Theory. SAGE Publications Ltd, 3 edition, 2007.

[23] John W Creswell. Research design: Qualitative, quantitative, and mixed methods approaches. SAGE Publications, Incorporated, 2009.

[24] Oxford Living Dictionaries. Definition: Pattern. https://en.oxforddictionaries.com/ definition/pattern, 2017. [Último acesso em 25 de Novembro de 2017].

[25] Amin Milani Fard e Ali Mesbah. JSNOSE: Detecting javascript code smells. pages 116-125, 2013.

[26] Arlene Fink. How to sample in surveys. The survey kit. SAGE Publications, Incorporated, 1995.

[27] Martin Fowler. Analysis Patterns: Reusable Object Models. Addison-Wesley Professional, 1997.

[28] Martin Fowler e Kent Beck. Refactoring: improving the design of existing code. Addison-Wesley Professional, 1999.

[29] Erich Gamma, Richard Helm, Ralph Johnson e John Vlissides. Design Patterns: Elements of Reusable Object-oriented Software. Addison-Wesley, 1995. 
[30] Golnaz Gharachorlu. Code smells in Cascading Style Sheets: an empirical study and a predictive model. $\mathrm{PhD}$ thesis, University of British Columbia, 2014.

[31] Barney G. Glaser e Anselm L. Strauss. Discovery of grounded theory: Strategies for qualitative research. Routledge, 2017.

[32] Google. Android - plataform architecture. https://developer.android.com/guide/ platform/index.html. [Último acesso em 25 de Novembro de 2017].

[33] Google. Android - UI events. https://developer.android.com/guide/topics/ui/ ui-events.html. [Último acesso em 25 de Novembro de 2017].

[34] Google. Android - activities. https://developer.android.com/guide/components/ activities.html, 2016. [Último acesso em 25 de Novembro de 2017].

[35] Google. Android - activity reference. https://developer.android.com/reference/ android/app/Activity.html, 2016. [Último acesso em 25 de Novembro de 2017].

[36] Google. Android - async task. https://developer.android.com/guide/components/ broadcasts.html, 2016. [Último acesso em 25 de Novembro de 2017].

[37] Google. Android - async task. https://developer.android.com/reference/android/os/ AsyncTask.html, 2016. [Último acesso em 25 de Novembro de 2017].

[38] Google. Android - building your first app. https://developer.android.com/training/ basics/firstapp/creating-project.html, 2016. [Último acesso em 25 de Novembro de 2017].

[39] Google. Android - drawable resources. https://developer.android.com/guide/topics/ resources/drawable-resource.html, 2016. [Último acesso em 25 de Novembro de 2017].

[40] Google. Android - fragments. https://developer.android.com/guide/components/ fragments.html, 2016. [Último acesso em 25 de Novembro de 2017].

[41] Google. Android - layout resources. https://developer.android.com/guide/topics/ resources/layout-resource.html, 2016. [Último acesso em 25 de Novembro de 2017].

[42] Google. Android - layouts. https://developer.android.com/guide/topics/ui/ declaring-layout.html, 2016. [Último acesso em 25 de Novembro de 2017].

[43] Google. Android - providing resources. https://developer.android.com/guide/topics/ resources/providing-resources.html, 2016. [Último acesso em 25 de Novembro de 2017].

[44] Google. Android - resource type. https://developer.android.com/guide/topics/ resources/available-resources.html, 2016. [Último acesso em 25 de Novembro de 2017].

[45] Google. Android - string resources. https://developer.android.com/guide/topics/ resources/string-resource.html, 2016. [Último acesso em 25 de Novembro de 2017].

[46] Google. Android - style resources. https://developer.android.com/guide/topics/ resources/style-resource.html, 2016. [Último acesso em 25 de Novembro de 2017].

[47] Google. Android studio. https://developer.android.com/studio/index.html, 2016. [Último acesso em 25 de Novembro de 2017]. 
[48] Google. Documentação site android developer. https://developer.android.com, 2016. [Último acesso em 25 de Novembro de 2017].

[49] Google. Android - fundamentals. https://developer.android.com/guide/components/ fundamentals.html, 2017. [Último acesso em 25 de Novembro de 2017].

[50] Google. Android - handling lifecycles with lifecycle-aware components. https: //developer.android.com/topic/libraries/architecture/lifecycle.html, 2017. [Último acesso em 25 de Novembro de 2017].

[51] Google. Android - optimizing view hierarchies. https://developer.android.com/topic/ performance/rendering/optimizing-view-hierarchies.html, 2017. [Último acesso em 25 de Novembro de 2017].

[52] Google. Android - processes and threads. https://developer.android.com/guide/ components/processes-and-threads.html\#Threads, 2017. [Último acesso em 25 de Novembro de 2017].

[53] Google. Android - project overview. https://developer.android.com/studio/projects/ index.html, 2017. [Último acesso em 25 de Novembro de 2017].

[54] Google. Android - recyclerview. https://developer.android.com/reference/android/ support/v7/widget/RecyclerView.html, 2017. [Último acesso em 25 de Novembro de 2017].

[55] Google. Android - services. https://developer.android.com/guide/components/ services.html, 2017. [Último acesso em 25 de Novembro de 2017].

[56] Marion Gottschalk, Mirco Josefiok, Jan Jelschen e Andreas Winter. Removing energy code smells with reengineering services. GI-Jahrestagung, 208:441-455, 2012.

[57] Robert B. Grady e Deborah L. Caswell. Software Metrics: Establishing a CompanyWide Program. Prentice Hall, 1987.

[58] Robert J Grissom e John J Kim. Effect sizes for research: A broad practical approach. Lawrence Erlbaum Associates Publishers, 2005.

[59] G. Hecht, R. Rouvoy, N. Moha e L. Duchien. Detecting antipatterns in android apps. In 2015 2nd ACM International Conference on Mobile Software Engineering and Systems, pages 148-149, May 2015.

[60] Geoffrey Hecht. An approach to detect android antipatterns. In 2015 IEEE/ACM 37th IEEE International Conference on Software Engineering, volume 2, pages 766768. IEEE Press, May 2015.

[61] Mário Hozano, Alessandro Garcia, Baldoino Fonseca e Evandro Costa. Are you smelling it? investigating how similar developers detect code smells. Information and Software Technology, 93:130-146, 2018.

[62] ISO. IEC25010: 2011 systems and software engineering-systems and software quality requirements and evaluation (SQuaRE)-system and software quality models. International Organization for Standardization, 34:2910, 2011.

[63] BSEN ISO9000. ISP 9000:2000 - quality management systems: Fundamentals and vocabulary. London: British Standards Institution, 2000. 
[64] Arthur J. Riel. Object-Oriented Design Heuristics, volume 335. Addison-Wesley Publishing Company, 1996.

[65] Java. What is java technology and why do i need it? https://www.java.com/en/ download/faq/whatis_java.xml. [Último acesso em 25 de Novembro de 2017].

[66] Juran Joseph M. e Godfrey A. Blanton. Juran's Quality Handbook. McGraw-Hill, 5? edition, 1998.

[67] Kerievsky Joshua. A timeless way of communicating. https://www.slideshare.net/ JoshuaKerievsky/a-timeless-way-of-communicating-alexandrian-pattern-languages, 2010. [Último acesso em 25 de Novembro de 2017].

[68] Foutse Khomh, Massimiliano Di Penta e Yann-Gaël Guéhéneuc. An exploratory study of the impact of code smells on software change-proneness. In Proceedings of the 2009 16th Working Conference on Reverse Engineering, WCRE '09, Washington, DC, USA, 2009. IEEE Computer Society.

[69] Foutse Khomh, Massimiliano Di Penta, Yann-Gaël Guéhéneuc e Giuliano Antoniol. An exploratory study of the impact of antipatterns on class change-and fault-proneness. Empirical Softw. Engg., 17(3), June 2012.

[70] Andrew Koenig. Patterns and antipatterns. The patterns handbook: techniques, strategies, and applications, 13:383, 1998.

[71] Wei Li e Raed Shatnawi. An empirical study of the bad smells and class error probability in the post-release object-oriented system evolution. Journal of systems and software, 80(7):1120-1128, 2007.

[72] Mario Linares-Vásquez, Sam Klock, Collin McMillan, Aminata Sabané, Denys Poshyvanyk e Yann-Gaël Guéhéneuc. Domain matters: bringing further evidence of the relationships among anti-patterns, application domains, and quality-related metrics in java mobile apps. pages 232-243, 2014.

[73] Umme Mannan, Danny Dig, Iftekhar Ahmed, Carlos Jensen, Rana Abdullah e M Almurshed. Understanding code smells in android applications. 2017.

[74] Robert C. Martin. Clean Code: A Handbook of Agile Software Craftsmanship. Prentice Hall PTR, Upper Saddle River, NJ, USA, 1 edition, 2008.

[75] Jim A. McCall, Paul K. Richards e Gene F. Walters. Factors in software quality: Concept and definitions of software quality. I:188, 1977.

[76] Steve McConnell. Code Complete. Microsoft Press, Redmond, WA, USA, 2004.

[77] Roberto Minelli e Michele Lanza. Software analytics for mobile applications, insights \& lessons learned. In Proceedings of the 2013 17th European Conference on Software Maintenance and Reengineering, 2013.

[78] Jacques Moscarola. Enquêtes et analyse de données. Paris: Vuibert, 307, 1990.

[79] Jakob Nielsen. Why you only need to test with 5 users. https://www.nngroup.com/ articles/why-you-only-need-to-test-with-5-users, 2000. [Último acesso em 25 de Novembro de 2017]. 
[80] Juliana Oliveira, Deise Borges, Thaisa Silva, Nelio Cacho e Fernando Castor. Do android developers neglect error handling? a maintenance-centric study on the relationship between android abstractions and uncaught exceptions. Journal of Systems and Software, 136:1 - 18, 2017.

[81] OpenSignal. Android fragmentation visualized. http://opensignal.com/reports/2015/ 08/android-fragmentation, 2015. [Último acesso em 25 de Novembro de 2017].

[82] Fabio Palomba, Gabriele Bavota, Massimiliano Penta, Rocco Oliveto e Andrea Lucia. Do they really smell bad? a study on developers' perception of bad code smells. pages 101-110, 2014.

[83] Ralph Peters e Andy Zaidman. Evaluating the lifespan of code smells using software repository mining. In Software Maintenance and Reengineering (CSMR), 2012 16th European Conference on, pages 411-416. IEEE, 2012.

[84] Martin Pinzger, Felienne Hermans e Arie van Deursen. Detecting code smells in spreadsheet formulas. In Proceedings of the 2012 IEEE International Conference on Software Maintenance (ICSM), ICSM '12, pages 409-418, Washington, DC, USA, 2012. IEEE Computer Society.

[85] Jan Reimann e Uwe Assmann. Quality-aware refactoring for early detection and resolution of energy deficiencies. 2013.

[86] Jan Reimann e Martin Brylski. A tool-supported quality smell catalogue for android developers. 2014.

[87] Johnny Saldaña. The Coding Manual for Qualitative Researchers. SAGE Publications Ltd, 2 edition, 2015.

[88] Dag IK Sjøberg, Aiko Yamashita, Bente CD Anda, Audris Mockus e Tore Dybå. Quantifying the effect of code smells on maintenance effort. IEEE Transactions on Software Engineering, 39(8):1144-1156, 2013.

[89] Sandra A. Slaughter, Donald E. Harter e Mayuram S. Krishnan. Evaluating the cost of software quality. Commun. ACM, 41(8):67-73, August 1998.

[90] Statista. Global mobile OS market share in sales to end users from 1st quarter 2009 to 1st quarter 2017. https://www.statista.com/statistics/266136/ global-market-share-held-by-smartphone-operating-systems, 2017. [Último acesso em 25 de Novembro de 2017].

[91] Girish Suryanarayana, Ganesh Samarthyam e Tushar Sharma. Refactoring for software design smells: Managing technical debt. Morgan Kaufmann, 2014.

[92] Davide Taibi, Andrea Janes e Valentina Lenarduzzi. How developers perceive smells in source code: A replicated study. Information and Software Technology, 92:223-235, 2017.

[93] Software Engineering Institute Carnegie Mellon University. Carnegie mellon sei and omg announce the launch of cisq-the consortium for it software quality (www.itcisq.org), 2009. 
[94] Eva Van Emden e Leon Moonen. Java quality assurance by detecting code smells. In In Proceedings of the Working Conference on Reverse Engineering (WCRE), pages 97-106. IEEE Computer Society, 2002.

[95] Daniël Verloop. Code smells in the mobile applications domain. Master's thesis, TU Delft, Delft University of Technology, 2013.

[96] Stefan Wagner. Software Product Quality Control. Springer-Verlag Berlin Heidelberg, 2013.

[97] Bruce Webster F. Pitfalls of Object-Oriented Development. M \& T Books, 1995.

[98] Ward's Wiki. Code smell. http://wiki.c2.com/?CodeSmell, 1995. [Último acesso em 05/10/2017].

[99] Wikipedia. Code smell — Wikipedia, the free encyclopedia. http://en.wikipedia.org/ w/index.php?title=Code\%20smell\&oldid $=810572249,2017$. [Último acesso em 25 de Novembro de 2017].

[100] Wikipedia. IOS - Wikipedia, the free encyclopedia. http://en.wikipedia.org/w/index. php?title $=$ IOS\&oldid=812046680, 2017. [Último acesso em 25 de Novembro de 2017].

[101] Aiko Yamashita e Leon Moonen. Do code smells reflect important maintainability aspects? In 2012 28th IEEE International Conference on Software Maintenance (ICSM), pages 306-315. IEEE, Sept 2012.

[102] Aiko Yamashita e Leon Moonen. Do developers care about code smells? an exploratory survey. In Reverse Engineering (WCRE), 2013 20th Working Conference on, pages 242-251. IEEE, 2013.

[103] Aiko Yamashita e Leon Moonen. Exploring the impact of inter-smell relations on software maintainability: An empirical study. In Proceedings of the 2013 International Conference on Software Engineering (ICSE), ICSE '13, pages 682-691, Piscataway, NJ, USA, 2013. IEEE Press. 